\title{
240
}

\section{Untersuchungen an Beauveria tenella (NRRL 2334, 2335, 2336; bisher Agaricus campestris)}

Dissertation zur Erlangung des Doktorgrades der Mathematisch-Naturwissenschaftlichen Fakultät der Georg-August-Universität zu Göttingen

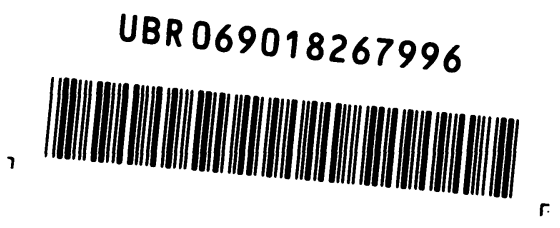

vorgelegt von

Hans-Peter Molitoris

aus Erlangen

8200

M725

Göttingen 1963

B3 


\section{$\because)(1 N \geqslant 3) M ?$}

Diese Arbeit wurde im Institut für Mikrobiologie der Georg-August-Universität zu Göttingen durchgeführt.

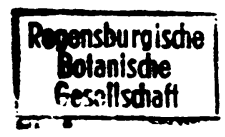

13935

D 7

Referent:

Professor Dr.H. -G. Schlegel Korreferent:

Professor Dr. A. Pirson

Tag der mündlichen Prüfung:

8. November 1963 


\section{Untersuchungen an Beauveria tenella (NRRL 2334, 2335, 2336; bisher Agaricus campestris) *}

\section{Systematik}

Von

\section{H. P. Molitoris}

Mit 7 Textabbildungen

(Eingegangen am 2\%. Juli 196:3)

Die modernen Methoden der Submerskultur im Rühr- oder Schüttelverfahren mit Belüftung vermeiden weitgehend die Nachteile der herkömmlichen Verfahren, indem sie ein schnelles, homogenes Wachstum des Mycels unter reproduzierbaren Bedingungen ermöglichen. Damit wird eine exakte Untersuchung des Zellmaterials, seines Stoffwechsels und der Stoffwechselprodukte ermöglicht.

Die Vorteile der Submerskultur lassen sich im allgemeinen nur bei der Heranzucht von Hefen und anderen einzelligen Mikroorganismen wahrnehmen, während bei höheren Pilzen (vornehmlich Basidiomyceten) gewisse S'chwierigkeiten auftreten. Sie wachsen in Submerskultur meist nur langsam und begrenzt und bilden Kugeln (..pellets") oder Klumpen (Birkholder u. Siscott 1945; Sugihara u. Humfeld 1954; Jexsison 1956; Bexko 1958; Robbiss 1958). Diese Mycelklumpen sind wachstumsphysiologisch inhomogen. da in verschiedenen Zonen unterschiedliche Sauerstoff- und Nährstoff bedingungen herrschen, so daß im Inneren bereits Autoly'se einsetzen kann. während das Mycel an der Oberfläche noch aktiv wächst.

1948 fand jedoch Humfeld bei dem Versuch, den Basidiomyceten Agaricus campestris ${ }^{1}$ in Submerskultur heranzuziehen, einige Stämme (NRRL 2334, 2335, 2336), die bei einfachen Nährstoffansprüchen in Submerskultur ein schnelles, homogenes, hefeähnliches Wachstum zeigten, das für höhere Pilze ungewöhnlich war. Diese Stämme wurden, vor allem unter kommerziellen Gesichtspunkten, in der Folgezeit mehrfach untersucht (Humfeld 1948; Humfeld u. Sugihara 1949; Humfeld 1950/51;

* Gekürzte gleichlautende Dissertation der mathematisch-naturwissenschaft. lichen Fakultät der Lniversität Göttingen.

${ }^{1}$ In den angelsächsischen Ländern werden häufig noch die in der Champignonkultur verwandten Stämme als Agaricus campestris bezeichnet, obwohl dieser Name allein der Wildform mit viersporigem Basidium zukommt, die auch nicht auf Pferdemist wächst. Der Kulturchampignon trägt wegen seines zweisporigen Basidiums dagegen den Namen Agaricus (oder Psalliota) bisporus Lange, forma albida (weiß) und forma arellanea (braun). 


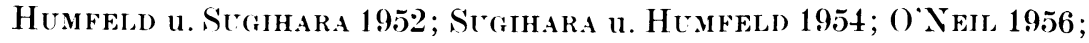
Bexko 1958; Moustafa 1960).

Hierbei hatten sich die erwähnten Stämme für stoffwechselphỵisologische Untersuchungen als besonders geeignet erwiesen. Eigene Voruntersuchungen hatten ergeben, daß die Stämme Fett zu speichern vermochten. Die günstigen Wachstumseigenschaften in Verbindung mit den Möglichkeiten, moderne Methoden der Stoffwechsel- und Fettanalyse anzuwenden, ließen daher Untersuchungen über die Fett. synthese besonders aussichtsreich erscheinen; bei höheren Pilzen liegen $\mathrm{zu}$ diesem Problem nur wenige Arbeiten ror (Jennison, Richberg $u$. Krikszexs 1957; Reusser. Spexcer u. Sallaxs 1958; Falaxghe 1962; Hughes 1962). Für diese Untersuchungen sollten nun zunächst in Submerskultur unter normalen Agaricus-Stämmen solche selektioniert und allgemein charakterisiert werden, die in ihren Eigenschaften den von HrMfELD beschriebenen Stämmen weitgehend entsprachen.

\section{A. Organismen und Methoden}

\section{Organismen}

Die Agaricus bisporus-Stämme wurden von Prof. Kxembone, Penn. State University und den Firmen Hullen/Erlangen. Hullen/Osterode und Witt/Bernkastel bezogen. - Die als Agaricus campestris bezeichneten Stämme NRRL :2.3.34, 2.3.3.5. 2.3.36 wurden von Prof. Hesseltive, Northern Regional Research Laboratory. Peoria, zur Verfügung gestellt. - Die Vergleichsstämme Beauveria bassiana und Beauceria tenella stammten aus der Sammlung des Centraalbureaus voor Schimmelcultures in Baarn/Holland.

\section{Nährmedien}

Sämtliche Stämme wurden regelmäßig auf Biomalzagar-Schrägröhrchen $\left(2,5^{0}{ }_{0}\right.$ Biomalz, Kirner Vitabornwerk ( $\mathrm{imbH} ; 1,5 \%$ Agar; $\mathrm{p}_{\mathrm{H}}$ etwa 5.5$)$ vermehrt, sowie in Stammkulturen in Reagensgläsern mit kompostiertem. sterilem Pferdemist gehalten. Yon den $N R R L$-Stämmen und den Beauceria-Stämmen aus Baarn wurden Dauerkulturen nach RHODEs (1950) angefertigt.

Zur Untersuchung der Wachstumsgeschwindigkeit und anderer Kulturcharakteristica wurden feste Substrate aus Kartoffel-. Haferflocken, Kirsch- und Heuagar angesetzt. Der $\mathrm{p}_{\mathrm{H}}$-Wert lag dabei jeweils zwischen 5 und 6.

Als flüssiges Nährmedium wurde einmal Biomalz-Nährlösung verwendet. Hierzu wurde eine entsprechende Menge Biomalz in aqua dest. gelöst und mit $\mathrm{NaOH}$ auf $p_{\mathrm{H}}=8,0$ gebracht. Die Sterilisationszeit in den Erlenmeyerkolben betrug, wie auch bei allen anderen Substraten. $15 \mathrm{~min}$ bei 1.2 atü.

Weiterhin wurde das Medium nach Humfeld u. Sughinara (1949) verwendet. (irundmedium: $\mathrm{KH}_{2} \mathrm{PO}_{4} 0,8 \mathrm{~g}$; $\mathrm{MgHPO}_{4} 0.40 \mathrm{~g} ; \mathrm{CaCl}_{2} \cdot 2 \mathrm{H}_{2} \mathrm{O} 0.37 \mathrm{~g} ; \mathrm{H}_{2} \mathrm{SO}_{4} 2.0 \mathrm{n}$ $5.7 \mathrm{ml}$; Npurenelementlösung $\left(\mathrm{FeCl}_{3} \cdot 6 \mathrm{H}_{2} \mathrm{O} 0,50 \mathrm{~g} ; \mathrm{MnCl}_{2} \cdot 4 \mathrm{H}_{2} \mathrm{O} 0,36 \mathrm{~g} ; \mathrm{ZnCl}_{2}\right.$ $0,20 \mathrm{~g}$; $\mathrm{CuSO}_{4} \cdot 5 \mathrm{H}_{2} \mathrm{O} 0.05 \mathrm{~g}$; aqua dest. auf $\left.1000 \mathrm{ml}\right) 20.0 \mathrm{ml}$; Glucose $50,0 \mathrm{~g}$ $(=5 \%)$; aqua dest. auf $900 \mathrm{ml}$. Stickstoffquelle: $3 \%$ Harnstoff lösung in aqua dest.. steril filtriert. Das Grundmedium wurde mit $\mathrm{NaOH}$ auf $\mathrm{p}_{\mathrm{H}}$ 4.5 gebracht, in Mengen zu je $36 \mathrm{ml}$ in $300 \mathrm{ml}$ Erlenmeyerkolben mit Watte- oder Schaumstoff hauben eingefüllt, autoklaviert (15 min bei 1,2 atii) und dann unter sterilen Bedingungen mit je $4 \mathrm{ml}$ der Harnstofflösung versetzt (Endkonzentration Harnstoff $=0,3 \%$, Stickstoff $=0,14 \%$ ). 
Für die Vergleichsversuche mit Beaureria wurde zusätzlich das Medium nach MACLEOD (1954a) verwendet. Grundmedium: $\mathrm{KH}_{2} \mathrm{PO}_{4} 1.5 \mathrm{~g} ; \mathrm{Na}_{2} \mathrm{HPO}_{4} \cdot 12 \mathrm{H}_{2} \mathrm{O}$ $1.5 \mathrm{~g} ; \mathrm{MgSO}_{4} \cdot 7 \mathrm{H}_{2} \mathrm{O} 0,025 \mathrm{~g} ; \mathrm{CaCl}_{2} \cdot 2 \mathrm{H}_{2} \mathrm{O} 0.025 \mathrm{~g}$; $\left(\mathrm{NH}_{4}\right)_{2} \mathrm{SO}_{4} 3,0 \mathrm{~g}$ (N-Konzentration $=0.064 \%)$; Spurenelementlösung $\left[\mathrm{Fe}\left(\mathrm{NH}_{4}\right)_{2}\left(\mathrm{SO}_{4}\right)_{2} \cdot 6 \mathrm{H}_{2} \mathrm{O} 0,05 \mathrm{~g} ; \mathrm{ZnSO}_{4}\right.$ - $7 \mathrm{H}_{2} \mathrm{O} 0.05 \mathrm{~g}$; $\mathrm{MnSO}_{4} \cdot \mathrm{H}_{2} \mathrm{O} 0.05 \mathrm{~g}$; aqua dest. auf $\left.1000 \mathrm{ml}\right] 20.0 \mathrm{ml}$; Glucose $10.0 \mathrm{~g}$ $(=1 \%)$; aqua dest. auf $1000 \mathrm{ml}$. Der $\mathrm{p}_{\mathrm{H}}$-Wert wurde mit $\mathrm{H}_{2} \mathrm{SO}_{4}$ ebenfalls auf 4,\%) eingestellt und je $40 \mathrm{ml}$ der Lösung in $300 \mathrm{ml}$ Kolben sterilisiert. Bei einem Anfangs$p_{H}$ von 4,5 war unter den gewählten Sterilisationsbedingungen die Caramelisierung des Kohlenhydrats so gering, daß sich eine getrennte Sterilisation erübrigte.

\section{Methodik}

a) Versuche auf festem Substrat. Einsporkulturen wurden durch Ausspateln verdünnter Sporensuspensionen auf Agarplatten und Uberimpfung der gekeimten Einzelsporen (mikroskopische Kontrolle!) auf Schrägröhrchen hergestellt.

Die Mikroaufnahmen wurden mit einem Zeiss-Winkel-Standard-Mikroskop) (Neofluare), der Contax-Kleinbildkamera und der Leitz Mikrophotoausrüstung (Photoaufsatz Grundkörper II, Belichtungsmeßgerät, Elektronenblitzgerät Ukatron II) angefertigt.

Für die Infektionsversuche wurden Agaricus-Fruchtkörper (autoklaviert und nicht autoklaviert) in Erlenmeverkolben mit Wattehauben mit dem BeauveriaIycel beimpft und bei $25^{2} \mathrm{C}$ inkubiert.

Lm die Stämme zur Fruchtkörperbildung zu bringen, wurde aus den Mycelien ..Brut" hergestellt und diese unter verschiedenen normalen Betriebsbedingungen (Fa. Hullen/Erlangen) weiterverarbeitet.

Zum Nachweis der Katalase wurde ein Mycelstück einer aktiv wachsenden Biomalzagarkultur mit frisch angesetzter $3 \% \quad \mathrm{H}_{2} \mathrm{O}_{2}$-Lösung überspült. Blasenbildung zeigte einen positiven Ausfall der Reaktion an.

Die Enzyme Laccase, Peroxydase und Tyrosinase wurden an Biomalzagarkulturen nach LYR (19:58) nachgewiesen.

b) Versuche in Submerskultur. Die Anzucht der Zellen erfolgte in Schüttelkultur. Beimpft wurde mit Mycelstückchen $(5 \times 5 \mathrm{~mm})$ einer mindestens 3 Wochen alten Biomalzagarkultur. $300 \mathrm{ml}$ Erlenmeyerkolben mit Schaumstoff oder Wattehauben und je $40 \mathrm{ml}$ Nährlösung wurden nach der Beimpfung aerob bei $27^{\circ} \mathrm{C}$ auf der Schüttelmaschine $(3 \mathrm{~cm}$ Weg, $150 \mathrm{Hin}$ - und Hergänge/min) inkubiert. Es erwies sich als vorteilhaft, täglich den sich bildenden Mycelrand abzuschütteln.

Die $\mathrm{p}_{\mathrm{H}}$-Messung wurde mit der Glaselektrode und dem $\mathrm{p}_{\mathrm{H}}$-Meßgerät der Fa. Metrohm, Herisau/Schweiz, vorgenommen.

Die Ernte des Zellmaterials erfolgte durch Abnutschen auf Kieselgur-Filterpapier (Schl. \& Sch. Nr. 287) und zweimaliges Waschen mit aqua dest.

Zur Bestimmung des Trockengewichtes wurden die Filter bis zur (iewichtskonstanz bei $105^{\supset} \mathrm{C}$ getrocknet und nach Abkühlung im Exsiccator gewogen. Für die Leergewichtsbestimmung wurden die Filter entsprechend vorbehandelt.

Die Bestimmung der Gilucose im Kulturmedium wurde mit dem Anthronreagens nach HewitT (1958) mit dem Zeiss-Photometer PMQ II durchgeführt.

\section{B. Versuche und Ergebnisse}

\section{Versuche zur Mutantenisolierung aus Agaricus bisporus-Stämmen}

Zur Auswahl der für die geplanten Untersuchungen geeigneten Stämme wurden zunächst Submers-Schüttelkulturen mit normalen Stämmen von Agaricus bisporus angesetzt. Diese Voruntersuchungen 
zielten darauf ab. selbst Stämme zu selektionieren, die in Submerskultur gut wachsen. eine homogene Suspension liefern und in ihren Eigenschaften den von Humfeld auf ähnlichem Wege (1950/51) isolierten Stämmen gleichen. Es wurden dazu normale, in der Champignonkultur verwendete Vielsporenkulturen. sowie aus Sporen gezogene Einsporkulturen eingesetzt.

Die Erlenmeyerkolben mit $40 \mathrm{ml}$ Nährlösung $(5 \%$ Biomalz bzw. Humfeld-Medium) wurden mit aktiv wachsendem Mycel von BiomalzSchrägröhrchen beimpft und auf der Schüttelmaschine bei $27^{\circ} \mathrm{C}$ inkubiert. Am 9. Tag wurde geerntet und die Kolben auf $\mathrm{p}_{\mathrm{H}}$, Trockengewicht. makroskopisches und mikroskopisches Aussehen untersucht. Von den untersuchten 14 Vielspor- und 44 Einsporkulturen zeigte keine Merkmale. wie sie von Humfend beschrieben wurden. Es wurden daher die von Humfeld isolierten Stämme vom Northern Regional Research Laboratory. Peoria, als Agaricus campestris NRRL 2334, 233:5. 2336 bezogen und mit den normalen Agaricus-Stämmen nach verschiedenen Gesichtspunkten verglichen.

\section{Vergleich der NRRL-stämme mit Agaricus bisporus:}

a) Eigenschaften auf festem Substrat

Bei der Cberimpfung der NRRL-Stämme auf festes Nährsubstrat zeigten sich viele Einzelkolonien, die auf eine starke Conidien-oder Oidienproduktion hinwiesen. Das Mycel war pelzartig bis wattig, bis etwa $8 \mathrm{~mm}$ hoch, zunächst rein weiß, bildete keine Stränge, wuchs schnell, wurde im Alter gelblich unter Hautbildung und zeigte dann Guttationstropfen.

Tabelle 1. Enzymnachueise auf Biomalz-Agarplatten

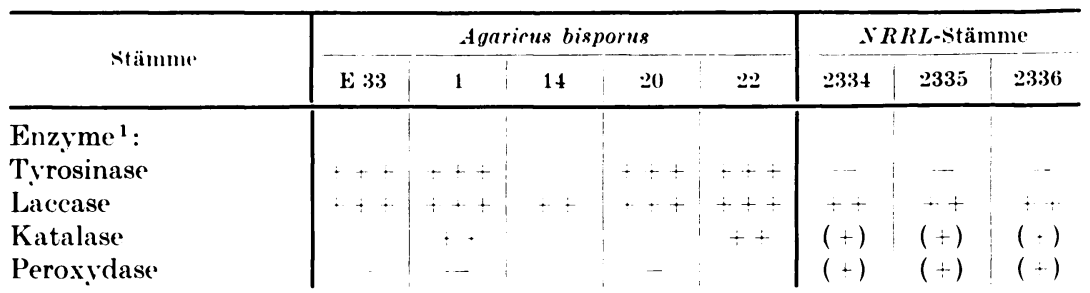

1 Stärke der Enzvmreaktion: $+++=$ sehr stark positiv ; $++=$ stark positiv; $-=$ deutlich positiv $;(+)=$ schwach oder unregelmäßig positiv: $-=$ negativ .

Normales Agaricus-Mycel wuchs langsamer, zeigte häufig Strangund Sektorenbildung und schied keine Guttationstropfen aus. Auf kompostiertem Pferdemist riefen die NRRL-Stämme nicht die für Agaricus typische Rotbraunfärbung hervor, sondern färbten das Substrat schwärzlich. Sie wuchsen hier zunächst schnell, blieben dann aber im Wachstum zurück. 
Ein Vergleich der Wachstumsgeschwindigkeiten auf Biomalzagarplatten $\left(25^{\circ} \mathrm{C} ; 7\right.$ Tage) ergab bei neun getesteten Agaricus-Stämmen einen durchschnittlichen täglichen Zuwachs des Koloniedurchmessers von $0.19 \mathrm{~cm}$, bei den $N R R L$-Stämmen jedoch von $0.36 \mathrm{~cm} / \mathrm{Tag}$.

Eine Untersuchung der auf Biomalzagarplatten gebildeten Enzyme ergab die in Tab. 1 gezeigten Verhältnisse (vgl. auch BExкo 1958).

Tabelle 2. Vergleich normaler Agaricus-stämme mit den NRRL-Stämmen

\begin{tabular}{c|cc}
\hline Entersuchung/Merkmal & $\begin{array}{c}\text { Agarirus bisporus } \\
\text { (Mittelwerte) }\end{array}$ & $\begin{array}{c}\text { NRRL-Stämme } \\
\text { (Nittelwerte) }\end{array}$ \\
\hline
\end{tabular}

A. Festes substrat

Biomalzagar:

Einzelkolonien b. C'berimpfen

Strang- und Sektorenbildung

Mycelfarbe

Aites Mycel: Hautbildung

Enzyme: Tyrosinase (iuttationstropfen

Laccase

Katalase

Peroxydase

komp. Pferdemist:

Anfangswachstum

Verfärbung

Durchwachsung

Fruchtkörperbildung

\section{B. Submerskultur}

Sudanophile Granula

Sekundärsporenbildung

('hampignon-(ieruch und (ieschmack

Kulturcharakter

Vakuolisierung der Zellen

Hyphendurchmesser $\mu$

Ernte: 9. Tag ${ }^{2} \mathrm{mg}$ Tr.S. $\mathrm{ml}$ N.M. Humfeld-Medium

Biomalzmedium

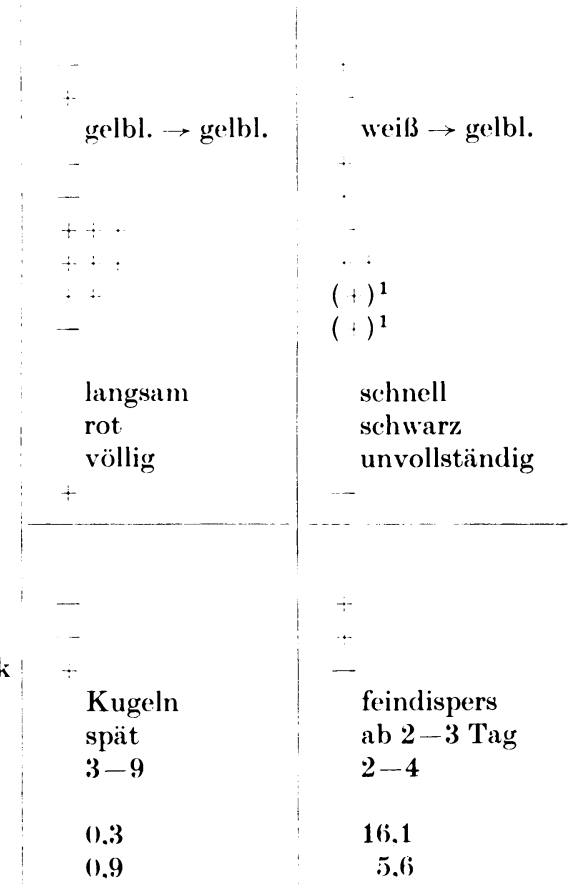

1 Sichwache oder unbeständige Reaktion.

2 Schüttelkultur. beimpft mit Agarmycelstückchen; mg Tr.S./mI N.MI. =mg Trockensubstanz/ml Nährmedium.

\section{b) Eigenschaften in Submerskultur}

In Schüttelkultur (Beimpfung mit Mycelstückchen, Ernte am 9. Tag), wuchsen die $N R R L$-Stämme in einem einfachen, synthetischen Nährmedium (Hunfeld u. Sugihara 1949) gut, die normalen AgaricusStämme jedoch nicht. In einfacher $5 \%$ Biomalzlösung gediehen beide, die NRRL-Stämme jedoch auch hier weit besser (Tab.2). 
Die NRRL-Stämme unterschieden sich von den normalen Stämmen auch morphologisch (HUMFELd 1948; HUMFELd 1950/51). Vom dritten Kulturtage an wurden nämlich massenhaft sporenähnliche Gebilde produziert, die Humfeld in Anlehnung an Kuigman (1942) „secondary spores" nennt.

KuIgman bezeichnete damit chlamydosporenartige, meist runde Zellen in (ab 3 Monate) alten Hyphenverbänden auf festem Substrat, die durch Längen-

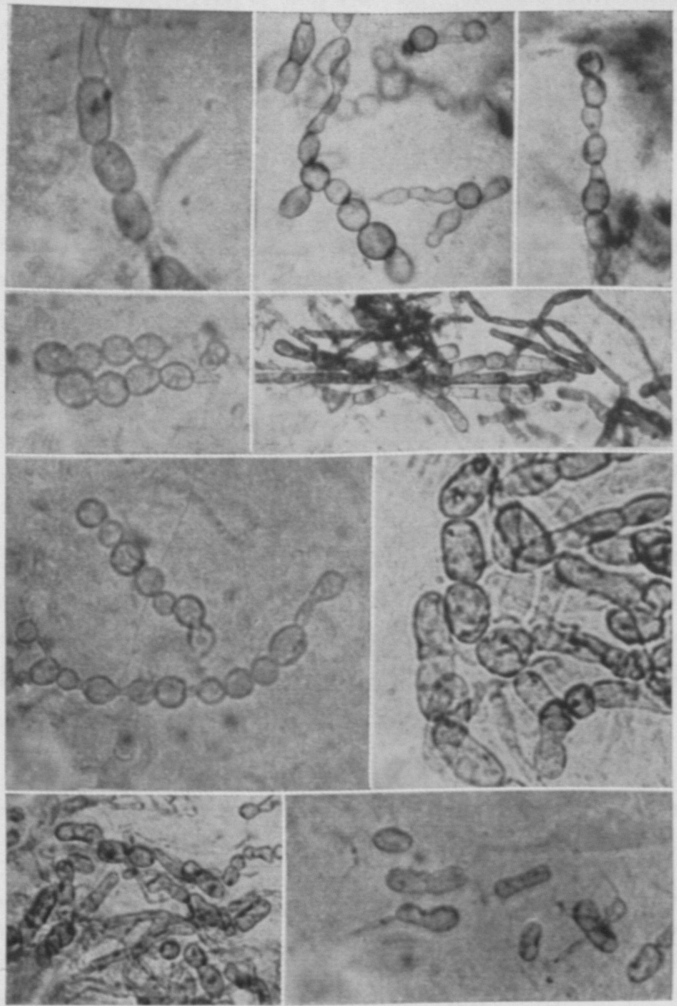

Abb.1. Sekundärsporen bei normalen Agaricus-Stämmen in festem Substrat [aus KLIGMaN (1942)] verkürzung und Anschwellen intercalar, also im Zellverband entstehen und diesem ein charakteristisches kettenähnliches Aussehen verleihen (Abb.1). Diese „Kette" kann dann in die einzelnen Sekundärsporen zerbrechen und jede davon zu einem neuen Mycel auskeimen.

Beiden von HumFELD beschriebenen Stämmen entstehen die von ihm ebenfalls als ,,secondary spores" bezeichneten, meist ovalen bis länglichen Zellen dagegen terminal an jungen, aktiv wachsenden Mycelien in Flüssigkeitskulturen und bilden keine ,Ketten" (Abb.2). Diese in großer Zahl gebildeten Sekundärsporen (sie sollen im folgenden weiter so bezeichnet werden) geben der Suspension ein ziemlich homogenes, feinflockiges Aussehen, während die normalen Agaricus-Stämme in Submerskultur in Form von Klumpen und Kugeln verschiedener Größe wuchsen.

Die Hyphen der NRRL-Stämme waren dünner, länger und früher vakuolisiert als beinormalen Agaricus-Stämmen und wiesen stark lichtbrechende Granula auf, die sich als Sudan-positiv erwiesen. Die Wachstumskurve (Beimpfung mit Agarmycelstückchen) erreichte bei den NRRL-Stämmen ihr Maximum am 6.-7. Kulturtag, während die normalen AgaricusStämme ein Vielfaches dieser Zeit benötigten (vgl. auch Treschow 1944). 
Entwickelten die Agaricus-Stämme auch in Submerskultur einen angenehmen, typischen Champignongeruch und Geschmack (vgl. auch BENko 1958, sowie BLock in Eddy 1958), so fehlte dieser den NRRLStämmen ganz oder wurde nur als wohlriechend, angenehm und nußartig (Sugrhara u. Humfeld 1954) angegeben. In eigenen Versuchen konnte bei dem Mycel kein champignonartiger Geruch festgestellt

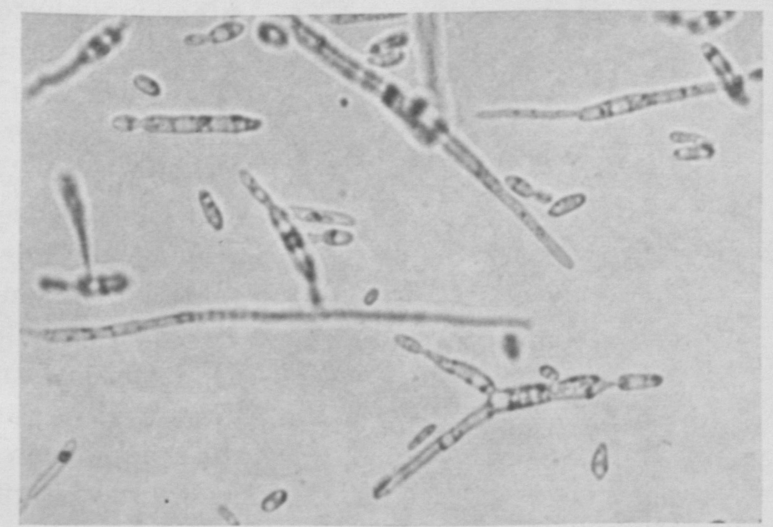

Abb.2. Sekundärsporenbildung in Submerskultur, Humfeld-Medium, Stamm NRRL $2334(\times 640)$

werden, der Geruch der Kulturen war teilweise sogar unangenehm und stechend, besonders bei höheren Stickstoffkonzentrationen (Ammoniak!).

c) Schlußfolgerungen

Humfeld hatte unter etwa 40 in Submerskultur untersuchten normalen Agaricus-Stämmen der weißen und braunen Form drei so ,,mutierte" oder ,adaptierte" Stämme gefunden (HuMFELD 1950/51). In eigenen Versuchen konnten jedoch aus einem noch größeren Vergleichsmaterial keine derartigen Stämme in Submerskultur selektioniert werden.

Betrachtet man nun ein in so vielen Punkten differierendes morphologisches und physiologisches Verhalten (Tab.2), so liegen Zweifel an der Identität der NRRL-Stämme nahe. Es ist auch unwahrscheinlich, daß durch einen Mutationsschritt in Submerskultur in mehreren Fällen so viele Merkmale gleichartig verändert wurden und daß sich in eigenen und auch anderen Nachuntersuchungen (BENKo 1958; EDDY 1958) keine derartigen Mutationen oder Adaptationen finden ließen. Vor weitergehenden physiologischen Untersuchungen erschien es daher angebracht, die Stämme nachzubestimmen. 


\section{Nachbestimmung der NRRL-Stämme}

a) Untersuchung der Hauptfruchtform

Zunächst wurde aus den NRRL-Stämmen und einigen normalen Agaricus-Stämmen im Labor der Fa. Hullen, Erlangen, „Brut“ zum „Bespicken“ der Beete hergestellt. In den Anlagen des Betriebes wurde

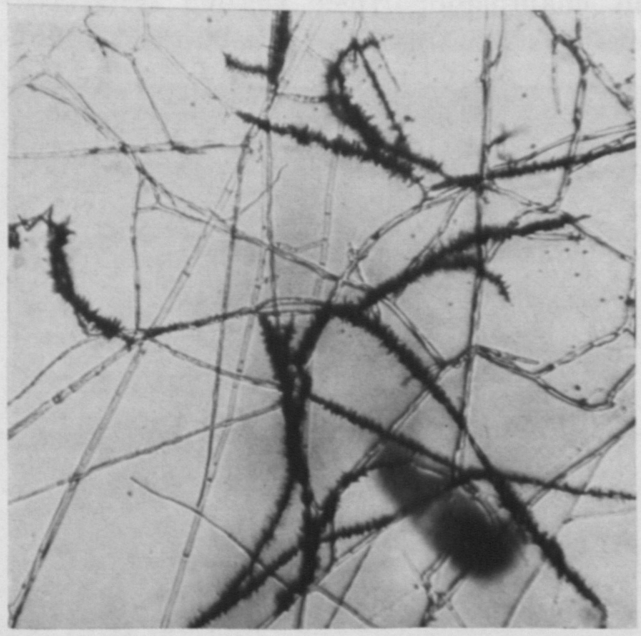

Abb. 3. Ca-Oxalat-Kristallnadeln, normaler AgaricusStamm, Hängetropfen, Biomalzagar $(\times 150)$

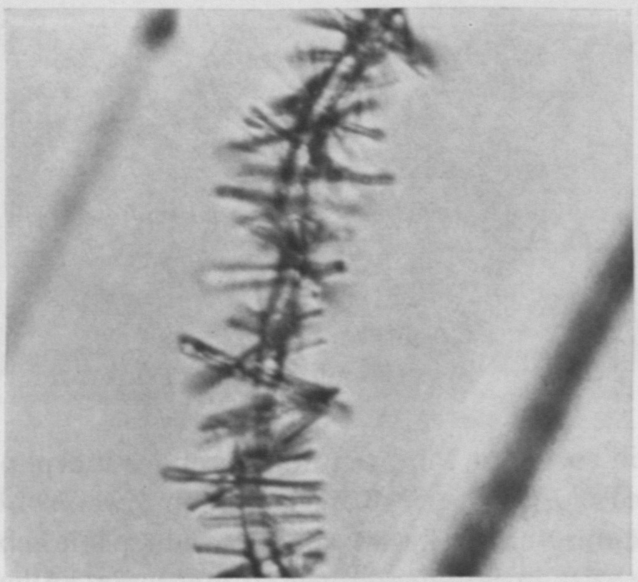

Abb. 4. Ca-Oxalat-Kristallnadeln, normaler AgaricusStamm, Hängetropfen, Biomalzagar $(\times 1000)$

bei den $N R R L$-Stämmen $1,1-4,7 \mu$. Letztere bildeten auch am Deckglas stets eigenartig angeschwollene, gekrümmte oder gelappte Verzweigungen in der Art von Appressorien (Abb.5), wie sie bei pathogenen Bedingungen versucht, die StämmezurFruchtkörperbildung zu bringen. Dies gelang bei den normalen Agaricus-Stämmeninallen Fällen, die $N R R L$-Stämme dagegen wuchsen nicht einmal in das Deckmaterial hinein, starben bald ab und bildeten keine Hauptfruchtform. Dieses Ergebnis bestätigt auch die Befunde von Humfeld u. Sugihara (1952).

b) Untersuchung der Nebenfruchtform

Zur Gewinnung von Nebenfruchtformen wurden Hängetropfenkulturen auf Biomalzagar angesetzt. Bei normalen Agaricus-Stämmen bildete sich in allen Fällen an ganzen Hyphenabschnitten ein typischer (SARAZIN 1951), dichter Besatz von nadelförmigen $\mathrm{Ca}$-Oxalatkristallen (Abb. 3 und 4), der bei den NRRL-Stämmen stets fehlte.

Der Hyphendurchmesser betrug bei Agaricus bisporus 2,5-5,8 $\mu$, dann unter verschiedenen 
Pilzen häufig sind, die aber bei den normalen Agaricus-Stämmen nicht auftraten.

In Abb.6 ist deutlich zu sehen, wie eine fertile Hyphe, die in der Tiefe Conidien ausgebildet hat, an ihrem Ende, beim Auftreffen auf das Deckglas der Hängetropfenkultur durch diesen mechanischen Reiz zur Appressorienbildung veranlaßt wird.

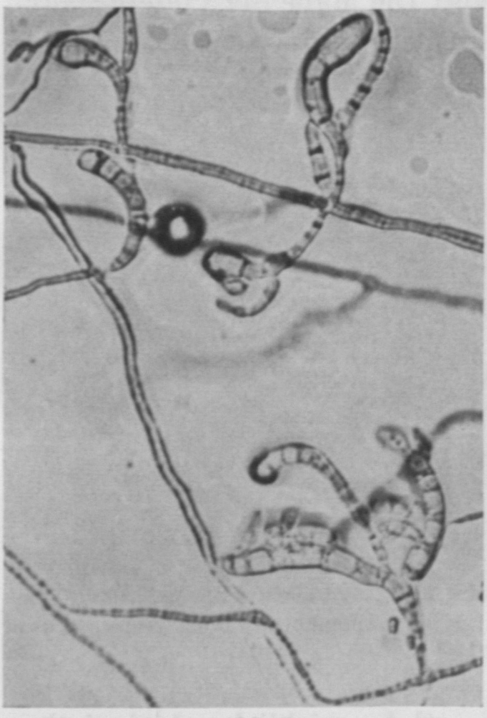

Abb. 5

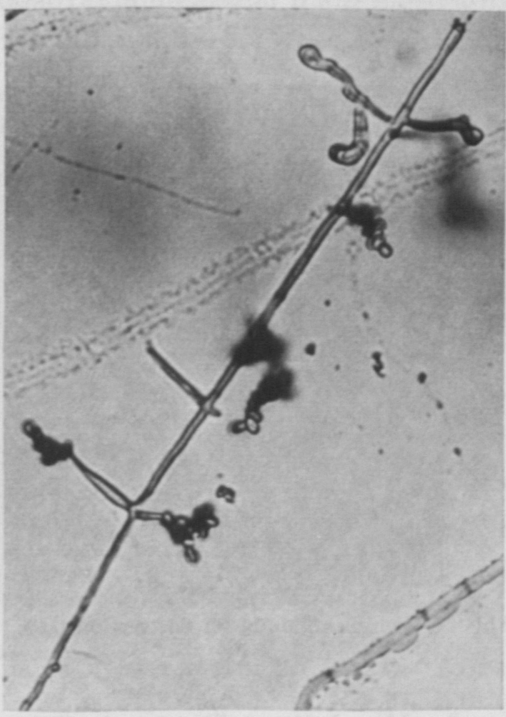

Abb. 6

Abb. 5. Appressorienbildung am Deckglas einer Hängetropfenkultur, Biomalzagar, Stamm NRRL 2335 $(\times 1000)$

Abb.6. Appressorien- und Conidienbildung, Hängetropfenkultur, Stamm NRRL 2335 ( $\times 640)$

Es wurden weiterhin nur bei den NRRL-Stämmen vom 3. Tage an farblose, asexuelle Sporen (Conidiosporen) an meist flaschenförmig angeschwollenen Zellen gebildet (Abb.6, 7).

Auf Grund der bis dahin gewonnenen Befunde (Tab.2) ließ sich bereits feststellen, daß die drei NRRL-Stämme, die untereinander kaum Unterschiede aufweisen, nicht zu den Basidiomyceten gehören, sondern innerhalb der Fungi imperfecti zu den Moniliaceen zu stellen sind.

\section{c) Morphologische Untersuchungen ${ }^{1}$}

Zunächst wurden Entwicklung und Form der asexuellen Fortpflanzungsorgane in Objektträger- und Hängetropfenkulturen genauer untersucht. Die Conidiophoren erscheinen als gewöhnliche, undifferenzierte, septierte Hyphen und tragen die sporogenen Zellen (MacLEoD

1 Die folgenden Untersuchungen zur Identifikation wurden im „Centraalbureau voor Schimmelcultures, Baarn, Holland" durchgeführt.

Arch. Mikrobiol., Bd. 47 
1954 b). Diese sitzen entweder terminal in Wirteln bis zu dreien oder einzeln direkt an den Conidiophoren und sind einzellig, variabel in Form und Größe, jedoch meist bauchig bis flaschenförmig (Abb.7).

Weit über $50 \%$ der Conidiosporen sind oval bis länglich. Sie sind farblos, hyalin, von glatter Oberfläche und sitzen so dicht am Mittelfaden, daß dieser kaum erkennbar ist. In älteren Kulturen kommen außerdem noch längliche Makrosporen vor. Die Maße der Conidiosporen sind 1,8-4,5 $\mu \times 1,8-3,2 \mu$, die der Makrosporen 6,6-9,4 $\mu \times 2,4-3,2 \mu$.

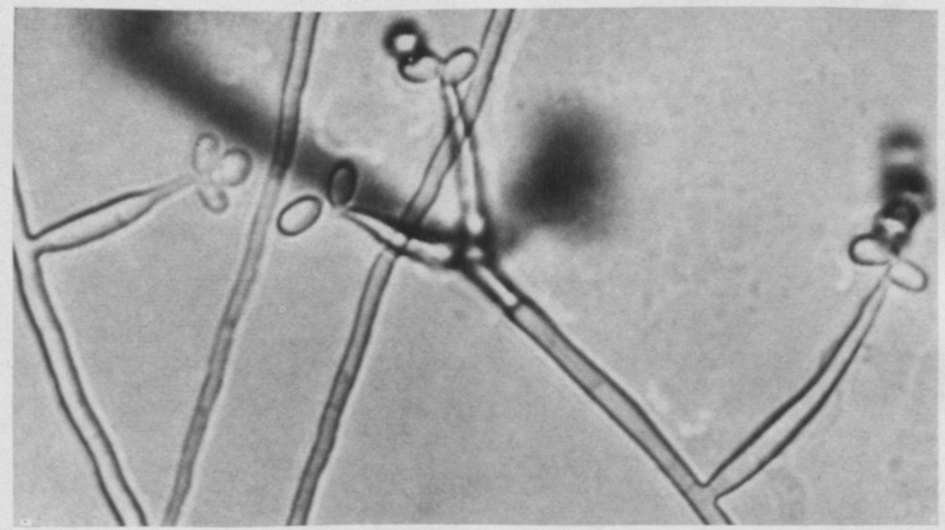

Abb. 7. Conidienbildung an flaschenförmigen Zellen, Hängetropfenkultur, Biomalzagar, Stamm NRRL $2336(\times 1600)$

An Hand dieser Daten, der Literatur und des reichlichen biologischen Vergleichsmaterials wurden die drei NRRL-Stämme als Gattung Beauveria bestimmt und auf Grund der überwiegend ovalen Sporenform zur Art Beauveria tenella (Delacr.) Siem. gestellt.

\section{Vergleich mit authentischen Beauveria-Stämmen}

Um die Bestimmung zu sichern, wurde nun noch die Conidiosporenund Sekundärsporenbildung bei den NRRL-Stämmen und zwei authentischen Beauveria-Stämmen (Beauveria bassiana und Beauveria tenella) untersucht. Außerdem wurde von Stamm NRRL 2335 eine Einsporkultur hergestellt und mit der entsprechenden Vielsporkultur verglichen, wobei weder auf festem noch in flüssigem Substrat Unterschiede festzustellen waren, so daß das Material als einheitlich angesehen werden konnte. Der Vergleich dieser Kulturen mit den authentischen Beauveria-Stämmen ergab ebenfalls keine Unterschiede auf festem und flüssigem Substrat.

Auf verschiedenen festen Nährmedien (Haferflocken-, Heu-, Kartoffel-, Kirsch- und Malzagar) zeigten die NRRL-Einspor- und Vielsporkulturen gegenüber den Beauveria-Stämmen kaum Unterschiede 
in Aussehen, Mycel- und Conidienfarbe. Die Werte der Wachstumsgeschwindigkeit bei den $N R R L$-Stämmen liegen ziemlich nahe beieinander und zwischen den Werten von Beauveria bassiana und Beauveria

Tabelle 3. Vergleich der NRRL-Stämme mit authentischen Beauveria-Stämmen

\begin{tabular}{|c|c|c|c|}
\hline Untersuchung/Merkmal & $\begin{array}{l}\text { Agaricus bisporus } \\
\text { (Mittelwerte) }\end{array}$ & $\begin{array}{c}\text { NRRL-Stämme } \\
\text { (Mittelwerte) }\end{array}$ & $\begin{array}{l}\text { Authent. Beauveria } \\
\text { (Mittelwerte) }\end{array}$ \\
\hline $\begin{array}{l}\text { A. Festes Substrat (Biomalz) } \\
\text { Platten: } \\
\text { Temperaturoptimum }{ }^{\circ} \mathrm{C} \\
\text { Wachstumsgeschwindig- } \\
\text { keit bei } 25^{\circ} \mathrm{C} \mathrm{cm} / \text { Tag } \\
\text { Mycelfarbe } \\
\text { Enzyme: Tyrosinase } \\
\text { Laccase } \\
\text { Katalase } \\
\quad \text { Peroxydase } \\
\text { Hängetropfen: } \\
\text { Ca-Oxalatnadeln } \\
\text { Appressorien } \\
\text { Sporogene Zellen } \\
\text { Länge } \mu \\
\text { größter } \varnothing \mu \\
\text { kleinster } \varnothing \mu \\
\text { Conidiosporen } \\
\text { Länge } \mu \\
\varnothing \quad \mu \\
\text { Makrosporen } \\
\text { Länge } \mu \\
\varnothing \quad \mu\end{array}$ & $\begin{array}{l}23-24 \\
0,19 \\
\text { gelbl. } \rightarrow \text { gelbl. }\end{array}$ & $\begin{array}{l}23-25 \\
0,36 \\
\text { wei } \rightarrow \text { gelbl. } \\
+ \\
++ \\
(+)^{2} \\
(+)^{2} \\
\\
- \\
+ \\
+ \text { farbl. } \\
3,0-25,0 \\
0,7-2,3 \\
0,3-1,1 \\
+ \text { farbl. } \\
1,8-4,5 \\
1,8-3,2 \\
+ \text { farbl. } \\
6,6-9,4 \\
2,4-3,2\end{array}$ & $\begin{array}{l}22-25 / 23-27^{1} \\
0,31 \\
\text { weiß } \rightarrow \text { gelbl. } \\
- \\
-/+++^{1} \\
+ \\
- \\
\\
+ \\
+ \\
+ \text { farbl. } \\
3,0-28,0 \\
1,0-3,5 \\
0,5-1,0 \\
+ \text { farbl. } \\
2,0-6,0 \\
1,5-3,0 \\
+ \text { farbl. } \\
7,0-12,0 \\
3,0-3,5\end{array}$ \\
\hline $\begin{array}{l}\text { B. Submerskultur } \\
\text { sudanophile Granula } \\
\text { Sekundärsporen } \\
\text { Humfeld-Medium : } \\
\text { Farbe, Geruch, Aus- } \\
\text { sehen } \\
\text { Ernte: 6.Tag }{ }^{3} \text { mg Tr.S./ } \\
\text { ml N.M. } \\
\text { pH-Änderung } \\
\text { MacLeod-Medium: } \\
\text { Farbe, Geruch, Aus- } \\
\text { sehen } \\
\text { Ernte: 6.Tag }{ }^{3} \text { mg } \\
\text { Tr.S./ml N.M. } \\
\text { pH-Änderung }\end{array}$ & - & $\begin{array}{l}\text { gleich } \\
\begin{array}{l}15,5 \\
4,3 \rightarrow 6,8 \\
\end{array} \\
\text { gleich } \\
3,1 \\
4,5 \rightarrow 2,2\end{array}$ & 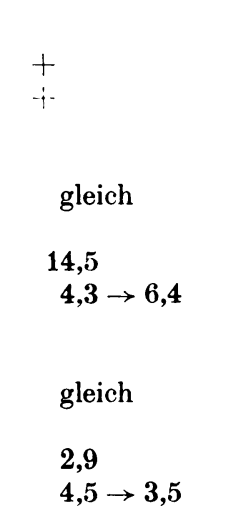 \\
\hline
\end{tabular}


tenella ('Tab.3). Das Temperaturoptimum befindet sich bei den $N R R L$. Stämmen zwischen 23 und $25^{\circ} \mathrm{C}$, bei Beauveria bassiana zwischen 22 und $25^{\circ} \mathrm{C}$. bei Beauveria tenella zwischen 23 und $27^{\circ} \mathrm{C}$.

Die Enzymuntersuchung ergab, daß von beiden Gruppen weder Tyrosinase noch Peroxydase gebildet wurde, Laccase war reichlich (bei Beauveria bassiana jedoch nicht) und Katalase wenig vorhanden (Tab.3).

In Hängetropfenkulturen zeigten auch die authentischen BeauveriaStämme Appressorien-Bildung und stimmten in Form und Größe der sporogenen Zellen und Conidien weitgehend mit den NRRL-Stämmen überein. die Conidiosporen saßen jedoch bei den authentischen BeauveriaStämmen lockerer am Mittelfaden.

In Submers-Schüttelkulturen wurden vergleichende Untersuchungen durchgeführt mit dem Nährmedium nach HumFeld und einem ähnlich zusammengesetzten synthetischen Nährmedium, das MAcLEod (1954a) für Beauveria angibt. In Farbe, Geruch, Feinheit der Verteilung, sowie im mikroskopischen Aussehen der Kulturen, der Tendenz der $\mathrm{p}_{\mathrm{H}}$ - ̈̈nderung im Medium und der Erntemenge herrschte auch hier weitgehende ర toereinstimmung (Tab.3). Während im Medium nach MAcLEoD jeweils stark aufgetriebene und vakuolisierte Zellen entstanden, wurde im Humfeld-Medium normales Mycel gebildet.

Faßt man die Ergebnisse dieser Versuchsreihe zusammen, so bestätigen sie die Bestimmung der NRRL-Stämme als Beauveria tenella (Molitoris 1962a, $1962 \mathrm{~b}$ ).

\section{Diskussion der Hauptergebnisse}

Bei Vorversuchen mit den für eingehendere physiologische Untersuchungen vorgesehenen drei ,Agaricus campestris"-Stämmen NRRL 2334, 2335. 2336 traten Zweifel an deren Identität mit Agaricus campestris auf. Wie nachgewiesen werden konnte, handelte es sich bei diesen Stämmen überhaupt nicht um die Basidiomyceten-Gattung Agaricus, sondern um eine zu den Fungi imperfecti gehörende Moniliacee, Beauveria tenella (Delacr.) Siem.

Um die Möglichkeit auszuschalten, daß bei den eigenen Untersuchungen eine Verunreinigung stattgefunden hatte, wurden die $N R R L$ Stämme noch ein weiteres Mal bezogen und untersucht. Sie zeigten jedoch wiederum die gleichen Eigenschaften.

Da die im Laufe dieser Arbeit gewonnenen Untersuchungsergebnisse mit den bisher über diese Stämme veröffentlichten Befunden übereinstimmen, kann man wohl eine Kontaminierung während der Zeit zwischen der Erstbeschreibung und den jetzigen Untersuchungen ausschließen. Die Stämme können während der Erstuntersuchung in Submerskultur als Verunreinigung eingeschleppt worden sein und das 
ursprüngliche, langsamer wachsende Agaricus-Impfmaterial überwachsen haben.

Es gibt aber auch noch eine weitere Erklärungsmöglichkeit: Der insektenpathogene Pilz Beauveria kommt allgemein auch dort vor, wo Champignons wachsen oder angebaut werden (BELs, persönliche Mitteilung), kann aber auch, wie im Verlaufe dieser Arbeit festgestellt werden konnte, zumindest saprophytisch auf Agaricus-Fruchtkörpern existieren. Bei der Erstisolierung der Stämme durch Humfeld (1948) wurde als Impfmaterial für die Submerskulturen Mycel verwendet, das von Agaricus-Fruchtkörpergewebekulturen stammte (SUgrHara u. Humfeld 1954). Diese konnten nun aber bereits mit Beauveria (Sporen) infiziert gewesen sein. Möglicherweise kam also das Beauveria-Material schon mit dem Impfmaterial in die Submerskultur. Dort überwuchs es wegen der ihm besser zusagenden Lebensbedingungen und der besseren Vermehrungsmöglichkeit durch seine Sekundärsporenbildung den langsamwüchsigen Agaricus-Stamm. Durch äußerliche Ähnlichkeit des Koloniewachstums blieb die Verunreinigung bisher verborgen.

Nach diesem Untersuchungsergebnis ist es nicht mehr verwunderlich, daß die Nahrungsmittelindustrie ihre mit den angeblichen AgaricusStämmen nach einigen Patenten (Humfeld 1952; HuMfeld 1954; SzUECS 1958) aufgenommene Mycelproduktion für Suppen und ähnliche Verwendungszwecke nach einiger Zeit wieder aufgab (STOLLER 1954), da dem Produkt der typische Champignongeschmack fehlte.

Vining, Kelleher u. Schwarting (1962) berichteten kürzlich über einen ähnlichen Fall; ein angeblicher Stamm von Amanita muscaria, der in Submerskultur unter Sekundärsporenbildung gut wuchs, konnte später als Beauveria bassiana identifiziert werden.

\section{Zusammenfassung}

Die drei als Agaricus campestris vom Northern Regional Research Laboratory, Peoria, Ill., bezogenen Stämme NRRL 2334, 2335, 2336, wurden mit authentischen Agaricus-Stämmen verglichen. Auffallende morphologische und physiologische Unterschiede veranlaßten eine Nachbestimmung der NRRL-Stämme. Danach gehören diese nicht den Basidiomyceten, sondern innerhalb der Fungi imperfecti der Moniliaceengattung Beauveria an.

\section{Summary}

Three fungal strains ( $N R R L 2334,2335,2336$ ), supposedly Agaricus campestris and obtained from the Northern Regional Research Laboratory, Peoria, Ill., were compared with authentic Agaricus strains. The observed morphological and physiological differences led to the identification of the former (NRRL 2334, 2335, 2336) as Fungi imperfecti (Family Moniliaceae, Genus Beauveria) and not as Basidiomycetes. 
Mit Unterstützung durch die Deutsche Forschungsgemeinschaft.

Herrn Prof. Dr. H. G. Schlegke danke ich für sein reges Interesse an der Arbeit und ihre stete Förderung.

Der Leitung des „Centraalbureau voor Schimmelcultures“ Baarn, Holland, bin ich für die Stellung eines Arbeitsplatzes zu Dank verpflichtet, ebenso der Fa. Hullen, Erlangen, für die Möglichkeit, in ihren Anlagen Versuche durchzuführen.

\section{Literatur}

Benko, P. J.: Studies on the submerged cultivation of edible mushrooms. MI. S. Thesis, Univ. Calif., Calif. (1958).

Burkholder, P. R., and E. IV. Sinnott: Morphogenesis of fungus colonies in submerged shaken cultures. Amer. J. Bot. 32, 424-431 (1945).

EDDY, B. P.: Production of mushroom mycelium by submerged cultivation. J. Sci. Food Agr. 9, 644-649 (1958).

Falanghe, H.: Production of mushroom mycelium as a protein and fat source in submerged culture in medium of vinasse. Appl. Microbiol. 10, 572-576 (1962).

HewitT, B. R.: Spectrophotometric determination of total carbohydrate. Nature (Lond.) 184, 246-247 (1958).

Hughes, D. H.: Preliminary characterisation of the lipid constituents of the cultivated mushroom Agaricus bisporus. Mushroom Sci. V, 540-546 (1962).

HUMFELD, H.: The production of mushroom mycelium in submerged culture. Science 107, 273-275 (1948).

- Production of mushroom mycelium. US. Dept. Agric., Yearbook Agric. 1951/52, 242-246.

- Production of mushroom mycelium. US. Pat. 2618900 (1952).

-, and T. F. Sugrhara: Mushroom mycelium production by submerged propagation. Food Technol. 3, 355-356 (1949).

- - The nutrient requirements of Agaricus campestris grown in submerged culture. Mycologia (N. Y.) 44, 605-620 (1952).

Jennison, M. W.: Cultivation of mushroom mycelium in submerged culture. Mushroom Sci. III. 268 (1956).

- C. G. Richberg and A. E. Krikszens: Physiology of woodrotting basidiomycetes. II. Nutritive composition of mycelium grown in submerged culture. Appl. Microbiol. 5, 87-95 (1957).

KLIgMan, A. M.: Secondary spores in the mycelium of the cultivated mushroom Psalliota campestris. Amer. J. Bot. 29, 304-308 (1942).

LYR, H.: Uber den Nachweis von Oxydasen und Peroxydasen bei höheren Pilzen und die Bedeutung dieser Enzyme für die Bavendamm-Reaktion. Planta (Berl.) 50, 359-370 (1958).

MacLeod, D. M.: Natural and cultural variation in entomogenous fungi imperfecti. Ann. N. Y. Acad. Sci. 60, 58-70 (1954a).

- Investigation on the genera Beauveria Vuill. and Tritirachium Limber. Canad. J. Bot. 32, 818-890 (1954 b).

Molitoris, H. P.: Identification of purported Agaricus campestris strains (NRRL $23.34,2335,2336$ ) as Beauceria tenella (Delacroix, Siem.). Nature (Lond.) 194, 316 (1962).

- Bestimmung der Agaricus campestris Stämme NRRL 2334, 2335, 2336 als Beauveria tenella (Delacroix, Siem.). Mushroom Sci. V, 218-230 (1962 b).

Moustafa, A. M.: Nutrition and the development of mushroom flavor in Agaricus campestris mycelium. Appl. Microbiol. 8, 63-67 (1960).

O'NeIL, J. J.: Studies in the submerged culture production of mushroom mycelium. M. S. Thesis, Mass. Inst. Technol., Cambridge, Mass. (1956). 
Reusser, F., J. F. T. Spencer and H. R. Sallans: Protein and fat content of some mushrooms grown in submerged culture. Appl. Microbiol. 6, 1-4 (1958).

Rhodes, M.: Viability of dried bacterial cultures. J. gen. Microbiol. 4, 450-456 (1950).

Robbiss, W. J., and A. Hervey: Wood, tomato and malt-extracts and growth of some Basidiomycetes. Mycologia (N. Y.) 50, 745-752 (1958).

Sarazin, A.: The cultivated mushroom. MGA Bulletin 24, 1-75 (1951).

Stoller, B. B.: Principles and practice of mushroom culture. Econ. Bot. 8, 48-95 (1954).

Stgihara. T. F., and H. Humfeld: Submerged culture of the mycelium of various species of mushroom. Appl. Microbiol. 2, 170-172 (1954).

SzuECS, J.: Method for growing mushroom mycelium and the resulting products. US. Pat. 2850841 (1958).

Treschow, C.: Nutrition of the cultivated mushroom. Dansk. bot. Ark. 11, 1-180 (1944).

Vising, L. C., W. J. Kelleher and A. E. Schwarting: Oosporein production by a strain of Beauveria bassiana originally identified as Amanita muscaria. Canad. J. Microbiol. 8, 931-933 (1962).

Dr. H. P. Molitoris,

Institut für Mikrobiologie der Universität, 34 Göttingen, Goßlerstraße 16 

Archiv für Mikrobiologie 47, 72-103 (1963)

Aus dem Institut für Mikrobiologie der Universität Göttingen

\section{Untersuchungen an Beauveria tenella \\ (NRRL 2334, 2335, 2336; bisher Agaricus campestris)}

II. Wachstum, Stoffwechsel, Fettspeicherung und Enzymaktivitäten
Von
H. P. Molitoris

Mit 13 Textabbildungen

(Eingegangen am 27. Juli 1963) 
In dem vorausgegangenen Teil der Arbeit (Molitoris 1963a) wurde über allgemeine Charakteristica, die Morphologie und systematische Stellung der Stämme NRRL 2334, 2335, 2336 berichtet. Sie konnten als Beauveria tenella (Delacr.) Siem. identifiziert werden. Im folgenden soll über die weiteren Untersuchungen bezüglich des Wachstums, des Stoffwechsels und der Fettspeicherung dieser Stämme sowie ihrer Enzym. aktivitäten berichtet werden.

Die Pilze der Gattung Beauceria erregten zuerst Aufmerksamkeit als Erreger der im 18. und 19. Jahrhundert berüchtigten Krankheit des Seidenspinners (Bombyx mori L.), die damals der Seidenindustrie beträchtliche Verluste verursachte. Agostixo Bassi isolierte 1834 von einer infizierten Seidenspinnerraupe den später nach ihm benannten Pilz Beauceria bassiana als den Erreger dieser Krankheit und war damit wohl der erste Untersucher (FILdes 1951), der ein ,kleines Lebewesen“ als Erreger einer Krankheit entdeckt und beschrieben hat.

Die systematische Stellung der Beauceria-Arten wechselte im Laufe der Zeit häufig, bis schließlich MACLEOD (1954a, 1954 b) diese Gattung eingehend nachuntersuchte. Er reduzierte die zahlreichen Arten nach Abtrennung anderer Gattungen auf zwei, nämlich Beauveria bassiana und Beauveria tenella, die sich nur durch ihre Sporenform unterscheiden.

Die Untersuchungen an Beaureria wurden hauptsächlich im Hinblick auf ihren Parasitismus an Insekten durchgeführt (MADELIx 1960), einerseits als unerwünschter Erreger der Seidenspinnerkrankheit, andererseits aber auch als willkommener Helfer in der biologischen Bekämpfung von Schadinsekten wie des Kartoffelkäfers (Leptinotarsa decemlineata L.), des Maikäfers (Melolontha melolontha L.) und anderer (vgl. Fraxz 1961).

In jüngerer Zeit wurden auch Versuche über die Wachstumsansprüche in Submerskultur angestellt (MacLeod 1954b; Huber 1958; Cordon u. Schwartz 1962), sowie über die Produktion von Chitinase (Huber 1958; Claus 1961), die der Pilz für die Durchdringung der Insektencuticula benötigt.

Durch die Identifizierung der bisher als Agaricus campestris geltenden Stämme NRRL 2334, 2335, 2336 als Beauveria tenella, tragen nun auch die an ihnen durchgeführten Untersuchungen zur Kenntnis der Gattung 
Beauveria bei. Diese Versuche wurden vor allem unter kommerziellen Aspekten zum Einsatz des Pilzes in der Champignonkultur, oder zur Herstellung von Mycel für Suppen und ähnlichem durchgeführt.

Sie beschäftigten sich mit Kulturverfahren, Nährstoffansprüchen und dem Einfluß verschiedener Faktoren auf Entstehung und Verbesserung des erwünschten Champignongeschmackes (Humfeld 1948; HumFeld u. SUgrhara 1949; HumFeld 1950/51; Humfeld u. Sugihara 1952; Sugihara u. Humfeld 1954; Szuecs 1956; O'Neil 1956; Benko 1958; Reusser, Spencer u. Sallans 1958; Moustafa 1960; Falanghe 1962).

Ein in Submerskultur gut wachsender Stamm des Fliegenpilzes Amanita muscaria L., wurde kürzlich ebenfalls als Beauveria (bassiana) identifiziert. Mit ihm waren bereits Submerskulturversuche über Nährstoffansprüche und einen ausgeschiedenen Farbstoff durchgeführt worden (PACIFICI et al. 1960; Vining, KeLLEHER u. SCHWARTING 1962).

\section{A. Organismen und Methoden}

\section{Organismen}

Es wurden wiederum die Stämme NRRL 2334, 2335, 2336 verwendet und auf Biomalzagar-Schrägröhrchen $\left(2,5 \%\right.$ Biomalz, 1,5\% Agar, $\mathrm{p}_{\mathrm{H}}$ 5,5) durch Sporenüberimpfung vermehrt.

\section{Nährmedien}

Wie in der vorhergehenden Arbeit (MoLIToRIs $1963 \mathrm{a}$ ) kamen Biomalznährlösung und das Medium nach Humfeld u. Sugrhara (1949) zur Verwendung und wurden ebenso angesetzt. Weiterhin wurde ein Mineralmedium folgender Zusammensetzung benutzt: Grundmedium: $\mathrm{KH}_{2} \mathrm{PO}_{4} 1,0 \mathrm{~g} ; \mathrm{MgSO}_{4} \cdot 7 \mathrm{H}_{2} \mathrm{O} \mathrm{0,4} \mathrm{g} ; \mathrm{CaCl}_{2} 0,15 \mathrm{~g} ; \mathrm{H}_{2} \mathrm{SO}_{4}$ $1,0 \mathrm{n} \mathrm{1,5} \mathrm{ml}$; Spurenelementlösung $\left(\mathrm{FeCl}_{3} \cdot 6 \mathrm{H}_{2} \mathrm{O} 0,25 \mathrm{~g} ; \mathrm{MnCl}_{2} \cdot 4 \mathrm{H}_{2} \mathrm{O} \mathrm{0,36} \mathrm{g}\right.$; $\mathrm{ZnCl}_{2}$ 0,20 g; $\mathrm{CuSO}_{4} \cdot 5 \mathrm{H}_{2} \mathrm{O} 0,005 \mathrm{~g}$; aqua dest. auf $1000 \mathrm{ml}$ ) $20,0 \mathrm{ml}$; C-Quelle (verschiedene Mengen Biomalz oder Glucose); aqua dest. auf $900 \mathrm{ml}$; mit $\mathrm{NaOH}$ auf $p_{H}$ 7,5. Stickstoffquelle: $1 \%$ Harnstofflösung in aqua dest., steril filtriert. Das Grundmedium wurde zu je $36 \mathrm{ml}$ in $300 \mathrm{ml}$ Erlenmeyerkolben gefüllt, autoklaviert (15 min bei 1,2 atü) und dann unter sterilen Bedingungen mit je $4 \mathrm{ml}$ der Harnstofflösung versetzt (Endkonzentration Harnstoff $=0,1 \%$; Stickstoff $=0,05 \%$ ).

Aus Testbestimmungen ergab sich, daß unter den gewählten Bedingungen die Caramelisierung der Glucose so gering war, daß sich eine getrennte Sterilisation erübrigte. Bei Versuchen mit zusätzlichen C-Quellen in kleinen Mengen (Crotonat, Acetat, Lactat, Pyruvat) wurden diese mit dem Harnstoff steril filtriert und zugegeben.

\section{Methodik}

\section{a) Zellanzucht und Ernte}

Die Anzucht der Zellen erfolgte entweder in Schüttelkolben (300 ml Erlenmeyerkolben, $40 \mathrm{ml}$ Inhalt, Watte oder Schaumstoffhauben, Schüttelmaschine mit $3 \mathrm{~cm}$ Weg und $150 \mathrm{Hin}$ - und Hergängen/min) oder in Rührkultur bei jeweils $27^{\circ} \mathrm{C}$ im Dunkeln. Von den Kolben wurde täglich der sich bildende Rand abgeschüttelt. Die Rührkultur wurde in 21 -Zweihals-Rundkolben durchgeführt. Diese enthielten je 1 l Nährlösung, die magnetisch gerührt (etwa $650 \mathrm{U} / \mathrm{min}$ ) und gleichzeitig mit steriler, befeuchteter Luft (etwa $60 \mathrm{l} / \mathrm{Std} / \mathrm{l}$ Nährlösung) durchströmt wurde (Schlegel, Kaltwasser u. GotTschalk 1961).

Beimpft wurde jeweils entweder direkt mit Agarmycelstückchen $(5 \times 5 \mathrm{~mm})$ einer mindestens 3 Wochen alten Biomalzagarkultur oder im Verhältnis 1:10 mit 
einer 3 Tage alten Vorkultur, die bei $27^{\circ} \mathrm{C}$ auf der Schüttelmaschine angezogen wurde.

\section{Tabelle 1. Aufarbeitungs-Schema der Flüssigkeitskulturen}

A

Dreimal je 1 Schüttelkolben

(oder Rührkulturprobe)

$\downarrow$

$p_{H}$, makroskop. und mikroskop. Lnters.<smiles>[V]</smiles>

Abnutschen auf Kieselgurfilterpapier

(Schl. \& Sch. Nr. 287), waschen

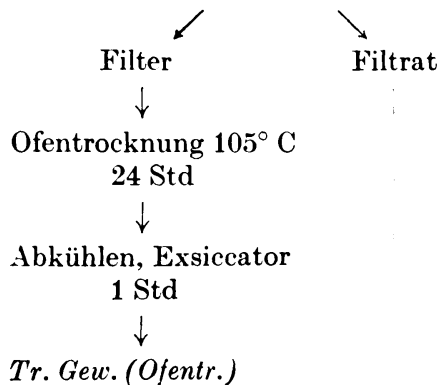

Tr. Gew. (Ofentr.)

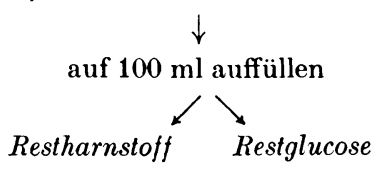

B

Inhalt von mind. 3 Schüttelkolben (oder Rührkulturproben)

$p_{H}$, makroskop. und mikroskop. Unters.

Abzentrifugieren, zweimal waschen

Gefriertrocknen, 24 Std, $-40^{\circ} \mathrm{C}$

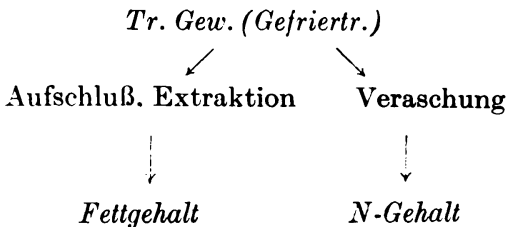

(Mikrokjeldahl)

Die Ernte der Zellen erfolgte nach dem Schema in Tab.1. Falls erforderlich, wurden die Zellen nach dem Abzentrifugieren bis zur Weiterverarbeitung bei $-20^{\circ} \mathrm{C}$ eingefroren. Wenn nicht anders vermerkt, wurden für jeden Wert drei Kolben oder Proben aufgearbeitet und das Mittel der Parallelbestimmungen angegeben.

\section{b) Bestimmungsmethoden}

Das Trockengewicht der Zellen wurde wieder durch Ofentrocknung $\left(105^{\circ} \mathrm{C}\right)$ bestimmt, oder das Material wurde in einer Gefriertrocknungsanlage der Fa. Schütt/ Göttingen bei $-40^{\circ} \mathrm{C}$ und $10^{-2}$ Torr bis zur Gewichtskonstanz getrocknet und in den Trocknungskolben gewogen.

Die $p_{H}$-Messung wurde mit der Glaselektrode und dem $p_{H}$-Meßgerät der Fa. Metrohm, Herisau/Schweiz vorgenommen.

Die Bestimmung der Glucose im Kulturmedium wurde mit dem Anthronreagens nach HEwITT (1958) in einem Zeiss-Photometer (PMQ II) durchgeführt; die Methode wurde durch einige Parallelbestimmungen mit dem Fehlingschen Reagens nach Lehmann, Maquenne u. Schoorl (1932) geprüft.

Der Harnstoff im Kulturfiltrat wurde enzymatisch mit Urease (Merck 8489) nach BACER u. MoLL (1960, modifiziert nach eigenen Erfahrungen) bestimmt.

Die Ermittlung des Mycelstickstoffgehaltes erfolgte im Mikrokjeldahl nach Pelczar, Hansen u. Konetzka (1956). 


\section{c) Lipiduntersuchung}

Für alle Extraktionen wurde gefriergetrocknetes Mycel verwendet.

Extraktion ohne vorhergehenden Aufschluß: Das Mycel wurde allein durch Schütteln mit verschiedenen Lösungsmitteln in Erlenmeyerkolben auf der Schüttelmaschine bei $27^{\circ} \mathrm{C}$ extrahiert. Anschließend wurde es auf Kieselgur-Filterpapier (Schl. \& Sch., Nr. 287) abfiltriert, nachgewaschen und der Extrakt auf ein bestimmtes Volumen aufgefüllt.

Zur Extraktion im Soxhlet-Perforator wurden je $500 \mathrm{mg}$ Trockensubstanz mit je $50 \mathrm{ml}$ Äther bei $50^{\circ} \mathrm{C} 24$ Std lang behandelt.

Aufschluß mit dem Mickle-Desintegrator: Je $250 \mathrm{mg}$ Trockensubstanz wurden durch Schütteln mit je $1 \mathrm{~cm}^{3}$ Glaskugeln $(1 \mathrm{~mm} \varnothing)$ und $5 \mathrm{ml}$ Äther je Gefäß mechanisch aufgeschlossen. Schüttelzeit und Intensität wurden variiert. Das aufgeschlossene Mycel wurde mit $45 \mathrm{ml}$ Äther in $300 \mathrm{ml}$ Erlenmeyerkolben überführt und $24 \mathrm{Std}$ wie oben auf der Schüttelmaschine extrahiert und weiterbehandelt.

Aufschluß im Potter-Elvehjem-Homogenisator (Potter u. Elvehjex 1935): $250 \mathrm{mg}$ Trockensubstanz wurden mit $10 \mathrm{ml}$ Äther verschieden lange bei verschiedener Umdrehungszahl zerrieben, mit $40 \mathrm{ml}$ Äther in $300 \mathrm{ml}$ Erlenmeyerkolben überführt und wie oben weiterbehandelt.

Zur Bestimmung von Anwesenheit und Menge von Poly- $\beta$-Hydroxy-Buttersäure (PHBS) wurde die gewogene Mycelmenge mit Chloroform im Verhältnis 1:24 24 Std bei Zimmertemperatur extrahiert, abfiltriert und nachgewaschen. Im Filtrat kann vorhandene PHBS mit Äther ausgefält, auf gewogener Fritte abgenutscht und nach dem Trocknen gravimetrisch bestimmt werden.

Zur gravimetrischen Bestimmung der Gesamtlipide wurde der von einer bestimmten Mycelmenge gewonnene Ätherextrakt in einem gewogenen Becherglas unter der IR-Lampe bis zur völligen Vertreibung des Lösungsmittels eingedampft, über $\mathrm{CaCl}_{2}$ und Paraffin getrocknet und gewogen.

Die serienmäßige Lipidbestimmung wurde mit der Estergruppenbestimmung nach SNyder u. Stephexs (1959) vorgenommen. Prinzip: Das aus dem alkalischen Hydroxylamin und den hydrolysierten Fetten gebildete Fettsäurehydroxamat reagiert mit $\mathrm{Fe}^{+++}$im Sauren zu einem purpurnen Komplex, der gegen die reine Reagentienlösung bei $530 \mathrm{~m} \mu$ im Zeiss-Photometer gemessen wird. Bei jeder Bestimmung liefen Triolein-Eichwerte mit. Die Reagentien wurden täglich frisch angesetzt.

\section{d) Arbeiten mit zellfreien Extrakten}

Zur Herstellung von Arylaminacetylase wurde das Acetontrockenpulver aus frischen Taubenlebern in Anlehnung an KaPLAN u. LipManv (1948) hergestellt. Das teilweise gereinigte Enzym wurde im Prinzip nach Chou u. LipManv (1952) und Tabor, Mehler u. Stadtian (1953) nach Verwerfen der ersten Acetonfällung $(\mathbf{4 4} \%$ Sättigung) als Acetonniederschlag bei $\mathbf{7 5 \%}$ Sättigung hergestellt, in Phosphatpuffer $\left(\mathrm{m} / 2000 ; \mathrm{p}_{\mathrm{H}} 6,8 ; \mathrm{m} / 1000 \mathrm{ADTA}^{1} ; \mathrm{m} / 1000\right.$ Cystein) aufgenommen und bei $-20^{\circ} \mathrm{C}$ in kleinen Portionen eingefroren.

Herstellung zellfreier Extrakte: Normale Schüttelkulturzellen von HumfeldMedium wurden nach 27 stündiger Hauptkultur aus der aktivsten Wachstumsphase

${ }^{1}$ Die folgenden Abkürzungen werden benutzt: Acetyl-CoA = Acetyl-

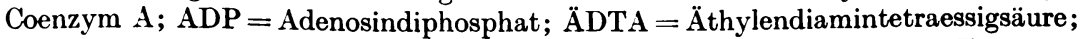
BTS = Brenztraubensäure; F-6-P = Fructose-6-Phosphat; F-1,6-DP = Fructose1,6-Diphosphat; IDP = Inosindiphosphat; $\mathrm{NADH}_{2}=$ Nicotinamid-Adenin-Dinucleotid (reduziert); PEP = Phosphoenolbrenztraubensäure; Ri-5-P = Ribose-5Phosphat; Ru-1,5-DP = Ribulose-1,5-Diphosphat; $\quad$ Tr.S. = Trockensubstanz; Tris-Puffer $=$ Tris-(Hydroxymethyl)-Aminomethan-HCl-Puffer. 
geerntet und mit der Cepa-Schnellzentrifuge (C. Padberg, Lahr/Baden) bei $14000 \cdot g$ abzentrifugiert, in Phosphatpuffer (m/20; $p_{H} 7,4 ; \mathrm{m} / 2000$ ÄDTA; m/2000 Cystein; $0^{\circ} \mathrm{C}$ ) aufgenommen, nochmals zentrifugiert und bei $-20^{\circ} \mathrm{C}$ in kleinen Portionen eingefroren.

Für die Herstellung der Extrakte zur Bestimmung der BTS-Dehydrogenase, Phosphoketolase und Aldolase wurde das Zellmaterial nach Hughes (1951) in der sogenannten „Hughes-Presse“ (Schandon Scientific Co./London) auf $-30^{\circ} \mathrm{C}$ unterkühlt, die gefrorene Zellmasse dann hydraulisch durchgepreßt und dabei aufgeschlossen. Die Abtrennung der Zellreste erfolgte durch Zentrifugieren (30 min, $17000 \cdot g, 0^{\circ} \mathrm{C}$ ). Das Ưberstehende wurde soweit nötig, bis zur Weiterverarbeitung in kleinen Portionen bei $-20^{\circ} \mathrm{C}$ eingefroren.

Da bei der Bestimmung der Ru-1,5-DP-Carboxylase, PEP-Carboxylase und Triosephosphat-Isomerase Phosphationen stören, wurde das Mycel hierfür vor dem Aufschluß mit reichlich Pufferlösung ( $\mathrm{p}_{\mathrm{H}} 7,4 ; \mathrm{m} / 2000$ ÄDTA; m/2000 Cystein) gewaschen, wie oben aufgeschlossen und anschließend in Tris-Puffer $\left(\mathrm{m} / 20 ; p_{H} 7,6\right)$ aufgenommen, abzentrifugiert und eingefroren.

Bestimmungsmethoden: Die Proteinbestimmung wurde nach der von BEISENHERZ et al. (1955) abgewandelten Biuretmethode vorgenommen. Zur Entfernung störender Salzkonzentrationen im Enzymextrakt wurden die Proteine nach BücHER (unveröffentlicht) umgefällt und der nach Reagenszugabe entstehende gefärbte Komplex bei $546 \mathrm{~m} \mu$ im Eppendorf-Photometer gemessen.

Aldolase wurde mit der Boehringer Testkombination „Aldolase“ (Boehringer a) bestimmt. Meßgröße war dabei die Abnahme der $\mathrm{NADH}_{2}$-Extinktion bei $366 \mathrm{~m} \mu$ im Eppendorf-Photometer. Nach Auftragen der Extinktionswerte gegen die Zeit kann aus dem Bereich der linearen Extinktionsabnahme $\Delta \mathrm{E} /$ Zeiteinheit bestimmt werden. Aus $\Delta E$, dem molaren Extinktionskoeffizienten des Substrats und dem Proteingehalt des Enzymextraktes kann die spezifische Aktivität des Enzyms in $\mu \mathrm{M}$ Substrat/mg Enzymprotein/min berechnet werden.

Triosephosphat-Isomerase wurde nach Biochemica-Boehringer (Boehringer b) bestimmt. Meßgröße war wiederum die Abnahme der $\mathrm{NADH}_{2}$-Extinktion.

BTS-Dehydrogenase und Phosphoketolase wurden in einem kombinierten optischen Test (Schindler, persönliche Mitteilung) bestimmt. Als Substrate der Phosphoketolase wurden F-6-P und Ri-5-P eingesetzt.

Zur Bestimmung von Ru-1,5-DP-Carboxylase wurde der Einbau von radioaktivem $\mathrm{CO}_{2}$ und dessen Nachweis in den entstehenden Triosephosphaten nach PETERKOFSKY u. RACKER (1961) geprüft. Nach Abstoppen der Reaktion und Abzentrifugieren wurde $0,1 \mathrm{ml}$ des Uberstehenden auf ausgestanzte Aluminiumplättchen mit „Josephspapier“ aufgetragen und unter der IR-Lampe getrocknet (LAFFERTY 1963).

PEP-Carboxylase wurde nach Suzuki u. Werkman (1958) untersucht. Dabei wird der Einbau von radioaktivem $\mathrm{CO}_{2}$ in PEP im dadurch markierten Oxalacetat nachgewiesen.

Die Anwesenheit von Oxalessigsäure-Carboxylase wurde im gleichen Ansatz durch Zugabe von ADP (Boehringer) geprüft. Das Oxalacetat wurde mit dem 2,4-Dinitrophenylreagens nach SHRINER et al. (1956) ausgefällt und auf einem Membranfilter niedergeschlagen (SchlEgEL u. LAFFERTY 1961) und getrocknet.

Die Radioaktivität der Proben wurde mit einem Endfensterzählrohr (Massenbelag $1,15 \mathrm{mg} / \mathrm{cm}^{2}$ ) im Abstand von $5,0 \mathrm{~mm}$ gemessen. Die Meßeinrichtung (Frieseke \& Hoepfner/Erlangen) bestand aus dem Probenwechsler FH 448, dem Zählgerät FH 49 und dem Zeitdrucker FH 449. 


\section{B. Versuche und Ergebnisse}

\section{Wachstumsphysiologische Versuche}

Es sollte das Wachstum der drei Stämme mit verschiedenen Substraten und unter variierten Kulturbedingungen untersucht und schließlich durch Aufnahme einer Wachstumskurve der zeitliche Verlauf des Wachstumsvorganges verfolgt werden.

a) Einfluß des Nährmediums und des $p_{H}$-Wertes

Wie bereits Humfeld u. Sugihara (1949), Szuecs (1956) sowie Reusser, Spencer u. Sallass (1958) gefunden hatten, konnte eine ganze Reihe definierter und komplexer C-Quellen zum Wachstum verwertet werden. Ausnahmen bildeten lediglich Lactose, l-Rhamnose und

Tabelle 2. Vergleich der Trockensubstanzbildung in verschiedenen Nährmedien

\begin{tabular}{|c|c|c|c|c|c|c|c|}
\hline \multirow[b]{2}{*}{ Nährmedium } & \multirow[b]{2}{*}{$\begin{array}{c}\text { Ernte- } \\
\text { tag }\end{array}$} & \multicolumn{2}{|c|}{ St. 23.34} & \multicolumn{2}{|c|}{ st. 2.3.3.5 } & \multicolumn{2}{|c|}{ St. 23.36} \\
\hline & & $\begin{array}{l}\text { Tr. s. } \\
\mathrm{mg} / \mathrm{ml}\end{array}$ & $\begin{array}{c}\text { Aush. } \\
\%\end{array}$ & $\begin{array}{l}\text { Tr.s. } \\
\mathrm{mg} / \mathrm{ml}\end{array}$ & $\underset{\%}{A}{ }^{A}$ & $\begin{array}{l}\text { Tr. s.' } \\
\mathrm{mg} / \mathrm{ml}\end{array}$ & $\underset{\%}{\text { Aush. }{ }^{2}}$ \\
\hline $\begin{array}{l}5^{0^{\prime}}{ }_{0} \text { (iluc. (Humfeld-Med.. } \\
\left.p_{\mathbf{H}} 4,5\right)\end{array}$ & 6. & 15.4 & 30,8 & 16,6 & 33,2 & 14,6 & 29,2 \\
\hline $\begin{array}{l}1 \% \text { (iluc. (MacLeod-Med.) } \\
5 \%=0,28 \mathrm{~m} \text { Gluc. }\end{array}$ & 6. & 3.0 & 30.0 & 3.0 & 30.0 & 3.2 & 32.0 \\
\hline $\begin{array}{l}\left.\text { (Humfeld-Med.. } p_{H} 4.5\right) \\
4.10 \%=0,28 \mathrm{~m} \text { Acetat }\end{array}$ & 7. & 16.7 & & & & & \\
\hline $\begin{array}{l}\left.\text { (Humfeld-Med.. } \mathrm{p}_{\mathrm{H}} 4.5\right) \\
2,3 \%=0.28 \mathrm{~m} \text { Crot. }\end{array}$ & 7 . & $0.3^{3}$ & & & & & \\
\hline (Humfeld-Med., $\mathrm{p}_{\mathrm{H}}$ 4.5) & 7. & $0.3^{3}$ & & & & & \\
\hline $\begin{array}{l}5 \% \text { Gluc. (Humfeld-Med.. } \\
p_{\mathrm{H}} \text { 4,5) } \\
5 \% \text { Gluc. (Humfeld-Med.. }\end{array}$ & 9. & 18,5 & 37,0 & & & 15.7 & 31,4 \\
\hline $\begin{array}{l}\left.p_{H} 6.0\right) \\
2 \% \text { Gluc. + Min. Lösg. }\end{array}$ & 9. & 14.9 & 29,8 & & & & \\
\hline + Harnst. & 9. & 6,6 & 30,3 & 6,9 & 34,5 & 5,9 & 29,5 \\
\hline $5 \%$ Biomalz + Min. Lösg. & 9. & 6,5 & 13,0 & 5,8 & 11,6 & 5,2 & 10,4 \\
\hline $5 \%$ Biomalzlösung & 9. & 5,1 & 10,2 & 7,1 & 14.2 & 4,5 & 9,0 \\
\hline
\end{tabular}

1 Tr.S. = Trockensubstanz, Ofentrocknung, $24 \mathrm{Std} 105^{\circ} \mathrm{C}$.

2 Ausb. $=\%$ Ausbeute: $\frac{\text { g gebildete Trockensubstanz } \cdot 100}{\text { g eingesetzte C-Quelle }}$

${ }^{3}$ Praktisch kein Wachstum.

Die Beimpfung erfolgte in allen Fällen durch Agarmycelstückchen.

Na-Carboxymethylcellulose. Um Vergleichswerte über das Wachstum der drei Stämme zu erhalten und um einige weitere Substrate zu testen, wurden wie üblich Schüttelkulturen angesetzt und mit Agarmycelstückchen beimpft. Die Zusammensetzung der Nährlösungen, der Erntezeitpunkt sowie die erzielten Trockensubstanzmengen gehen aus Tab.2 hervor. 
Demnach konnte von den untersuchten Substraten das Medium nach Humfeld am besten verwertet werden. Ein Anfangs- $\mathrm{p}_{H}$ von $4, \tilde{5}$ erwies sich dabei als günstiger. Acetat und Crotonat waren als alleinige C-Quellen ungeeignet. Der Stamm NRRL 2335 lag in der Trockensubstanzbildung meist an der Spitze.

b) Wachstumskurven

Einfluß verschiedener Substrate. Impf- und Kulturverfahren

$\mathrm{Da}$ in den vorangegangenen Versuchen der Zeitfaktor nicht berücksichtigt worden war. wurden mit den bereits vorher untersuchten Nährmedien Wachstumskurven mit Stamm NRRL 2334 aufgenommen und dabei $\mathrm{p}_{\mathrm{H}}$ und Trockengewicht

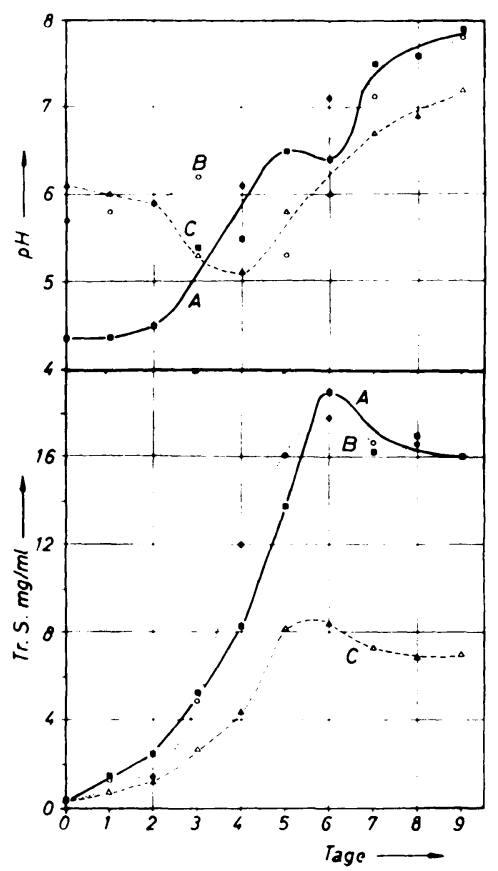

Abb.1. Wachstumskurven. Abhängigkeit der Trockensubstanzbildung und des $\mathrm{p}_{\mathrm{H}}$-Wertes von der Kulturdauer bei verschiedenen Nährmedien. $A \longrightarrow 5 \%$ Glucose, $0,3 \%$ Harnstoff (Humfeld-Medium, MI $^{4,5}$ ): B $\circ \cdots \cdots \circ 5 \%$ Glucose, $0,3 \%$ Harnstoff (Humfeld-Medium, pr 6,0);C $\Delta-\cdots \Delta 2 \%$ Glucose, $0,1 \%$ Harnstoff und Mineralmedium. Schüttelkultur, Beimpfung mit Agarmycelstückchen Stanm NRRL 2334 bestimmt. Beimpft wurden die Kolben mit Agarmycelstückchen. Mit dem Medium, das sich bei diesen Versuchen als das giinstigste herausstellte, sollte dann in weiteren Versuchen der Einfluß von Impfund Kulturverfahren auf das Wachstum festgestellt werden.

Die Abhängigkeit des Wachstums und $\mathrm{p}_{\mathrm{H}}$-Wertes von der Kulturdauer bei verschiedenen Nährmedien ist in Abb. 1 dargestellt. Bei allen Nährmedien wurde das Maximum der Trockensubstanzbildung zwischen dem 5. und 6. Kulturtag erreicht, bei Medium C (2\% Glucose) am ersten, bei Medium A (Humfeld-Medium, $5 \%$ Glucose, $\left.p_{H}=4,5\right)$ am letzten. Ansatz C erbrachte im Verhältnis zur eingesetzten Kohlenhydratmenge etwas höhere Erträge, doch waren im Hinblick auf die weiteren Versuche die Nährmedien günstiger, die bei höherer Substratkonzentration auch erhöhte Mycelmengen bringen. Die beiden Wachstumskurven mit dem Medium nach Humfesd zeigten wieder eine leichte Überlegenheit eines niedrigen Anfangs-p $p_{H}$ und bestätigten so die Ergebnisse des vorhergehenden Versuches.

Der vor allem bei Ansatz A (mit niedrigem Anfangs- $p_{H}$ ), in geringerem Maße aber auch bei $\mathrm{B}$ zu beobachtende anfängliche Anstieg des $p_{H}$-Wertes bis zu einem Maximum, ist durch die Spaltung des Harnstoffes zu erklären. Bei Medium C. dessen Harnstoffgehalt um zwei 
I)rittel unter dem der anderen Medien lag. kam es zu keinem anfänglichen $p_{H}$-Anstieg. Bei allen Ansätzen fällt der $p_{H}$-Wert unmittelbar vor oder bei Erreichen des Maximums der Trockensubstanzbildung auf ein Minimum ab, hervorgerufen durch die völlige Aufnahme der AmmoniumIonen in die Zellen. Der anschließende Anstieg des $\mathrm{p}_{\mathrm{H}}$-Wertes zeigt dann die beginnende Autolyse des Zellmaterials an, wobei $\mathrm{N}$-haltige Substanzen ins Medium abgegeben werden.

Lm Daten über die Ökonomie der Umwandlung des Kohlenhydrats in Zellmaterial zu erhalten, wurde bei den folgenden Versuchen neben Trockensubstanz und $p_{H}$ auch die Restglucose im Medium bestimmt.

Obwohl im vorhergehenden Versuch für jeden Punkt der Wachstumskurve $3-5$ Kolben geerntet und getrennt aufgearbeitet wurden, streuten die Werte zu stark. Das konnte sicher großenteils auf die Impfmethode zurückgeführt werden. Ziel des folgenden Versuches war es daher, die Beimpfung durch Agarmycelstück(hen und mit flïssiger Vorkultur bezüglich ihrer Einwirkung auf die Streuung unter den Parallelen. die zeitliche Verschiebung der Wachstumskurve und die Höhe des Ertrages zu untersuchen. Weiterhin sollten Rühr- und Schüttelkultur hinsichtlich ihres Einflusses auf das Wachstum und ihre methodischen Vor- und Nachteile verglichen werden.

Als Substrat wurde das Humfeld-Medium mit einem Anfangs- $\mathrm{p}_{H}$ von 4.5 verwendet, das sich in den vorhergehenden Versuchen als günstigstes erwiesen hatte. Als Impfmaterial für die Ansätze mit flüssiger Vorkultur wurde eine 3 Tage alte Vorkultur verwendet, deren Irvel sich. wie der letzte Versuch gezeigt hatte. in der aktirsten Wachstumsphase befindet. Die Proben wurden täglich zur gleichen Zeit entnommen. Für jeden Punkt der Wachstumskurve wurden mindestens drei Bestimmungen durchgeführt.

In Abb. 2 sind die Versuchsergebnisse in Kurvenform wiedergegeben. Daraus geht hervor, daß die mit Agarmycel beimpften Ansätze das Maximum ihrer Trockensubstanzbildung am 6. (Schüttelkultur), bzw. am 7. Tag (Rührkultur) erreichten. also jeweils etwa 4 Tage später als bei Beimpfung mit einer flüssigen Vorkultur. Die Impfmethode beeinflußte die Höhe der Trockensubstanzbildung kaum, wohl aber die Kulturmethode. indem die Maximalwerte des Wachstums bei der Schüttelkultur jeweils höher lagen. Bei den mit einer Zellsuspension beimpften Kulturen setzte die Autolyse der Zellen langsamer ein, und die Trockensubstanz nahm weniger stark ab als bei der anderen Impfmethode.

In allen Fällen war die Glucose zum Zeitpunkt des Maximums der Trockensubstanzbildung völlig verbraucht.

Der Vergleich der Kultur- und Impfmethoden zeigte, daß3 bei der S'chüttelkultur und bei Beimpfung mit flüssiger Vorkultur das Maximum des Ökonomischen Koeffizienten (Ö.K.) ${ }^{1}$ jeweils eher erreicht wurde.

Wie schon im vorhergehenden Versuch beobachtet, stieg der $\mathrm{p}_{\mathrm{H}}$-Wert zunächst bis zu einem Maximum an, das 1-2 Tage vor dem Höhepunkt der Trockensubstanzbildung erreicht wurde. $\mathrm{Zu}$ diesem Zeitpunkt waren

1 Ö.K. $=\frac{\text { g gebildete Tr. S. } \times 100}{\text { g verbrauchte C-Quelle }}$ (PFEFFER 189:5). 
die $\mathrm{p}_{\mathrm{H}}$-Werte inzwischen wieder auf ein Minimum abgesunken, um mit einsetzender Autolyse wieder zuzunehmen. Sie stiegen zunächst steil, dann flacher an, bis sie einen Sättigungswert erreichten, der bei den Schüttelkulturen jeweils höher lag.

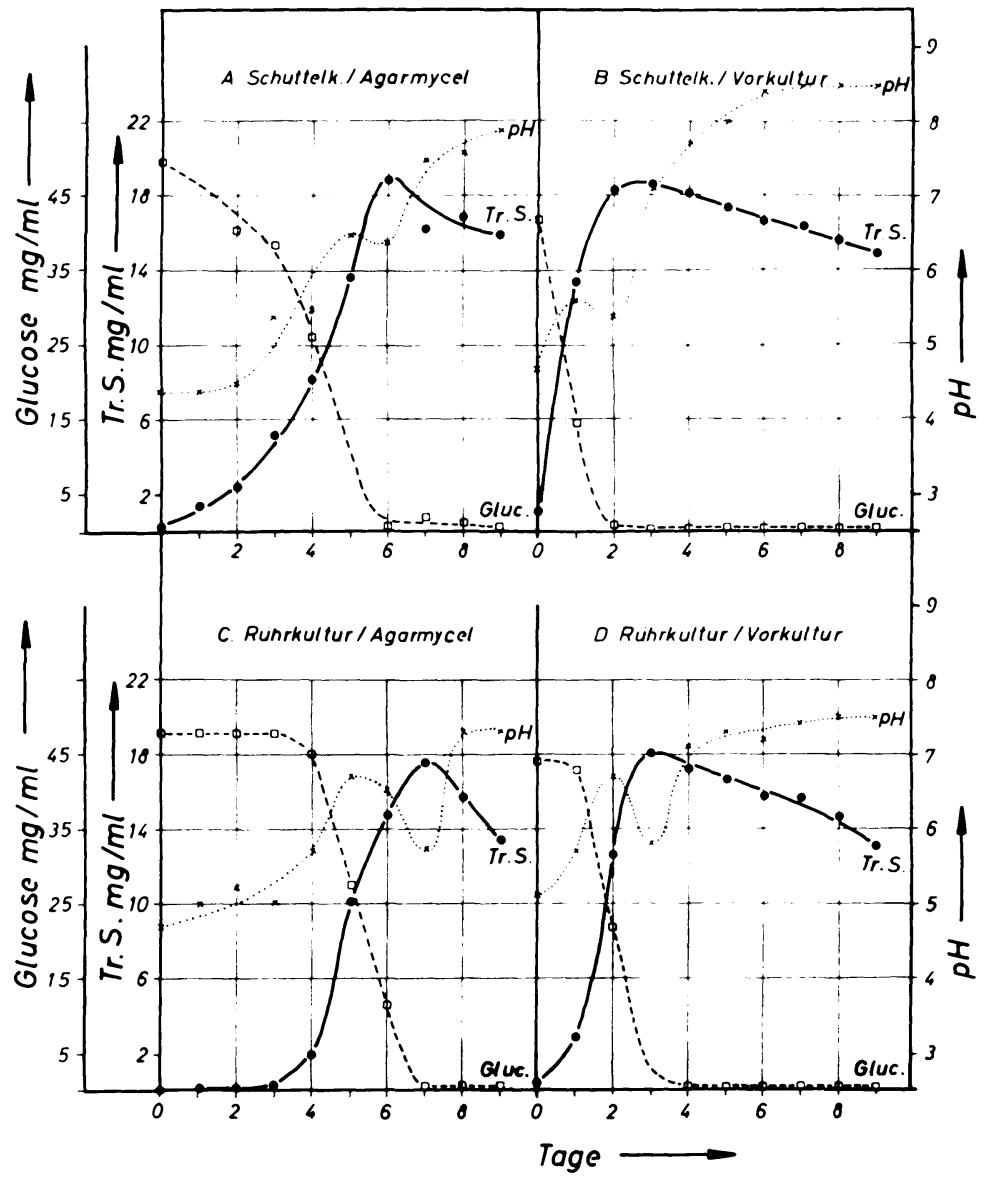

Ahb.2. Wachstumskurven. Abhängigkeit des Wachstums von verschiedenen Beimpfungs. und

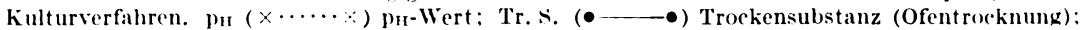

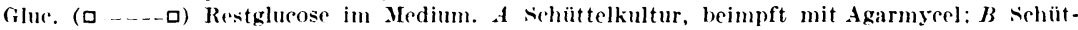
telkultur, beimpft mit $10 \%$ einer 3 Tage alten Vorkultur; $C$ Rührkultur, beimpft mit Agarmycel; I) Rührkultur, beimpft mit $10 \%$ einer 3 Tage alten Vorkultur, Humfeld-Medium, pu 4,5. Stamm VRRL 2.3 .34

In den Versuchen zeigte sich die Beimpfung der Kulturen mit flüssiger Vorkultur dem anderen Verfahren durch größere Homogenität des Zellmaterials, bessere Reproduzierbarkeit der Ergebnisse und schnelleres Wachstum eindeutig überlegen und wurde im folgenden stets angewendet. 
Da bei Rührkulturen im Verlaufe des Wachstums starke Klumpenbildung am Rande des Kulturgefäßes und an den Belüftungsstutzen auftrat und sich die Wachstumsbedingungen im Rührkolben durch die tägliche Probenentnahme und die Austrocknung ständig unkontrollierbar veränderten, wurde dem Schüttelverfahren der Vorzug gegeben. Hier liegt zudem das Maximum der Trockensubstanzbildung höher, es wird eher erreicht, die Infektionsgefahr ist geringer, und es bietet sich der Vorteil vieler voneinander unabhängiger Parallelen.

\section{Stoffwechselphysiologische Versuche}

a) Vorversuche

Lipidnachweis. Es war bereits bei den mikroskopischen Untersuchungen, vor allem während der Aufstellung der Wachstumskurven aufgefallen, daß im Verlaufe der Kultur in zunehmender Zahl kleine, stark

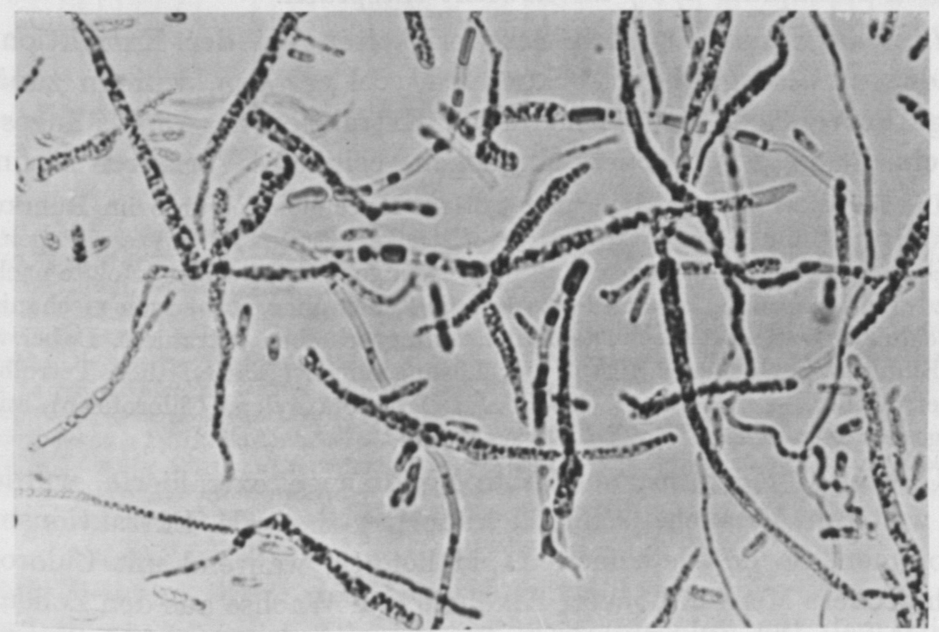

Abb.3. Fettgranula und Kugeln im Mycel, Submerskultur, Humfeld-Medium, ungefärbt, Stamm NRRL $2335(\times 640)$

lichtbrechende Granula in den Zellen gebildet wurden, die mit zunehmender Kulturdauer immer größer wurden und schließlich zu einer oder mehreren großen Kugeln je Zelle zusammenflossen (Abb.3). Beim Übergang der Zellen in das Autolysestadium traten dann sich vergrößernde Vacuolen auf, wobei die erwähnten lichtbrechenden Kugeln wieder kleiner wurden. Diese Granula ließen sich mit Sudanrot und Sudanschwarz nach den üblichen Verfahren gut anfärben, bestanden demnach also aus einer lipidartigen Substanz.

Es wurde zunächst auf Anwesenheit von Poly- $\beta$-Hydroxy-Buttersäure untersucht. Da in dem Chloroformextrakt der gefriergetrockneten 
Zellen bei Ätherzusatz kein Niederschlag auftrat, konnte die Anwesenheit von Poly- $\beta$-Hydroxy-Buttersäure ausgeschlossen werden.

Es ließen sich dagegen in dem Chloroformextrakt nach Sxyder u. Stephess (1959) größere Lipidmengen nachweisen. Da diese Methode sich als rasch, zuverlässig und auch für größere Zahlen von Bestimmungen als geeignet erwies, wurde sie für die weiteren Untersuchungen zur quantitativen Lipidbestimmung verwendet.

Um die Mengenangaben in Äquivalent Ester, die man nach dieser Methode erhält, in Gewichtsprozente der Trockensubstanz umrechnen zu können. wurde eine größere Mycelmenge extrahiert und aliquote Teile des so gewonnenen Rohlipids einmal nach Sxyder u. STEphexs (als $\mu$-Äquivalente Ester/mg Tr.S.) und zum anderen gravimetrisch (als Gewichts-Prozent der Tr.S.) bestimmt. Es ergab sich daraus, daß unter den gegebenen Bedingungen ein Mikroäquivalent Ester des untersuchten Rohlipides $387 \gamma$ an Gewicht entsprach.

Lipidextraktion. Da sich Schwierigkeiten bei der Extraktion der Lipide aus dem gefriergetrockneten Mycel ergaben, wurden zunächst einige Vorversuche zur Methodik der Extraktion des Lipids angestellt, um ein für die gegebenen Bedingungen geeignetes Verfahren zu finden.

Die für diese Untersuchungen benötigte Mycelmenge wurde im Rührkulturverfahren (Humfeld-Medium, Agarmycelstücke, Ernte 7. Tag) angezogen, wie üblich geerntet und gefriergetrocknet. Die Lipidgewinnung selbst erfolgte nach verschiedenen Methoden: Zunächst wurden die Zellen ohne vorherigen mechanischen Aufschluß 24 Std durch Schütteln in Erlenmeverkolben extrahiert. Dabei wurde der Einfluß verschiedener organischer Lösungsmittel (Diäthyläther, Petrolbenzin $=$ Petroläther, Siedebereich: $60-70^{\circ} \mathrm{C}$; Trichloräthylen, Chloroform) auf die Menge des extrahierten Lipids untersucht.

Obwohl Chloroform die größte Lipidmenge extrahierte, wurde für die weiteren Versuche schließlich doch Äther als Extraktionsmittel genommen, da er das reinste Lipid lieferte, während mit Chloroform auch größere Mengen höherer Alkohole und Wachse aus den Zellen herausgelöst werden (Pruess 1934). Die Ergebnisse sind in Abb.4 unter $A_{1}$ gezeigt.

Weiterhin wurde der Einfluß der Extraktionszeit, bzw. einer mehrmaligen Extraktion auf die Menge des extrahierten Rohlipids untersucht (Abb.4, $A_{2}, A_{3}$ ).

In einem anderen Ansatz wurden die in einer Gesamtextraktionszeit von 24 Std nach verschiedenen Verfahren gewonnenen Lipidmengen verglichen (Abb.4, $\left.A_{4}\right)$.

Da die verhältnismäßig derbe Pilzzellwand für die Extraktion ebenfalls ein Hindernis bildet, wurde weiterhin untersucht, inwieweit die Lipidausbeute durch mechanischen Aufschluß des Mycels vor der Extraktion gesteigert werden kann. Einmal wurde dazu der ...MickleDesintegrator" benutzt, wobei Schüttelzeit und Frequenz variiert 


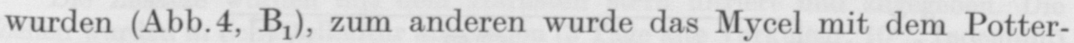
Elvehjem-Gerät aufgeschlossen. Hierbei wurden Aufschlußzeit und Umdrehungszahl des Kolbens verändert (Abb.4, $\mathrm{B}_{2}$ ).

Aus den Ergebnissen geht hervor, daß vorheriger Aufschluß des Mycels die Lipidausbeute beträchtlich erhöht und daß bei den beiden untersuchten Methoden die extrahierte Lipidmenge sowohl von der

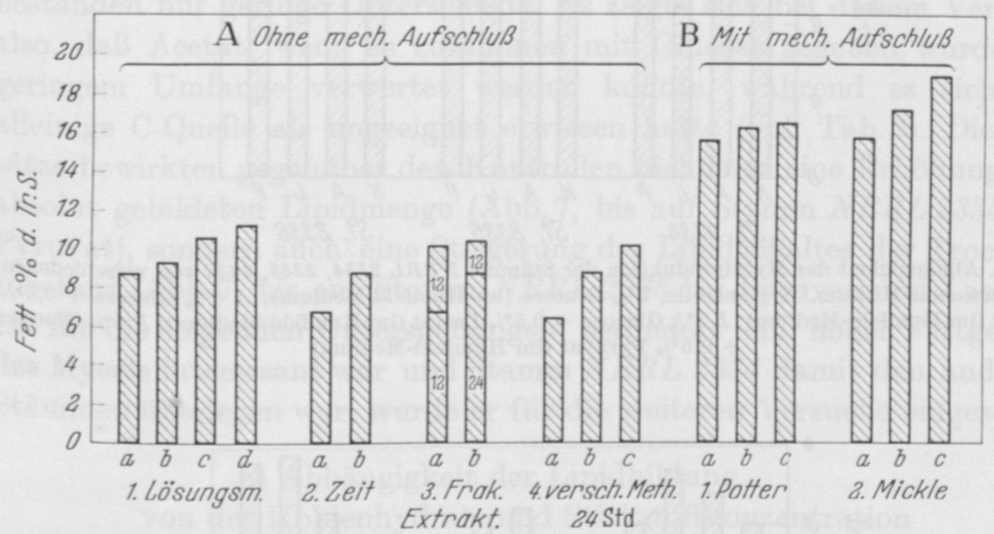

Abb.4. Abhängigkeit der gewonnenen Lipidmenge von der Methodik. Lipidbestimmung nach SNYDER u. STEPHENS (1953). Material: Gefriergetrocknetes Mycel (Rührkultur, Humfeld-Medium, Ernte am 7. Tag), Stamm NRRL 2334. A Ohne vorherigen mechanischen MycelaufschluB. 1. Verschiedene Lösungsmittel: Äther $(a)$, Petroläther $(b)$, Trichloräthylen $(c)$, Chloroform $(d)$; 2. verschiedene Extraktionszeiten (Schütteln mit Åther). $a 12$ Std, $b 24$ Std; 3. fraktionierte Extraktion (Schütteln mit Åther) $a 12+12$ Std, $b 24+12$ Std; 4. verschiedene (Åther-)Extraktionsverfahren, Dauer 24 Std Soxhlet $(a), 24$ Std Schütteln mit Äther $(b), 12+12$ Std Schütteln mit Ãther $(c)$. B Nach vorherigem mechanischen Mycelaufschluß (Ätherextraktion, Schüttelmaschine). 1. PotterElvehjem-Gerät. $a$ Aufschluß 5 min bei 600 Umdrehungen; $b$ AufschluB 5 min bei 1100 Umdrehungen; $c$ Aufschluß $10 \mathrm{~min}$ bei 1100 Umdrehungen. 2. Mickle-Gerät. $a$ Aufschluß 10 min, maximale Intensität (nicht geschüttelt); $b$ Aufschluß 5 min, halbe Intensität (geschüttelt); $c$ Aufschluß 10 min, maximale Intensität (geschüttelt)

Schüttelfrequenz bzw. der Umdrehungszahl als auch von der Aufschlußzeit abhängig ist. Obwohl ein Mycelaufschluß mit dem MickleGerät eine etwas höhere Ausbeute ergab, wurde für die folgenden quantitativen Serienbestimmungen doch mit dem Potter-Gerät gearbeitet, da hier die Streuung geringer und die Ergebnisse besser reproduzierbar waren.

\section{b) Stammteste}

Einfluß verschiedener C-Quellen auf die Lipidbildung

Zunächst sollte untersucht werden, ob und in welchem Maße Zusätze von $0,5 \%$ Acetat, Pyruvat und Lactat $\mathrm{zu}$ dem normalen, 5\% Glucose enthaltenden Humfeld-Medium zur Zellsubstanz- und Fettsynthese verwertet werden können. Gleichzeitig sollte unter den drei Stämmen derjenige ermittelt werden, der die günstigsten Werte für die Fettsynthese aufweist. 


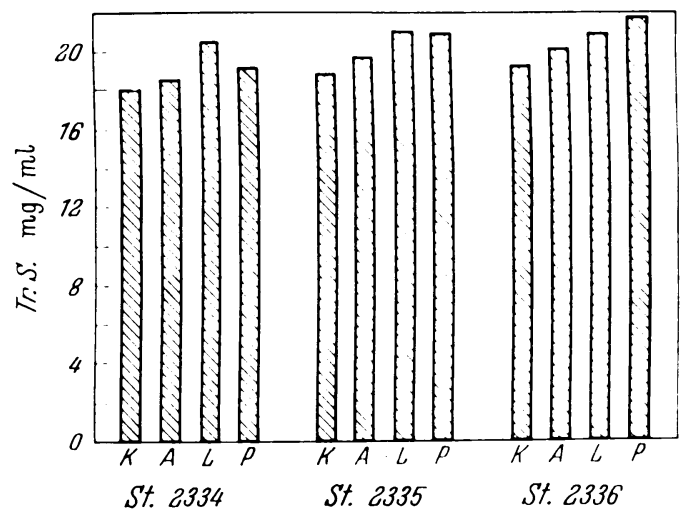

Abb.5. Abhängigkeit der Mycelproduktion der Stämme NRRL 2334, 2335, 2336 von verschiedenen Zusätzen zum Medium. $K$ Kontrolle, $5 \%$ Glucose (im Humfeld-Medium); $A 5 \%$ Glucose $+0,5 \%$ Acetat (im Humfeld-Nedium); $L 5 \%$ Glucose $+0,5 \%$ Lactat (im Humfeld-Medium); $P 5 \%$ Glucose $+0,5 \%$ Pyruvat (im Humfeld-Medium)

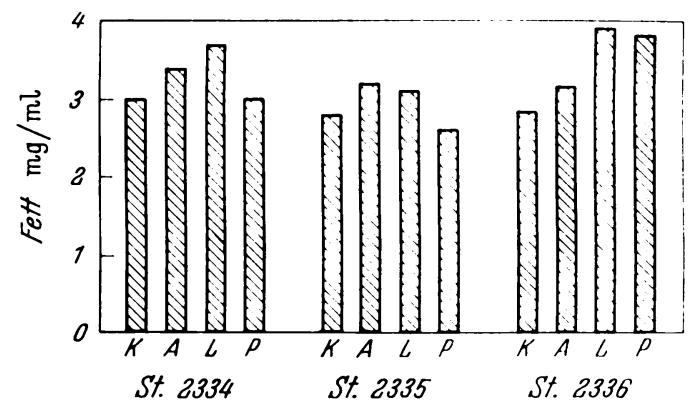

Abb.6. Abhängigkeit der absoluten Fettproduktion von verschiedenen Zusätzen zum Medium. Erklärung siehe Abb.5

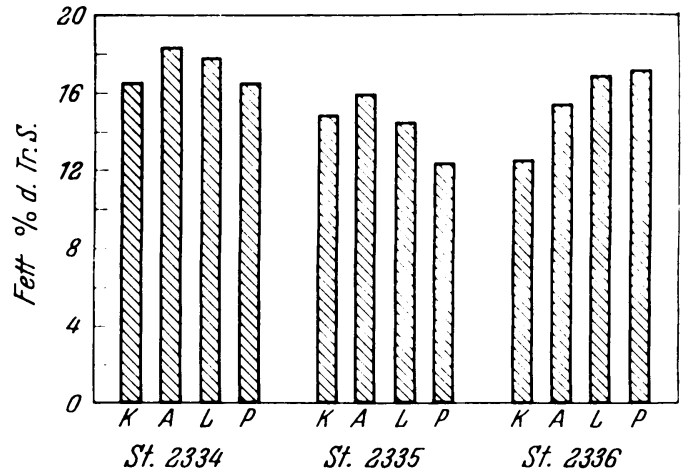

Abb.7. Abhängigkeit des Fettgehaltes des Mycels von verschiedenen Zusätzen zum Medium. Erklärung siche Abb.5 
Die Zusätze wurden mit dem Harnstoff steril filtriert und zugegeben. Die Zellen wurden in Schüttelkultur angezogen (3 Tage alte Vorkultur, 10\% Inoculum) und am 4. Tage der Hauptkultur geerntet.

Die Ergebnisse sind aus den Abb.5, 6 und 7 ersichtlich. In allen Fällen trat eine Erhöhung der Trockensubstanzmenge gegenüber der Kontrolle ein (Abb.5). Dabei konnte Lactat am besten, Acetat am schlechtesten in Zellsubstanz umgesetzt werden. Zwischen den drei Stämmen selbst bestanden nur geringe Unterschiede. Es zeigte sich bei diesem Versuch also, daß Acetat, wenn es zusammen mit Glucose gegeben wurde, in geringem Umfange verwertet werden konnte, während es sich als alleinige C-Quelle als ungeeignet erwiesen hatte (vgl. Tab.2). Die Zusätze bewirkten gegenüber den Kontrollen nicht nur eine Erhöhung der absolut gebildeten Lipidmenge (Abb.7, bis auf Stamm NRRL 2335 mit Pyruvat), sondern auch eine Steigerung des Lipidgehaltes der Trockensubstanz (Abb.7, bis auf Stamm NRRL 2335 bei Pyruvat und Lactat). Da für die folgenden Untersuchungen besonders ein hoher Fettgehalt des Mycels interessant war und Stamm NRRL 2334 damit den anderen Stämmen überlegen war, wurde er für die weiteren Versuche eingesetzt.

c) Abhängigkeit der Lipidbildung

von der Kohlenhydrat- und Stickstoffkonzentration

Zur Untersuchung des Einflusses verschiedener C- und N-Gehalte sowie verschiedener $\mathrm{C} / \mathrm{N}$-Verhältnisse des Mediums auf die Fettbildung wurde der C-Gehalt des Nährmediums von 1-30\% Glucose gesteigert, einmal bei einem gleichbleibenden $\mathrm{N}$-Gehalt von $1,0 \mathrm{mg} \mathrm{N} / \mathrm{ml}$ (Reihe $\mathrm{A}=$ steigendes $\mathrm{C} / \mathrm{N}$-Verhältnis) und einmal bei parallel gesteigertem $\mathrm{N}$-Gehalt von $0,2-6,0 \mathrm{mg} \mathrm{N} / \mathrm{ml}$ (Reihe $\mathrm{B}=$ gleichbleibendes $\mathrm{C} / \mathrm{N}$-Verhältnis).

Der Versuch wurde in Schüttelkultur (3 Tage Vorkultur, 10\% Inoculum, Humfeld-Grundmedium) durchgeführt und am 4. Tage geerntet. Für jede Substratkombination wurden fünf Kolben geerntet, in denen einzeln $\mathrm{p}_{\mathrm{H}}$-Wert, Trockengewicht (Ofen- und Gefriertrocknung) Restglucose und Reststickstoff im Medium, Stickstoffeinbau in die Zellen (Mikrokjeldahl) und der Fettgehalt bestimmt wurden.

Die Abb.8-10 zeigen die Ergebnisse. Mit zunehmendem Kohlenhydratgehalt des Mediums stiegen also die Trockensubstanz- und Fettbildung (mg/ml und Prozent der Tr.S.) an (Abb.8). In den Parallelen mit dem jeweils höheren N-Gehalt wurde mehr Trockensubstanz, jedoch weniger Fett je ml Nährlösung gebildet, auch der Fettgehalt des Mycels lag hier jeweils niedriger (Abb.9). Die Tatsache, daß Lipid- und Zellmaterialsynthese um die C-Quelle konkurrieren, geht auch aus dem Vergleich der Ökonomischen Koeffizienten und Fettkoeffizienten (F.K.) ${ }^{1}$ hervor (Abb.10). Ein höherer Ookonomischer Koeffizient ist jeweils mit

${ }^{1}$ F.K. $=\frac{\text { g gebildetes Fett } \cdot 100}{\mathrm{~g} \text { verbrauchte C-Quelle }}($ RIPPEL 1940). 
einem niedrigeren Fettkoeffizienten gekoppelt (über die Ausnahmen bei 20 und $30 \%$ Glucose im Medium siehe unten). Der synthetische Wirkungsgrad nimmt allgemein mit steigendem Kohlenhydratgehalt des Mediums ab. Es zeigte sich weiter, daß der N-Gehalt des Pilzmycels variabel und stark vom N-Gehalt des Mediums abhängig ist.

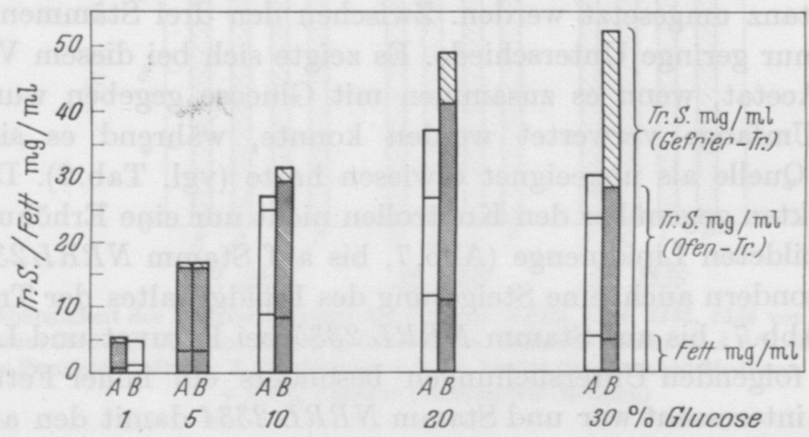

Abb. 8. Abhängigkeit der Fett- und Trockensubstanzbildung von der Kohlenhydrat- und Stickstoffkonzentration. Schüttelkultur, Grundmedium nach HUMFELD, beimpft mit $10 \%$ einer 3 Tage alten Vorkultur, Ernte am 4. Tag, Stamm NRRL 2334. A steigendes C/N-Verhältnis $(4,2 / 1 ; 21 / 1 ; 84 / 1$; 126/1); $B$ konstantes C/N-Verhältnis (21/1). $\square$ Parallelen mit dem jeweils niedrigeren N-Gehalt; $\square \llbracket$ Parallelen mit dem jeweils höheren N-Gehalt

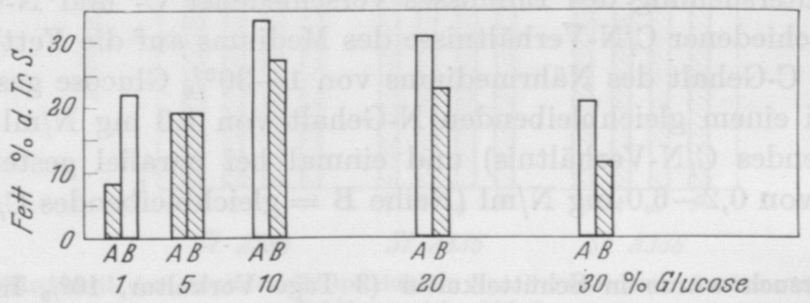

Abb.9. Abhängigkeit des Fettgehaltes von der Zusammensetzung des Mediums. Erklärung siehe Abb. 8

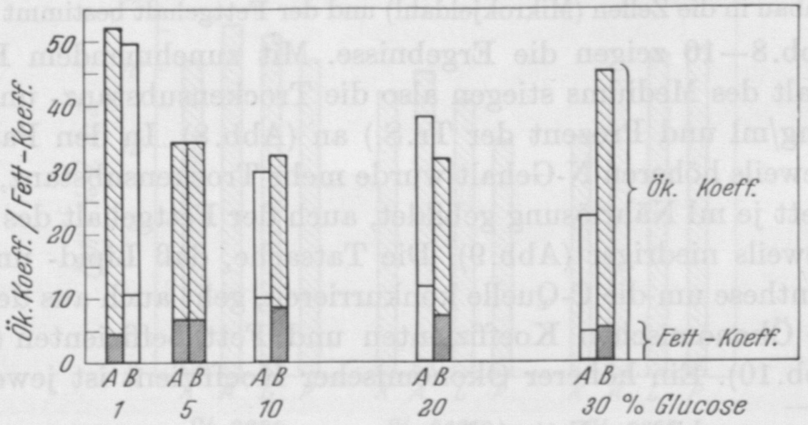

Abb.10. Abhängigkeit des Fett- und Ökonomischen Koeffizienten von der Zusammensetzung des Mediums. Erklärung siehe Abb.8 
Ein Vergleich der Trockengewichtsbestimmungen mit Ofen- und Gefriertrocknung (Abb.8) zeigt, daß die durch Ofentrocknung gewonnenen Werte jeweils niedriger liegen, daß bei diesem Verfahren also offenbar flüchtige Substanzen entweichen. Der Gehalt des Mycels an diesen Substanzen nimmt mit größerem Kohlenhydratgehalt des Mediums zu, entsprechend größeren Differenzen zwischen beiden Bestimmungsarten.

Wie aus den Werten der Mycel- und Fettproduktion für die Medien mit $20 \%$, besonders aber $30 \%$ Glucosegehalt ersichtlich ist, hat hier die Wachstumskurve am Erntetag offenbar ihr Maximum noch nicht erreicht. Das geht auch daraus hervor, daß Glucose und teilweise auch der Stickstoff des Mediums noch nicht völlig verbraucht waren. Da hier die Kulturdauer als begrenzender Faktor auftrat, sind die Werte der Medien mit 20 und $30 \%$ Glucose kaum mit denen vergleichbar, die von Substraten mit geringerer Kohlenhydratkonzentration gewonnen wurden.

d) Abhängigkeit der Lipidbildung vom C/N-Verhältnis und der Zeit Um die Zeit als begrenzenden Faktor für Mycel- und Fettsynthese auszuschalten, wurden Wachstumskurven über einen längeren Zeitraum hinweg bei täglicher Ernte aufgenommen. Dabei wurde der Einfluß des im Nährmedium verfügbaren Stickstoffs auf die Fettbildung untersucht.

Die Kohlenhydratkonzentration wurde mit $5 \%$ Glucose so gewählt, daß eine hohe Populationsdichte (ungenügende $\mathrm{O}_{2}$-Versorgung) ebenfalls nicht begrenzend wirken konnte. Die $\mathrm{N}$-Konzentration des Mediums wurde so eingestellt, daß einmal die Glucose (bei $5,0 \mathrm{mg} \mathrm{N} / \mathrm{ml}$ ) und einmal der Stickstoff (bei $0,2 \mathrm{mg} \mathrm{N} / \mathrm{ml}$ ) zuerst als begrenzende Faktoren auftreten mußten. während bei $1,4 \mathrm{mg} \mathrm{N} / \mathrm{ml}$ zu erwarten war, daß Stickstoff und C-Quelle etwa gleich schnell verbraucht würden.

Die drei Versuchsreihen I, II, III (mit $0,2,1,4$ und $5,0 \mathrm{mg} \mathrm{N} / \mathrm{ml}$ ) und je $5 \%$ Gilucose im Humfeld-Medium wurden in Schüttelkultur durchgeführt (3 Tage alte Vorkultur, $10^{\circ} /$ Inoculum). Täglich wurden je Versuchsreihe neun Kolben entnommen und für die verschiedenen Bestimmungen aufgearbeitet.

In Kultur I (0,2 $\mathrm{mg} \mathrm{N} / \mathrm{ml}, \mathrm{Abb} .11)$ kommt nach Verbrauch des im Medium enthaltenen Stickstoffs das Wachstum am zweiten Kulturtag praktisch zum Stillstand, während die Fettsynthese bis zu ihrem Maximum am 8. Kulturtag weiterläuft. Die nach dem 2. Kulturtag noch erfolgende geringe Zunahme des Wachstums (als Trockensubstanz) ist nur scheinbar. Sie beruht darauf, daß eine stärkere absolute Zunahme an Fett die bereits einsetzende schwache Autolyse überdeckt. Ein Ansteigen des N-Gehaltes des Mediums weist ebenfalls auf die einsetzende Autolyse hin. Es zeigte sich hier also, daß bei N-Mangel aus noch verfügbarem Kohlenhydrat weiter Fett synthetisiert werden kann. Der Fettgehalt der Zellen stieg dabei noch von $12,6 \%$ am 2 . Kulturtag auf $34,1 \%$ am 8 . Kulturtag an. 
Bei Kultur II (1,4 mg N/ml, Abb. 12) wird bei gleichzeitigem völligem Verbrauch der Stickstoff- und Kohlenhydratquelle am 2. Kulturtag auch das Maximum der Trockensubstanz- und Fettbildung erreicht. Der Fettgehalt der Zellen steigt bis zum 3. Kulturtag noch geringfügig von 13,9 auf $14,1 \%$ an. Vom 2.Tag an, wo Stickstoff und Kohlenhydrat bereits als wachstumsbegrenzende Faktoren auftraten, erfolgte mit einsetzender

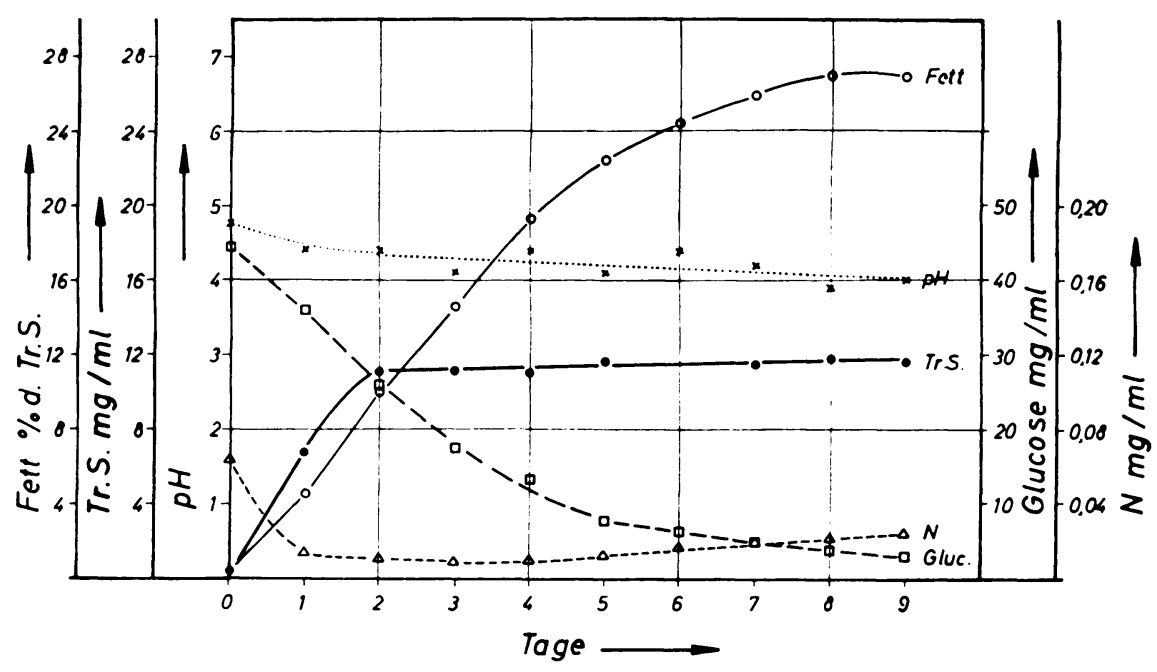

Abb.11. Wachstumskurve. Zeitlicher Verlauf der Trockensubstanz- (Tr. S. $\bullet-\bullet)$ und Fettbildung $(0-0)$, des $\mathrm{p}_{\mathrm{H}}$-Wertes $(x \cdots \cdots \times)$ sowie der Abnahme der Glucose (Gluc. a-...und des Stickstoffs $(\mathrm{N} \Delta \ldots . .-\Delta)$ im Medium. Schüttelkultur. Beimpfung mit $10 \%$ Vorkultur (3 Tage alt) Medium I. Humfeld-Medium mit $5 \%$ Glucose und 0,2 mg N/ml. Stamm NRRL 2334

Autolyse eine etwa parallel verlaufende Abnahme von Zellsubstanz und Fett. Ein Ansteigen des N-Gehaltes des Mediums deutete wieder auf die autolytischen Vorgänge in den Zellen hin.

In Versuchsreihe III (5,0 mg N/ml, Abb.13) ist ebenfalls am 2. Kulturtag das verfügbare Kohlenhydrat bereits verbraucht, und Mycel und Fettproduktion haben ihr Maximum erreicht. Da aber noch genügend Stickstoff im Medium verfügbar ist, tritt nur der Kohlenhydratmangel als begrenzender Faktor auf. Es kommt zur Autolyse, wobei die Zellsubstanz wesentlich schneller abnimmt als das Fett (absolut und prozentual).

Während sich der $\mathrm{p}_{\mathrm{H}}$-Wert bei Ansatz $\mathrm{I}$ wegen der geringen $\mathrm{NH}_{\mathbf{4}^{-}}$Mengen, die aus dem wenigen Harnstoff freigesetzt werden können, im Verlauf der Kultur nur wenig ändert, steigt er in Kultur II und III anfangs steil an. Am 1. Kulturtag erreicht er ein Maximum, sinkt am 2. Kulturtag, dem Maximum der Trockensubstanz und Fettproduktion, auf ein Minimum ab (Aufnahme des im Medium gelösten $\mathrm{NH}_{4}{ }^{+}$in die 


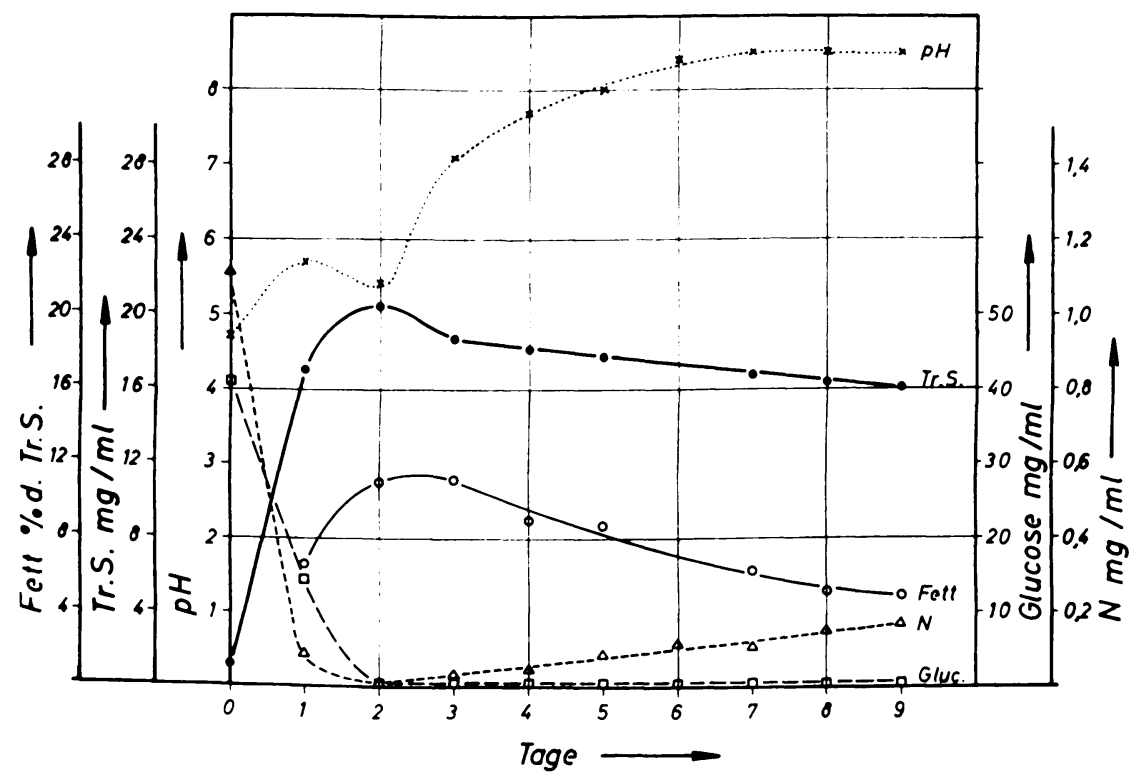

Abb.12. Wachstumskurve. Zeitlicher Verlauf der Trockensubstanz-(Tr. S. $\longrightarrow \bullet)$ und Fettbildung $(0-0)$, des $p_{H}$-Wertes $(x \cdots \cdots \times)$, sowie der Abnahme der Glucose (Gluc. $\left.\square \cdot \cdots \cdot-\cdots\right)$ und des Stickstoffs ( $\mathrm{N} \Delta \ldots \ldots \Delta$ ) im Medium. Medium II. Humfeld-Medium mit $5 \%$ Glucose und $1,4 \mathrm{mg} \mathrm{N} / \mathrm{ml}$. Sonstige Bedingungen wie Abb.11

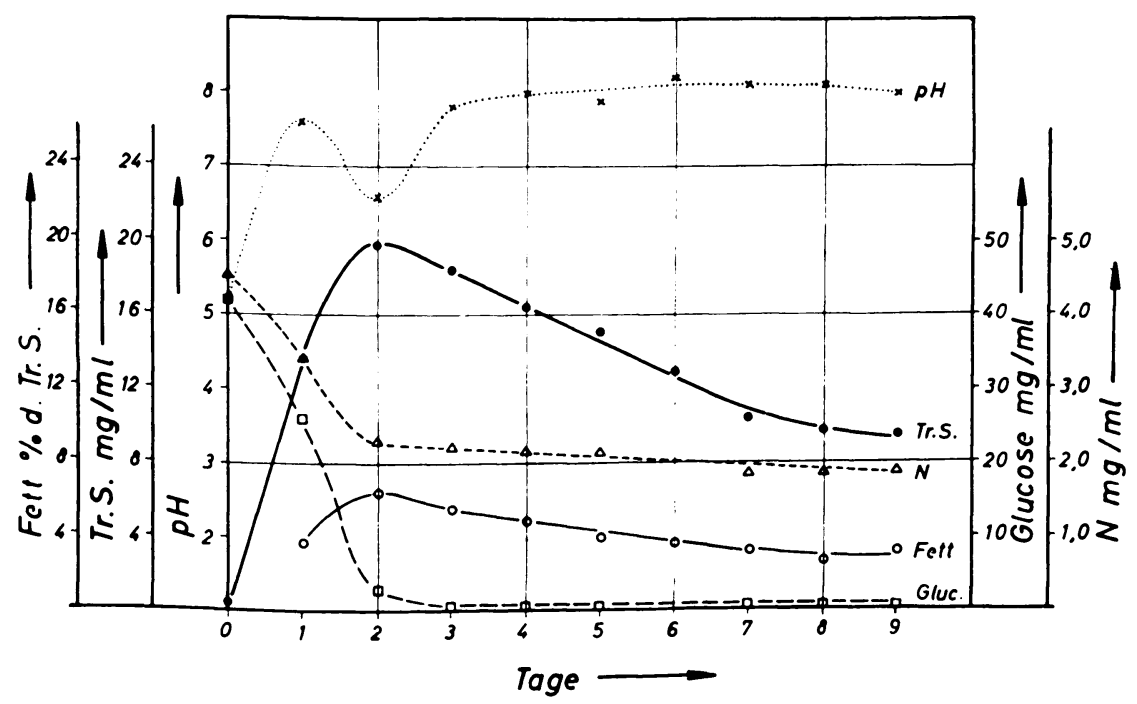

Abb.13. Wachstumskurve, Zeitlicher Verlauf der Trockensubstanz- (Tr. S. $-\longrightarrow)$ und Fettbildung $(0-0)$, des $\mathrm{pr}_{\mathrm{B}}$ Wertes $(\times \cdots \cdots \times)$, sowie der Abnahme der Glucose (Gluc. $\square \cdot \ldots$.... und des Stickstoffs $(\mathbf{N} \Delta \ldots . . . \Delta)$ im Medium. Medium III. Humfeld-Medium mit $5 \%$ Glucose und $5 \mathrm{mg} \mathrm{N} / \mathrm{ml}$. Sonstige Bedingungen wie Abb.11 
Zellen) und steigt dann wieder mit einsetzender Autolyse bis zu einem Sättigungswert an (Abb.11, 12 und 13).

Wie aus den Abbildungen hervorgeht, nimmt die Menge des gebildeten Fettes mit steigendem N-Gehalt der Medien ab, wogegen die Zellsubstanzproduktion zunimmt.

Diese Verhältnisse spiegeln sich auch in den Umsatzkoeffizienten wieder. Das Maximum des Ökonomischen Koeffizienten steigt mit zunehmendem N-Gehalt des Mediums und ist mit 57,6 (1. Tag) im Medium III am höchsten und mit 48,2 (1. Tag) in Medium I am niedrigsten. Umgekehrt weist die Fettsynthese in Medium I mit dem niedrigsten N-Gehalt den höchsten Fettkoeffizienten mit 8,8 (8. Tag) auf, wogegen der maximale Fettkoeffizient im Medium III mit einem Wert von nur 3,5 (2. Tag) am niedrigsten liegt.

Der Versuch zeigt also, daß Zellsubstanz- und Fettsynthese unter günstigen Bedingungen gleichzeitig ablaufen, jedoch durch Kohlenhydratmangel beide zum Stillstand gebracht werden, unabhängig von der noch im Medium verfügbaren N-Menge. Dagegen kommt bei N-Mangel nur das Wachstum zum Stillstand, während Fettsynthese und -Speicherung weiterlaufen, sofern noch Kohlenhydrat verfügbar ist.

Der Versuch zeigt ferner die Kulturbedingungen, unter denen am günstigsten eine größere Menge Fett zur Analyse gewonnen werden kann.

\section{Untersuchungen an zellfreien Extrakten}

Im folgenden sollten einige Hauptenzyme des Embden-MeyerhofAbbauweges der Kohlenhydrate, sowie charakteristische Enzyme anderer Stoffwechselwege nachgewiesen und in ihrer Aktivität bestimmt werden.

a) Schlüsselenzyme des Embden-Meyerhof-Abbauweges

Die zur Spaltung des F-1,6-DP nötige Aldolase wurde in einem zellfreien Extrakt nachgewiesen und ihre Aktivität bestimmt mit 0,074 $\mu \mathrm{MI}$ F-1,6-DP/mg Protein/min.

Triosephosphat-Isomerase, welche die Bildung des Glycerinaldehydphosphats aus dem zunächst durch die Aldolase hauptsächlich gebildeten Dioxyacetonphosphat katalysiert, konnte ebenfalls nachgewiesen werden. Die spezifische Aktivität betrug 1,704 $\mu \mathrm{M}$ Triosephosphat/mg Protein/min.

Eine zentrale Stellung im Stoffwechsel für Abbau-, Energiegewinnungs- und Synthesevorgänge nimmt die ,aktivierte Essigsäure“, das Acetyl-CoA ein. Es entsteht durch Decarboxylierung der im Verlauf des Embden-Meyerhof-Abbauweges gebildeten BTS. Das dabei beteiligte Enzym BTS-Dehydrogenase wurde nachgewiesen 
und seine spezifische Aktivität bestimmt mit 0,012 $\mu \mathrm{M}$ BTS/mg Protein/min. Ohne $\alpha$-Liponsäure wurde zwar keine Verminderung der Enzymaktivität festgestellt, doch kann daraus noch nicht unbedingt geschlossen werden, daß die Reaktion keiner katalytischen Mengen dieser Substanz bedarf, da mit einem rohen Enzymextrakt gearbeitet wurde, der Spuren der wirksamen Substanz enthalten konnte.

b) Phosphoketolase-Aktivität

Um die Frage zu klären, ob auch auf anderem Wege aktive Acetyleinheiten gebildet werden können, wurde der Enzymextrakt auf die Anwesenheit von Phosphoketolase untersucht. Diese spaltet Acetylphosphat von bestimmten Zuckerphosphaten ab. Als Substrate wurden F-6-P und Ri-5-P eingesetzt. Es konnte jedoch keine PhosphoketolaseAktivität festgestellt werden. Die Reaktionsfähigkeit der Ansätze selbst ließ sich durch Zugabe eines aktiven Lactobacillus-Extraktes und die dadurch bewirkte Extinktionsabnahme beweisen.

\section{c) Einbau von ${ }^{14} \mathrm{CO}_{2}$}

Die Anwesenheit carboxylierender Enzyme wurde in dem zellfreien Extrakt durch Einbauversuche mit ${ }^{14} \mathrm{CO}_{2}$ nachgeprüft.

Ru-1,5-DP-Carboxylase, die die Bildung von 2 Mol 3-Phosphoglycerinsäure aus $1 \mathrm{Mol} \mathrm{Ru}-1,5$-DP und $1 \mathrm{Mol}^{14} \mathrm{CO}_{2}$ katalysiert, ließ sich nicht nachweisen. Auch PEP-Carboxylase konnte in Form markierten Oxalacetats in dem zellfreien Extrakt nicht nachgewiesen werden durch Inkubation von PEP mit $\mathrm{NaH}^{14} \mathrm{CO}_{3}$. Da auch bei Zugabe von ADP zu obigem Ansatz kein markiertes Oxalacetat nachweisbar war, konnte auch die Anwesenheit der ADP-(oder IDP-)bedürftigen OxalessigsäureCarboxylase ausgeschlossen werden.

\section{Diskussion}

Wie aus den vorangegangenen Versuchen anderer Autoren zu erwarten war, erwies sich der Organismus wegen seines homogenen, hefeähnlichen Wachstums und der einfachen Nährstoffansprüche in Submerskultur für die geplanten stoffwechselphysiologischen Untersuchungen als sehr geeignet. Zur Gewinnung genauer qualitativer und quantitativer Daten über Menge und Zusammensetzung des Zellmaterials, sowie über die Veränderungen im Kulturmedium war die Submerskultur das geeignete Verfahren. Parallelversuche mit Rühr- und Schüttelkultur ließen letztere wegen ihrer überwiegenden Vorteile als die Methode der Wahl erscheinen.

Die Spezifität der drei untersuchten Stämme von Beauveria tenella für bestimmte C-Quellen war im Gegensatz zu vielen anderen vergleichbaren Pilzen nicht sehr ausgeprägt. So konnten nach Humferd u. Sugrhara (1949), Reusser, Spencer u. Sallans (1958), sowie Moustafa 
(1960) und eigenen Untersuchungen als C-Quelle verwertet werden: An komplexen Substraten die Abfallfüssigkeit bei der Spargel- und Birnenkonservierung (,,asparagus butt juice“, „pear waste juice“), Reisschrot-Extrakt (,,rice bran extract"), Mais-Sirup, GerstenkeimExtrakt (,malt sprout extract“), Malz-Sirup (,,malt syrup“), Biomalz, Melasse und lösliche Stärke, an definierten C-Quellen d-Glucose, d-Galactose, d-Mannose, d-Fructose, d-Xylose, d-Arabinose, Maltose, Saccharose, Dextrin, Lactat und Pyruvat. Acetat konnte, als einzige C-Quelle verabreicht, nicht verwertet werden. Aus den Untersuchungen ging weiter hervor, daß Lactat, Pyruvat und Acetat nicht nur die Ausbeute an Trockensubstanz, sondern auch an Fett steigerten. Das stimmt überein mit den Ergebnissen, die HoPPE (1960) von Versuchen an Hefen zitiert. Kleinzeller (1944) dagegen konnte bei Torula lipofera keine vermehrte Fettbildung durch Lactat-, Pyruvat- und Acetatzugabe beobachten. Als C-Quellen ungeeignet waren Crotonat, l-Rhamnose, Na-Carboxymethylcellulose und Lactose. Da die Hydrolyseprodukte der Lactose, Galactose und Glucose jedoch gut verwertet werden können, scheint dem Organismus nur das hydrolysierende Enzym, die Lactase zu fehlen. Es kann sich jedoch auch um eine Frage der Permeabilität handeln.

Daß Lactose und Cellulose eine schlechte C-Quelle für Pilze darstellen, ist häufig beobachtet worden (Heide 1939; Margolin 1942; Estienne, Castagne u. Bertrand 1947; Lilly u. Barnett 1953; Cochrane 1958). Dies wird auch durch Untersuchungen von HUBER (1958) an Beauveria bassiana bestätigt, der in Submerskultur einerseits ein ähnlich weites Spektrum von verwertbaren definierten und komplexen C-Quellen fand, andererseits aber ebenfalls feststellte, daß Lactose selbst schlecht genutzt werden konnte, während ihre Spaltprodukte gute C-Quellen darstellten. Er fand weiterhin lipolytische Aktivität, indem der Pilz verschiedene Fette als Substrat verwerten konnte (besonders deren Glycerinanteil). Dies paßt gut zu den Befunden, daß besonders das Fettgewebe der befallenen Insekten von dem Pilz angegriffen wird.

Da Glucose schnell und gut in Zellsubstanz und Lipide umgesetzt werden kann und leicht erhältlich ist, wurde sie als Haupt-C-Quelle benutzt.

Auch hinsichtlich der N-Quellen ist der Organismus sehr anspruchslos. Er kann sowohl Ammonsalze, Aminosäuren und Harnstoff, wie auch komplexe Formen organischen Stickstoffs verwerten (MACLEOD 1954a; Humfeld u. Sugihara 1952). Auch an Beauveria bassiana fand Huber (1958), daß eine ganze Reihe anorganischer $\left(\mathrm{NH}_{4} \mathrm{NO}_{3}, \mathrm{NaNO}_{3},\left(\mathrm{NH}_{4}\right)_{2} \mathrm{SO}_{4}\right)$ und organischer N-Quellen (Aminosäuren, Pepton, Casein, Harnstoff) gut verwertbar waren. Da Harnstoff bei seiner Verwertung den $\mathrm{p}_{\mathrm{H}^{-}}$ Wert des Mediums nicht zu stark beeinflußt, wurde er als einzige N-Quelle benutzt.

Diese Anspruchslosigkeit bezüglich der Nährstoffe dürfte auch eine der Hauptursachen für die weite Verbreitung von Beauveria darstellen 
(MacLeod 1954a und 1954 b; Huber 1958; Madelin 1960; Franz 1961). Der Besitz von Chitinase (Huber 1958; ('laus 1961) erklärt besonders die Befähigung zum Parasitismus an Insekten, doch wurde Beauveria auch von höheren Tieren (SмIтH 1897), ja sogar vom Menschen (KURU 1932) isoliert. Auch eine saprophytische Lebensweise wurde vereinzelt gefunden (VINCENS 1923; SACCAS 1948; MoLiTORIS 1963a), zumindest wurde das häufige Auftreten von Beauveria im Boden in der Richtung diskutiert, daß die Rückkehr zum Saprophytismus dem Pilz die Möglichkeit biete, ungünstige Lebensbedingungen zu überdauern (MADELIN 1960; FraNz 1961). Huber (1958) dagegen kommt auf Grund seiner Untersuchungen zu dem Schluß, daß Beauveria zu einer saprophytischen Lebensweise im Boden nicht befähigt sei.

Da im Verlauf der Untersuchungen insbesondere der Fettbildung und ihrer Abhängigkeit von verschiedenen Faktoren nachgegangen werden sollte, mußte der Methodik der Lipidgewinnung und Untersuchung zunächst besondere Aufmerksamkeit geschenkt werden.

Die Lipide der Zellen sind nicht nur in den verschiedenen organischen Lösungsmitteln zu verschiedenen Anteilen löslich. sondern auch die Zellwand besitzt für sie nicht die gleiche Durchlässigkeit. Weiterhin sind die Lipidtröpfchen in den Zellen teilweise von Proteinmembranen umgeben oder die Lipide liegen als ..gebundene Lipide" in schwer löslicher Form in Strukturelementen der Zelle vor. Die Ergebnisse der Lipidbestimmung sind daher in hohem Maß3e von der angewandten Methodik abhängig.

Die Problematik dieser Bestimmungen wird bei Foster (1949), Cochrane (1958) und Hoppe (1960) diskutiert. Der Einfluß von Lipid-Lösungsmitteln und Extraktionsmethoden wurde bei verschiedenen Organismen von Prusss (1934), Peck (1947) und Bersinaver (1950) eingehend untersucht. In eigenen Voruntersuchungen wurden diese Angaben für das spezielle Untersuchungsobjekt bestätigt.

Zur Extraktion wurde schließlich Diäthyläther verwendet, da er das reinste Lipid ergibt. Das gefriergetrocknete Mycel wurde vor der Extraktion noch mechanisch aufgeschlossen. Dadurch konnte die Lipidausbeute auf etwa das Doppelte gesteigert werden. Obwohl durch eine Hydrolyse die Ausbeute an Fett gegebenenfalls noch weiter zu steigern gewesen wäre, wurde auf sie verzichtet, da bei dieser neben der Aufspaltung der Lipidsymplexe auch eine Zerlegung des Neutralfettes und vor allem der Phosphatide erfolgt. Der Fehler kann bei hohen Phosphatidgehalten bis $30 \%$ betragen (HopPe 1960).

Bei den wachstumsphysiologischen Versuchen stellte sich heraus, daß der Ökonomische Koeffizient mit sinkender Kohlenhydratkonzentration der Medien zunimmt und auch von deren $\mathrm{C} / \mathrm{N}$-Verhältnis insofern abhängt, als er bei dessen Zunahme abfällt (vgl. Abb.10). Die Beeinflussung der Trockensubstanzbildung durch den Anfangs- $p_{H}$ des Mediums war nur gering, doch konnte bei niedrigen $p_{H}-$ Werten stets eine etwas bessere Ernte erzielt werden. 
Mocstafa (1960), der allerdings bei seinen Untersuchungen den Zeitfaktor unberücksichtigt ließ, fand in einem (Hlucosemedium mit komplexen organischen Bestandteilen ebenfalls bei niedrigen Kohlenhydrat-Konzentrationen $(2.3 \%$ Glucose) die höchsten Zellsubstanz-Ausbeuten und ein Ansteigen der Ausbeute mit sinkendem $\mathrm{C} / \mathrm{N}$-Verhältnis (Maximalwerte der Ausbeute bei $\mathrm{C} / \mathrm{N}=19 / 1: 46-51 \%$ ). Der Anfangs- $p_{H}$ beeinflußte in seinen Untersuchungen den Endertrag kaum.

Pilze verwerten im allgemeinen Kohlenhydrate besser und bilden mehr Zellsubstanz aus einer vorgegebenen Substratmenge als beispielsweise Bakterien. Wie bei den Hefen gibt es auch unter anderen niederen und verschiedenen höheren Pilzen einige, deren Fähigkeit zur Fettsynthese besonders ausgeprägt ist. Man nimmt an, daß das Fett intracellulär. wahrscheinlich im Zusammenhang mit cytoplasmatischen Partikeln gebildet wird. Die Hauptmenge findet man dabei in vacuolären Kugeln, geringere Anteile auch fein im Plasma verteilt und den Rest an Strukturen gebunden. Wie von verschiedenen Autoren auch schon an anderen Mikroorganismen beobachtet (Heide 1939; Steiner u. HeInemasy 1954; HeineMANN 1956) und bei HOPPE (1960) ausführlich besprochen worden ist, tritt das Fett in den Zellen häufig zuerst in Form sehr vieler kleiner, sich ständig vergrößernder Kugeln auf, die dann im weiteren Kulturverlauf zusammenfließen. S'TEINER u. Heinenasx (19:54) beobachteten die Fettbildung an (rana mit positiver NadiReaktion, was mit verschiedenen Befunden übereinstimmen würde, nach denen in den Mitochondrien ein Großteil der Enzyme der Oxydoreduktion, also auch der Fettsynthese lokalisiert ist. Neuere elektronenoptische Untersuchungen lieferten dagegen besonders bei höher organisierten Zellen, so bei Vertebraten und Insekten (Bargians u. Kroop 1959; v. Gaudecker 1963), Hinweise dafür, daß die Fettsynthese nicht im Zusammenhang mit den Mitochondrien steht. sondern im Ergastoplasma der Zelle vor sich geht.

Úber die Fettbildung der untersuchten Stämme ist bisher kaum etwas bekannt. Die von Humfeld u. Sugthara (1949); Reusser, Spexcer u. Sallaxs (1958) sowie von FALANiHe (1962) vorliegenden Untersuchungen geben einen Fettgehalt des Mycels zwischen 3.1 und $9.9 \%$, je nach Stamm und Kulturbedingungen. an. Da jedoch Erntedatum, Substratzusammensetzung und Fettbestimmungsmethode entweder nicht angegeben sind oder von den in dieser Arbeit benutzten Verfahren abweichen, sind diese Daten nicht ohne weiteres mit den hier vorliegenden Ergebnissen vergleichbar.

Bei der Untersuchung der Fettbildung in Abhängigkeit von der Zusammensetzung des Nährmediums, ohne Berücksichtigung des Zeitfaktors, lie $\beta$ sich bereits feststellen, da $\beta$ steigende Kohlenhydratmengen eine Steigerung der Trockensubstanz- und Fettbildung bedingen, wobei letztere besonders durch ein hohes $\mathrm{C} / \mathrm{N}$-Verhältnis gefördert wurde. Die mit steigenden Kohlenhydratmengen erhöhte Speichersubstanzbildung hatte einerseits ein Absinken des Ökonomischen Koeffizienten, andererseits aber ein Ansteigen des Fettkoeffizienten zur Folge, da die C-Quelle in steigendem Maße in intracellulär angehäuftes Fett umgewandelt wurde. Mit 52,1 und 11,6 erreichten dabei Ökonomischer bzw. Fettkoeffizient vergleichsweise hohe Werte ${ }^{1}$.

Während die Versuche über die Fettbildung ohne Berücksichtigung des Zeitfaktors nur bedingt allgemeingültige Aussagen zulassen, worauf

${ }^{1} \mathrm{Zu}$ Berechnungen über die Korrelation Ökonomischer Koeffizient/Fettkoeffizient vgl. RIPPEL (1940). 
besonders auch (OChrave (1958) hinweist. ergeben die Versuche über die Fettbildung in Abhängigkeit von der Zusammensetzung der Nährmedien und von der Zeit ein wesentlich klareres Bild.

LiNDser spricht bereits 1922 im Zusammenhang mit der Fettbildung bei Endomyces rernalis von zwei Synthesephasen, die zeitlich aufeinanderfolgen: 1. Die Eiweißgeneration. Hier findet in erster Linie Wachstum unter Eiweißbildung und rascher $\mathrm{N}$-Aufnahme statt, solange noch größere Mengen Stickstoff in der Nährlösung vorhanden sind. 2 . Die Fettgeneration. Sie tritt ein. sobald der Stickstoff der Nährlösung verbraucht ist. In dieser Phase wird aus noch verfügbarem Kohlenhydrat in der Hauptsache nur noch Fett gebildet.

Diese zwei Phasen wurden auch von verschiedenen anderen Autoren, besonders an Hefen, gefunden (Foster 1949; Luxdix 1950; MaAs-Förster 1955); Hoppe $1960)$.

Cimgekehrt wurden jedoch auch Fälle berichtet, in denen die Fettgeneration zeitlich neben der Eiweißgeneration herläuft (RAAF 1942; (GOODWIN u. WILLMER 1952).

Besonders die Ergebnisse von $\mathrm{RAAF}_{\mathrm{AA}}$ zeigen eine gute Cbereinstimmung mit den von den NRRL-Stämmen gewonnenen Daten. Durch die Zusammensetzung des Nährmediums (C/N-Verhältnis) ließ sich bei den hier beschriebenen Versuchen von vornherein entweder die Eiweißgeneration oder die Fettgeneration einseitig fördern. Die Wachstumsgeschwindigkeit war bei den Versuchen in der Eiweißgeneration (niedriges $\mathrm{C} / \mathrm{N}$-Verhältnis) etwa doppelt so hoch wie bei der Fettgeneration (vgl. auch RAAF 1942). Die Versuche zeigten weiter, daß Kohlenhydratmangel Wachstum und Fettsynthese zum Stillstand bringt, unabhängig von der noch verfügbaren $\mathrm{N}$-Menge. Dagegen kommt bei alleinigem N-Mangel nur das Wachstum (Proteinsynthese) zum Stillstand, während Fettsynthese- und Speicherung weiterlaufen, sofern noch assimilierbares Kohlenhydrat vorhanden ist. Die Ergebnisse der Versuche über die Einwirkung des $\mathrm{C} / \mathrm{N}$-Verhältnisses auf die Fettbildung stehen in guter "'bereinstimmung mit den Befunden anderer Autoren (zitiert in HopPE 1960), wonach eine Behinderung der Eiwei(3synthese eine vermehrte Fettbildung zur Folge hat. Die inverse Beziehung zwischen Proteinund Fettsynthese in der lebenden Zelle geht wahrscheinlich auf eine Konkurrenz der beteiligten Enzyme um das Substrat zurück, wobei die Geschwindigkeit der Aminosäuresynthese offenbar beträchtlich höher ist als die der Fettsynthese.

Das intracellulär gebildete und gespeicherte Fett wird allgemein als Reservesubstanz betrachtet, die bei Kohlenhydratmangel unter sonst günstigen Bedingungen (genügend N. P.S) Proteinbildung ermöglicht (Prill 1935; Chibsall 1939; RaAF 1942; Yexis u. Folkes 1954). Dabei unterscheidet Belix (1926) zwei Fraktionen: 1. ..élément constant"،, den für die Lebensfähigkeit der Zelle unbedingt notwendigen Lipidanteil (Phospholipide, Lipoproteine, besondere Teile des Plasmas), der ein gewisses Minimum nicht unterschreiten darf, und 2. ,élément variable“ als Reservematerial, dessen Menge in weiten Grenzen schwanken kann und das nicht als echter Teil des Protoplasmas anzusehen ist. 
Es sind aber auch Fälle beschrieben worden. in denen dem Fett keine Funktion als Reservesubstanz zukommt, es also bei C-Mangel nicht abgebaut wird und nur als unverwertbares speicherprodukt vorliegt ${ }^{1}$. Dazu wären auch die Fälle einer ..degenerativen Fettbildung“ aus Plasmasubstanzen. besonders bei höherem Kulturalter zu zählen (KORDEs 1923; (GEFFERs 1937; KLEINZELlek 1944).

Die eigenen Versuche geben keinen eindeutigen Aufschluß über die physiologische Wertigkeit des gespeicherten Lipids, das zwar nach Verbrauch des Kohlenhydrats im Medium, während der Autolyse absolut und prozentual (zur Trockensubstanz) abnimmt. doch wesentlich weniger stark als die Zellsubstanz selbst.

Unter natürlichen Lebensbedingungen findet bei den Mikroorganismen im allgemeinen keine nennenswerte Fettbildung statt, bei unphysiologisch hohen Kohlenhydratkonzentrationen im Nährmedium wird jedoch mehr Kohlenhydrat gespalten. als zum Zellaufbau und zur Energiegewinnung verwendet werden kann. Der das Substrat völlig oxydierende Enzymmechanismus wird so abgesättigt (Foster 1949: ,,bottle-neck enzymes". .overflow metabolism“) und die im ("berschuß vorhandenen. teilweise oxydierten Abbauprodukte werden entweder ausgeschieden oder zu sekundären Hilfsenzymsystemen weitergeleitet. Diese können nur verhältnismäßig geringe Veränderungen an den Zwischenprodukten vornehmen, die daraufhin ausgeschieden oder wie im Falle der Lipide. intracellulär angehäuft werden.

Obwohl die Pilze aerobe Organismen sind, bauen sie im allgemeinen die Hauptmenge der angebotenen Kohlenhydrate über den an sich anaeroben Embden-Meyerhof-Stoffwechselweg ab. So konnten SHU, Funk u. Neish (1954) durch Isotopenversuche nachweisen, daß Aspergillus niger et wa $80 \%$ der angebotenen Glucose auf diesem Wege abbaut. Es zeigte sich, daß der Embden-Meyerhof-Weg nicht auf anaerobe Bedingungen beschränkt ist, sondern auch unter aeroben Verhältnissen streckenweise zum Kohlenhydrat-Abbau beschritten werden kann, indem er terminal mit aeroben Prozessen gekoppelt ist. Dabei wird reduziertes Co-Enzym durch ein Oxydase-System regeneriert. Die Decarboxylierung des Pyruvats zur aktiven Essigsäure stellt dabei die Verbindung zum Tricarbonsäure-Cyclus her, der eine hohe Energieausbeute aus dem abgebauten Kohlenhydrat gewährleistet. Das für die terminale Oxydation benötigte Cytochrom-System scheint in Pilzen ebenso wie die Enzyme des Embden-Meyerhof-Weges allgemein vorhanden zu sein (Cochrase 1958).

In den eigenen Versuchen konnte ebenfalls durch den Nachweis der Schlüsselenzyme Aldolase, Triosephosphat-Isomerase und B'TS-Dehydrogenase dieser Abbauweg und die Verbindung zum TricarbonsäureCyclus nachgewiesen werden. Die letztgenannte Reaktion liefert die

${ }^{1}$ Vgl. hierzu Steiner u. Kating (1963). 
Acetyl-CoA-Einheiten für den Tricarbonsäure-Cyclus und die Fettsynthese. Da aus dem Tricarbonsäure-Cyclus für weitere Synthesen Dicarbonsäuren abgezweigt werden, ist, um ein Weiterlaufen des Cyclus zu gewährleisten, eine de novo-Bildung von Dicarbonsäuren auf anderem Wege nötig, etwa über den Glyoxylsäure-Cyclus oder durch Carboxylierungs-Reaktionen. Bei Pilzen wurde häufig eine Wachstumsförderung durch $\mathrm{CO}_{2}$ nachgewiesen und auch der Einbau von $\mathrm{CO}_{2}$ in Brenztraubensäure, Milchsäure, Oxalessigsäure, Bernsteinsäure und Citronensäure (Cleland u. Johnson 1954) festgestellt (Cochrane 1958). Im Rohextrakt des Mycels der NRRL-Stämme ließ sich jedoch eine Fixierung von ${ }^{14} \mathrm{CO}_{2}$ in Oxalacetat weder durch PEP-Carboxylase (BANDURSKI 1955), noch durch Oxalessigsäure-Carboxylase (UtTER, KURAhashi u. Rose 1954; Suzuki u. Werkman 1958), ebensowenig wie die Carboxylierung des Ru-1,5-DP durch die Ru-1,5-DP-Carboxylase nachweisen. Dieses Enzym wurde unter anderem bisher im Spinat und in anderen grünen Pflanzen (J $\mathrm{J}_{\mathrm{AKOB}}$, BRUmmond u. OChOA 1956), Algen (CalviN 1956; Peterkofski u. RaCker 1961) und chemolithotrophen Mikroorganismen (Trudinger 1956) gefunden. Auch die Phosphoketolase, die von Zuckerphosphaten Acetylphosphat abspaltet und bisher bei Lactobacillen (Lampen, Gest u. Sowden 1951; Heath et al. 1958), bei Leuconostoc (HURwitz 1958) und Acetobacter (Schramm, Kly bas u. RACKER 1958), nicht jedoch bei Pilzen gefunden wurde, ließ sich in dem Enzymextrakt von Beauveria nicht nachweisen.

\section{Zusammenfassung}

Für die serienmäßige quantitative Lipidbestimmung bei Beauveria tenella auf der Grundlage der optischen Hydroxamsäureester-Bestimmung wurde eine für die vorliegenden Bedingungen geeignete Mycelaufschlußund Extraktionsmethode entwickelt. Das gefriergetrocknete Mycel wurde im Potter-Elvehjem-Homogenisator mit Äther aufgeschlossen und auf der Schüttelmaschine extrahiert. In Submerskulturversuchen wurde das Wachstum der drei Stämme NRRL 2334, 2335, 2336 in Abhängigkeit von der Kohlenstoff-Quelle und ihrer Konzentration, dem Zusatz anorganischer Salze und vom $\mathrm{p}_{\mathrm{H}}$-Wert geprüft.

Es wurden Wachstumskurven mit Rühr- und Schüttelkultur aufgenommen. Als günstigste Methode erwies sich die Schüttelkultur, beimpft mit einer flüssigen Vorkultur.

Die Fettbildung der Stämme in Abhängigkeit von verschiedenen zusätzlichen Kohlenstoffquellen wurde geprüft. Acetat, Pyruvat und Lactat konnten in Zellsubstanz und Fett umgewandelt werden. Stamm NRRL 2334 war der beste Fettbildner.

Die Auswirkung verschiedener Kohlenhydrat- und Stickstoffkonzentrationen auf die Lipidsynthese wurde untersucht. Trockensubstanz- 
und Lipidsynthese nehmen mit steigendem Kohlenhydratgehalt des Mediums zu, doch sinkt dabei der synthetische Wirkungsgrad. Ein hohes $\mathrm{C} / \mathrm{N}$-Verhältnis begünstigte die Fettbildung. Fett- und Zellsubstanzbildung konkurrieren um die Kohlenstoff-Quelle. Ein höherer Ökonomischer Koeffizient ist jeweils mit einem niedrigeren Fettkoeffizienten gekoppelt. Es wurde in Wachstumskurven die Abhängigkeit der Lipidsynthese vom $\mathrm{C} / \mathrm{N}$-Verhältnis und der Zeit bestimmt. Die Fettbildung setzt schon ein, bevor Stickstoff zum wachstumsbegrenzenden Faktor wird. Sie schreitet nach Aufbrauch der Stickstoff-Quelle bis zu einem Fettgehalt von $34 \%$ des Myceltrockengewichts fort.

Als Schlüsselenzyme des Embden-Meyerhof-Abbauweges wurden in zellfreien Extrakten Aldolase, Triosephosphat-Isomerase und Brenztraubensäure-Dehydrogenase nachgewiesen und in ihrer Aktivität bestimmt.

Phosphoenolbrenztraubensäure-Carboxylase, Oxalessigsäure-Carboxylase und Ribulose-1,5-Diphosphat-Carboxylase ließen sich nicht nachweisen; ${ }^{14} \mathrm{CO}_{2}$ wurde mit den entsprechenden Enzymsubstraten nicht eingebaut. Phosphoketolase konnte ebenfalls nicht aufgefunden werden.

\section{Summary}

A method for the breaking up and extraction of fungal mycelium (Beauveria tenella) prior to the quantitative determination of lipids by means of the hydroxamic acid-ester reaction was developed. The lyophilized mycelium, suspended in ether, was broken up using a PotterElvehjem homogenisor and further extracted on a shaker.

The growth of three fungal strains (NRRL 2334, 2335, 2336) in relation to the carbon source and concentration, the presence of inorganic salts and the $\mathrm{p}_{\mathrm{H}}$-value of the medium was examined.

Growth curves of shaken and stirred cultures were recorded. The best growth method found was the shake-culture method using a liquid pre-culture.

The production of fat in these strains in relation to the carbon source utilized was investigated. Acetate, pyruvate and lactate were incorporated into cell-substance and fats. Strain NRRL 2334 was the best fatproducer.

The effect of various carbohydrate and nitrogen concentrations on lipid synthesis was examined. The synthesis of cell material and lipids increases with higher concentrations of carbohydrates; at the same time, the synthetic efficiency is lowered. A high $\mathrm{C} / \mathrm{N}$ ratio favoured fat production. The synthesis of fat and cell material from carbohydrates is a competitive reaction. A higher economic coefficient is coupled with a 
lower fat-coefficient. The relationship between lipid synthesis and the $\mathrm{C} / \mathrm{N}$ ratio and between lipid synthesis and time was determined. Lipid production commences before nitrogen becomes growth-limiting. Following complete consumption of the nitrogen-source the fat content rises to a maximum of $34 \%$ on a dry-weight basis.

The key enzymes of the Embden-Meyerhof scheme-aldolase, triosephosphate-isomerase and pyruvic dehydrogenase-were found and their activity determined.

The presence of phosphoenol pyruvate-carboxylase, oxalaceticcarboxylase and ribulose-1,5-diphosphate-carboxylase could not be demonstrated; ${ }^{14} \mathrm{CO}_{2}$ was not incorporated in enzymatic tests with the respective substrates. Phosphoketolase activity could not be found.

Mit Unterstützung durch die Deutsche Forschungsgemeinschaft.

Herrn Prof. Dr. H. G. Schlegel danke ich für sein reges Interesse an der Arbeit und ihre stete Förderung.

Fräulein Marita MaU danke ich für stets zuverlässige Hilfeleistung bei den abschließenden Versuchen.

\section{Literatur}

BANDURSKI, R. S.: Further studies on the enzymatic synthesis of oxal-acetate from phosphorylenol-pyruvate and carbon-dioxide. J. biol. Chem. 217, 137-150 (195̃5).

Bargmann, W., u. A. Knoop: Uber die Morphologie der Milchsekretion: Lichtund elektronenoptische Studien an der Milchdrüse der Ratte. Z. Zellforsch. 49, $344-388$ (1959).

Bauer, H., u. H. Moll: Die organische Analyse, 4. Aufl. Leipzig: Akad. Verlagsges. Geest u. Portig KG. 1960.

Beisenherz, G., H. J. Boltze, Th. Bücher, R. Czok, K. H. Garbade, E. MeyerAhrendt u. G. Pfleiderer: Diphosphofructose-Aldolase, Phosphoglyceraldehyd-Dehydrogenase, Milchsäure-Dehydrogenase, Glycerophosphat-Dehydrogenase und Pyruvat-Kinase aus Kaninchenmuskel in einem Arbeitsgang. Z. Naturforsch. 8b, 555-577 (1955).

BELIs, P.: Généralité de la distinction entre deux catégories de matières grasses: Élément constant et élément variable. Bull. Soc. Chim. biol. (Paris) 8, 1081 bis 1102, 1120-1150 (1926).

Bexko, P. J.: Studies on the submerged cultivation of edible mushrooms. M. S. Thesis, Univ. Calif., Calif. (1958).

Bernhater, K. P., P. Müller u. E. Theile: Beiträge zur mikrobiologischen Eiweiß- und Fettsynthese. V. Mitteilung. Notiz über die vergleichende Prüfung verschiedener Verfahren zur Fettextraktion von Pilzmycel. Biochem. Z. 320, $294-298$ (1950).

Boehringer, C.F., \& Soehne, Mannheim: a) Firmenschrift: Biochemica „Boehringer". Aldolase-Test.

- b) Firmenschrift: Biochemica „Boehringer“. Triosephosphat-Isomerase (1961).

Bǘher, Th. : Ưber ein phosphatübertragendes Gärungsferment. Biochim. biophys. Acta (Amst.) 1, 292 (1947).

Calvis, M.: Der Photosynthese-Cyclus. Angew. Chem. 68, 253-264 (1956).

Chibsall, A. C.: Protein metabolism. New Haven: Yale Univ. Pr. 1939. 
Chov, T. C., and F. LIPMAnN: Separation of acetyl transfer enzymes in pigeonliver extract. J. biol. Chem. 196, 89-103 (1952).

Claus, L.: Untersuchungen über die Chitinasewirkung des insektentötenden Pilzes Beauveria bassiana (Bals.) Vuill. Arch. Mikrobiol. 40, 17-46 (1961).

Cleland, W. W., and M. J. Johnson: Tracer experiments of the mechanism of citric acid formation by Aspergillus niger. J. biol. Chem. 208, 679-689 (1954).

Cochraxe, V.: Physiology of fungi. New York: J. Wiley, Sons Inc. 1958.

Cordon, T. C., and J. H. Schwartz: The fungus Beauveria tenella. Science 138, 1265 (1962).

Enebo, L.: Sätt att framställa fett på mikrobiell väg. Schwed. Pat. 127186. (Zusatz z. Schwed. Pat. 124071) (1950).

Estienne, V., E. Castagne et E. Bertrand: La lactase des champignons. Bull. Soc. Chim. biol. (Paris) 29, 620-627 (1947).

Falanghe, H.: Production of mushroom mycelium as a protein and fat source in submerged culture in medium of vinasse. Appl. Microbiol. 10, 572-576 (1962).

Fildes, Sir P.: The evolution of microbiology. Proc. roy. Soc. B 138, 65-74 (1951).

Franz, J. M.: Biologische Schädlingsbekämpfung. In Soraukr, P.: Handbuch der Pflanzenkrankheiten, Bd. VI, 3. Liefg., 2. Aufl. Berlin: Parey 1961.

Foster, J. W.: Chemical activities of fungi. New York: Academic Press Inc. 1949.

GaUdecker, B. v.: Utber den Formwechsel einiger Zellorgane bei der Bildung der Reservestoffe im Fettkörper von Drosophila-Larven. Z. Zellforsch. (im Druck) (1963).

Geffers, H.: Untersuchungen über das Fettbildungsvermögen bei Pilzen der Gattung Oospora Wallroth (em. Sacc.). Arch. Mikrobiol. 8, 66-98 (1937).

Goodwin, T. W., and J. S. Willmer: Studies in carotenogenesis. 4. Nitrogen metabolism and carotene synthesis in Phycomyces blakesleeanus. Biochem. J. 51, 213-217 (1952).

Heath, E. C., J. Hurwitz, B. L. Horecker and M. Ginsburg: Pentose fermentation by Lactobacillus plantarum. I. The cleavage of xylulose-5-phosphate by phosphoketolase. J. biol. Chem. 231, 1008-1064 (1958).

HeIde, S.: Zur Physiologie und Cytologie der Fettbildung bei Endomyces vernalis. Mit einem Beitrag zur Methodik der quantitativen Bestimmung kleinster Fettmengen. Arch. Mikrobiol. 10, 135-188 (1939).

Heineman, H.: Untersuchungen über die Physiologie und Cytologie der Fettbildung bei Pilzen. Diss. d. math.-nat. Fak. Univ. Bonn (1956).

Hewit, B. R.: Spectrophotometric determination of total carbohydrate. Nature (Lond.) 184, 246-247 (1958).

Hoppe, W.: In Reiff, F., R. Kautzmann, H. L. Lüers u. M. Lindemann: Die Hefen. I. Band. Die Lipide der Hefen, S. 465-507. Lipidstoffwechsel, S. 819 bis 872. Nürnberg: H. Carl 1960.

Huber, H.: Untersuchungen zur Physiologie insektentötender Pilze. Arch. Mikrobiol. 29, 257-267 (1958).

Hughes, D. E.: A press for disrupting bacteria and other microorganisms. Brit. J. exp. Path. 32, 97-109 (1951).

HuMfeld, H.: The production of mushroom mycelium in submerged culture. Science 107, 273-275 (1948).

- Production of mushroom mycelium. US. Dept. Agric., Yearbook Agric. 242 to $246(1950 / 51)$.

-, and T.F. Suginara: Mushroom mycelium production by submerged propagation. Food Technol. 3, 355-356 (1949).

- - The nutrient requirements of Agaricus campestris grown in submerged culture. Mycologia (N. Y.) 44, 605-620 (1952). 
Hurwitz, J.: Pentose phosphate cleavage by Leuconostoc mesenteroides. Biochim. biophys. Acta (Amst.) 28, 599-602 (1958).

JAKOBY, W. B., D. O. BRUMMOND and S. OCHOA : Formation of 3-phosphoglyceric acid by carbon dioxide fixation with spinach leaf enzymes. J. biol. Chem. 218, $811-822$ (1956).

Kaplan, N. O., and F. Lipmama: The assay and distribution of coenzyme A. J. biol. Chem. 174, 37-44 (1948).

Kleinzeller, A.: Fat formation in Torulopsis lipofera. Biochem. J. 38, 480-492 (1944).

Kordes, H.: Biologische Untersuchungen über das in Dauerzellen und Hyphen verschiedener Pilze auftretende Fett. Bot. Arch. 3, 282-311 (1923).

KURU, M.: Uber einen neuen pathogenen Schimmelpilz „Isaria shiotae, nov. spec.“ von einem pseudoxanthomatosen Herde des Menschen kultiviert. Japan. J. Med. Sci. IX. Surg. 2, 327-358 (1932).

Lafferty, R. M.: Kohlendioxyd-Fixierung durch organotrophe Bakterien. Arch. Mikrobiol. 44, 373-405 (1963).

LAMPEN, I. O., H. Gest and I. C. SowDEn: Observations on the mechanism of fermentation of ${ }^{1-14} \mathrm{C}-\mathrm{D}$-Xylose by Lactobacillus pentosus. J. Bact. 61, 97-98 (1951).

Lehmann, F., L. Maquense u. N. Schoorl: Zuckerbestimmung. In Klein, G.: Handbuch der Pflanzenanalyse. II. Band. 1. Teil. Wien: Springer 1932.

Lilly, V. G., and H. L. BarnetT: Utilisation of sugars by fungi. West Va. Univ. agr. exp. Sta. Bull. 362 T, $1-58$ (1953).

Lindner, P.: Das Problem der biologischen Fettbildung und Fettgewinnung. Z. angew. Chem. 35, 110-114 (1932).

Lundin, H.: Fettsynthese durch Mikroorganismen und Möglichkeiten ihrer technischen Verwertung. Mitt. Vers. Anst. Gärungsweg. 1-2, 5-12 (1950).

MaAs-Förster, M.: Der Fett- und Eiweißstoffwechsel von Endomyces vernalis unter dem Einfluß von Phosphor- und Kaliummangel. Arch. Mikrobiol. 22, 115-144 (1955).

MacLeod, D. M.: Natural and cultural variation in entomogenous fungi imperfecti. Ann. N. Y. Acad. Sci. 60, 58-70 (1954a).

- Investigation on the genera Beauveria Vuill. and Tritirachium Limber. Canad. J. Bot. 32, 818-890 (1954 b).

Madklin, M. F.: Pilze als Insektenparasiten. Endeavour XIX 76, 181-190 (1960).

Margolin, A. S.: The effect of various carbohydrates upon the growth of some fungi. Thesis, West Va. Univ. (1942).

Molitoris, H. P.: Untersuchungen an Beauveria tenella (NRRL 23.34, 2335, 2336; bisher Agaricus campestris). I. Systematik. Arch. Mikrobiol. 47, 57-71 (1963a).

Moustafa, A. M.: Nutrition and the development of mushroom flavor in Agaricus campestris mycelium. Appl. Microbiol. 8, 63-67 (1960).

O'NeIL, J. J.: Studies in the submerged culture production of mushroom mycelium. M. S. Thesis, Mass. Inst. Technol, Cambridge, Mass. (1956).

Pacifici, L. R., R. N. Blonster, H. J. Lukowski and A. E. Schwarting: Preliminary growth and nutrition studies of Amanita muscaria in submerged culture. Lloydia 23, 43-50 (1960).

Peck, R. L.: In: Nickerson, W. J.: Biology of pathogenic fungi. S. 167-188. Waltham, Mass., Chronica Botanica Co. (1947).

Pelczar, M. J., A. Hansen and W. A. Konetzka: Quantitative bacterial physiology. Laboratory Experiments. Minneapolis: Burgess Publishing Co. 1956. 
Peterkofsky, A., and E. RACker: The reductive pentose phosphate cycle. III. Enzyme activities in cell-free extracts of photosynthetic organisms. Plant Physiol. 36, 409-414 (1961).

Pfeffer, W.: Úber Election organischer Nährstoffe. Jb. wiss. Bot. 28, 205-268 (1895).

Potter, V. R., and C. A. Elvehuem: A modified method for the study of tissue oxidations. J. biol. Chem. 114, 495-504 (1936).

Prill, E. A., P. R. Wenck and W. H. Peterson: The chemistry of mould tissue. VI. Factors influencing the amount and nature of the fat produced by Aspergillus fischeri. Biochem. J. 29, 21-33 (1935).

Pruess, L. M., E. C. Eichinger and W. H. Peterson: The chemistry of mould tissue. III. Composition of moulds with special reference to the lipid content. Zbl. Bakt., II. Abt. 89, 370-377 (1934).

RAAF, H.: Beiträge zur Kenntnis der Fett- und Eiweißsynthese bei Endomyces vernalis und einigen anderen Mikroorganismen. Arch. Mikrobiol. 12, 131-182 (1942).

Reusser, F., J. F. T. Spencer and H. R. Sallans: Protein and fat content of some mushrooms grown in submerged culture. Appl. Microbiol. 6, 1-4 (1958).

RIPPEL, A.: Energetische Betrachtungen zur Ökonomie der Fettbildung bei Mikroorganismen. Arch. Mikrobiol. 11, 271-284 (1940).

SaCCAS, A.: Étude morphologique et biologique d'un nouveau champignon papyricole, la Beauveria heimii sp. nov. Rev. Mycol. 13, $61-81$ (1948).

Schlegel, H. G., u. R. M. Lafferty: Radioaktivitätsmessung an Einzellern auf Membranfiltern. Arch. Mikrobiol. 38, 52-54 (1961).

- H. Kaltwasser u. K. Gottschalk: Ein Submersverfahren zur Kultur wasserstoffoxydierender Bakterien: Wachstumsphysiologische Untersuchungen. Arch. Mikrobiol. 38, 209-222 (1961).

Schramm, M., V. Klybas and E. Racker: Phosphorolytic cleavage of fructose6-phosphate by fructose-6-phosphate phosphoketolase. J. biol. Chem. 233, 1283-1288 (1958).

Shriner, L. R., R. C. Fuson and D. Y. Curtix: The systematic identification of organic compounds, 4. Aufl. New York: J. Wiley Sons Inc. 1956.

Shu, P., A. Funk and A. C. NeIsh: Mechanism of citric acid formation from glucose by Aspergillus niger. Canad. J. Biochem. 32, 68-80 (1954).

Sirith, A. L.: British mycology. Trans. Brit. Mycol. Soc. 1, 70 (1897).

SNyder, F., and N. Stephens: A simplified spectrophotometric determination of ester groups in lipids. Biochim. biophys. Acta (Amst.) 34, 244-245 (1959).

Steiner, M.: Zur Verwendung von Permutit bei Stoffwechselversuchen mit Mikroorganismen. Biochem. Z. 307, 330-332 (1941).

- , u. H. Heinemanv: Grana mit positiver Nadi-Reaktion als Ort der primären Fettbildung in Pilzzellen. Naturwissenschaften 41, 40-41 (1954).

-, u. H. Kating: Ist das Fett von Penicillium javanicum im Reservestoff? Arch. Mikrobiol. 46, 185-189 (1963).

Sugihara, T. F., and H. Humfeld : Submerged culture of the mycelium of various species of mushroom. Appl. Microbiol. 2, 170-172 (1954).

Suzuki, J., and C. H. Werkmax: Chemoautotrophic carbon dioxide fixation by extracts of Thiobacillus thiooxidans. I. Formation of oxalacetic acid. Arch. Biochem. 76, 103-111 (1958).

Szofcs, J.: Submerged culture. Mushroom Sci. III, 269-272 (1956).

Tabor, H., A. H. Mehler and E. R. Stadtman: The enzymatic acetylation of amines. J. biol. Chem. 204, 127-138 (1953). 
Trudinger, P. A.: Fixation of carbon dioxide by extracts of the strict autotroph Thiobacillus denitrificans. Biochem. J. 64, 274-286 (1956)

CTter, M. F., K. Kurahashi and I. A. Rose: Some properties of oxalacetic carboxylase. J. biol. Chem. 207, 803-819 (1954).

Viscess, F.: Observations sur le Sclerotium oryzae faites en Cochinchine. Rev. pathol. végétale et entomol. agr. 10, 112-131 (1923).

Visisg, L. C., W. J. Kelleher and A. F.. Schwarting: Oosporein production by a strain of Beauveria bassiana originally identified as Amanita muscaria. Canad. J. Microbiol. 8, $931-933$ (1962).

YexM, E. W., and B. F. Folkes: The regulation of respiration during the assimilation of nitrogen in Torulopsis utilis. Biochem. J. 57, 495-508 (1954).

Dr. H. P. Molitoris,

Institut für Mikrobiologie der Universität, 34 Göttingen, Goßlerstraße 16 

Aus dem Institut für Mikrobiologie der Universität Göttingen

\section{Untersuchungen an Beauveria tenella (NRRL 2334, 2335, 2336; bisher Agaricus campestris)}

III. Analyse des Speicherfettes

$$
\text { Von }
$$

H. P. MOLITORIS

Mit 4 Textabbildungen

(Eingegangen am 27. Juli 1963) 
Im Teil II dieser Arbeit (MoLItoris $1963 \mathrm{~b}$ ) ist über die Abhängigkeit der Speicherfettbildung bei Beauveria tenella von verschiedenen Faktoren sowie den zeitlichen Verlauf dieses Vorganges berichtet worden. Gegenstand dieser Mitteilung ist die Isolierung und analytische Untersuchung des gebildeten Speicherfettes.

Bei der Isolierung der Lipide aus den Pilzzellen geht eine Vielzahl von Verbindungen in Lösung, deren Trennung nicht ohne weiteres durchgeführt werden kann. Zum einfacheren und schnelleren Vergleich mit Lipiden anderer Herkunft führt man daher üblicherweise zunächst summarische Untersuchungen durch. Auf diese Weise gelingt es in vielen Fällen bereits einen Einblick in die Zusammensetzung des Lipidgemisches zu erhalten, bevor es im weiteren Verlauf der Untersuchung aufgetrennt und analytisch bestimmt wird. Diese Verfahren werden auf chemischem Gebiet als Kennzahlbestimmungs- Wethoden bezeichnet und ermöglichen zusammen mit den physikalischen Konstanten einen Vergleich mit anderen Lipidgemischen.

\section{A. Material und Methoden \\ 1. Mycelanzucht und Lipidgewinnung}

Nach den in der vorangegangenen Arbeit (Molitoris 1963 b) gewonnenen Erfahrungen wurden Schüttelkulturen des Stammes NRRL 2.3.3t angesetzt (Vorkultur: Humfeld-Medium, 3 Tage. $10 \%$ Inoculum; Hauptkultur: Humfeld-Grundmedium mit $\tilde{5}^{\%}$, Glucose und $0,04^{0}$. Harnstoff $=0,2 \mathrm{mg} \mathrm{N} / \mathrm{ml}$ ) und das Mycel am 10. Kulturtage geerntet. Die Ernte betrug insgesamt $104 \mathrm{~g}$ gefriergetrocknetes Mycel. Um das Lipid möglichst quantitativ aus den Zellen herauszulösen, und um Zeit zu sparen, wurde das Hycel mit dem Mickle-Homogenisator aufgeschlossen und mehrmals mit Äther extrahiert [je Aufschluß zwei Proben mit je $500 \mathrm{mg}$ Tr.S., $1 \mathrm{~cm}^{3}$ Glaskugeln, $5 \mathrm{ml}$ Äther, $10 \mathrm{~min}$ bei maximaler Intensität; Inhalt dreier Aufschlußgefäße $+35 \mathrm{ml}$ Äther 24 Std auf der Schüttelmaschine bei $27^{\circ} \mathrm{C}$ extrahiert; Zellreste auf Kieselgur-Filterpapier (Schl. \& Sch. Nr. 287) abfiltriert].

Nach Verdampfen des Lösungsmittels und Trocknen des Rohlipids über $\mathrm{CaCl}_{2}$ und Paraffin im Exsiccator wurden so aus den $104 \mathrm{~g}$ Trockensubstanz 46,6 g Rohextrakt gewonnen, was einem Lipidgehalt des Mycels von $44,8 \%$ entspricht. Das Lipid wurde bis zur Weiterverarbeitung jeweils vor Luft und Licht geschützt im Kühlraum aufbewahrt. 


\section{Physikalische Methoden}

Die Dichte wurde gravimetrisch nach Küster, Thiel u. Fischbeck (1958) bestimmt als $\varrho_{24}$ bezogen auf Wasser von $4^{\circ} \mathrm{C}$.

Die Refraktion wurde gemessen als $\mathrm{n}_{D}^{20}$ mit einem Abbé-Refraktometer bei $20,2^{\circ} \mathrm{C}$ und der Na-D-Linie des Spektrums.

Die relative Viscosität gegenüber Wasser wurde nach Matula (1932) mit einem Ostwald-Viscosimeter ermittelt.

Die Bestimmung der Oberflächenspannung erfolgte nach der Blasenmethode (EUCKen u. SuHrmann 1954) in dyn/cm.

Die spezifische Drehung wurde mit dem Polarisationsgerät der Fa. Schmidt und Haensch/Berlin, untersucht.

Die Absorptionsspektren wurden mit einem Zeiss-Photometer (PMQ II) aufgenommen und gegen reines Lösungsmittel gemessen. Im UV-Bereich wurde n-Hexan und Methanol, im sichtbaren Spektralbereich Äther als Lösungsmittel verwendet.

Die gravimetrische Fettbestimmung erfolgte wie in der vorangegangenen Arbeit (MOLITORIS 1963 b).

\section{Chemische Verfahren}

Säurezahl, Verseifungszahl, Esterzahl und Äquivalentgewicht wurden nach Winkler (in BAGer u. Moll 1960) bestimmt durch Titration und Verseifung des Lipids mit n-propylalkoholischer 0,5 $\mathrm{n} \mathrm{KOH}$.

Die Jodzahl wurde nach KaUfManN (in BAUER u. Moll 1960) bestimmt.

Zur Verseifung des Lipids und zur Gewinnung des Unverseifbaren und der freien Fettsäuren wurde wie üblich vorgegangen: Die Arbeiten erfolgten unter $\mathrm{CO}_{2}$-Schutz. Es wurde mit methylalkoholischer 0,5 $\mathrm{n} \mathrm{KOH}$ verseift. Das Unverseifbare wurde mit Petroläther/Äthergemisch ausgeschüttelt, abgetrennt, eingedampft und gewogen. Aus der methyl-alkoholischen Phase wurden die Fettsäuren durch Ansäuern mit $\mathrm{HCl}$ freigesetzt, durch Schütteln mit Petroläther/Äther abgetrennt, getrocknet, eingedampft und gewogen. Die freien Fettsäuren wurden bis zur Weiterverarbeitung in trockenem p.a. Aceton gelöst und unter Luftabschluß bei $-20^{\circ} \mathrm{C}$ auf bewahrt.

Die Methylester der freien Fettsäuren wurden nach GLICK (1960) hergestellt, doch wurde an Stelle der methanolischen $\mathrm{HCl}$ mit methanolischer $\mathrm{H}_{2} \mathrm{SO}_{4}$ gearbeitet. Das Material wurde in trockenem p.a. Aceton unter Luftabschluß bei $-20^{\circ} \mathrm{C}$ bis zur Aufarbeitung aufbewahrt.

\section{Gaschromatographie und Auswertung}

Es wurde ein Argon-Gaschromatograph der Fa. Pye Co., Cambridge, verwendet. Die benutzte Säule hatte eine Länge von $122 \mathrm{~cm}$ und einen Durchmesser von $0,4 \mathrm{~cm}$. Das Trägermaterial war Chromosorb $\mathrm{W}$, die aufgezogene stationäre Phase $(10 \%)$ bestand aus Polyäthylenglykol-Adipat (PEGA). Als Trägergas wurde Argon verwendet. Die Verdampfertemperatur lag bei $275^{\circ} \mathrm{C}$, die Säulentemperatur bei $175^{\circ} \mathrm{C}$.

Die qualitative und quantitative Auswertung der Chromatogramme erfolgte nach JAMES (1962). Nach Berechnung der korrigierten Retentionsvolumina aus den Kurven und den Versuchsbedingungen wurden die einzelnen Fettsäuren durch Vergleich mit den Werten reiner Eichsubstanzen ermittelt.

Zur quantitativen Auswertung wurden die Flächen der einzelnen Gipfel durchgepaust, ausgeschnitten und gewogen. Die Summe der Gewichte wurde gleich 100\% gesetzt und daraus der prozentuale Anteil der einzelnen Fettsäuren(methylester) an der Gesamtmenge errechnet. 


\section{B. Versuche und Ergebnisse \\ 1. Aufarbeitung des Ätherextraktes}

Das Rohlipid war bei $25^{\circ} \mathrm{C}$ von gelblich-brauner Farbe, öliger Konsistenz und enthielt einen geringen Bodensatz von farblosen, wachsartigen Schuppen. Die Aufarbeitung und Auftrennung in die einzelnen Fraktionen wurde nach folgendem Schema durchgeführt.

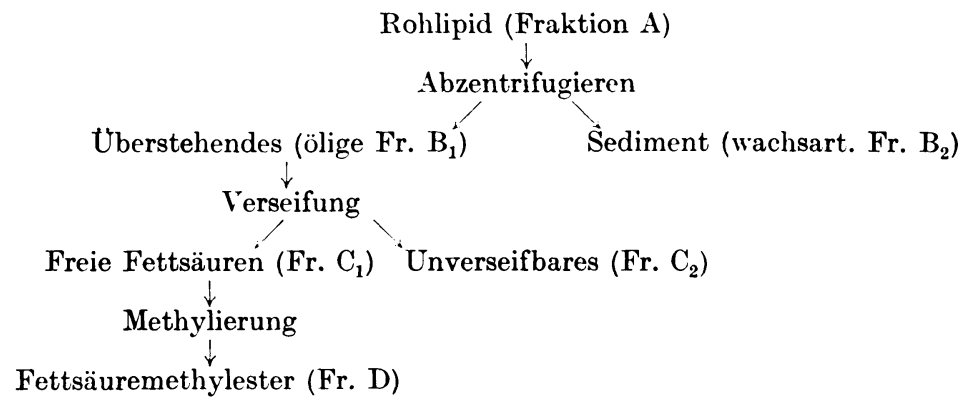

Um für die Untersuchungen ein homogenes Material zu erhalten, wurde zunächst durch mehrmaliges Zentrifugieren $\left(25^{\circ} \mathrm{C}, 30 \mathrm{~min}\right.$, $5000 \mathrm{U} / \mathrm{min}$ ) die wachsartige Fraktion $B_{2}$ von der öligen Fraktion $B_{1}$ abgetrennt.

\section{Physikalische und chemische Kennzahlen und Eigenschaften}

Die Lipidfraktion $B_{1}$ wurde zunächst auf diese Daten hin untersucht. Die Ergebnisse sind der Tab.1 zu entnehmen.

Bei der Untersuchung der Absorptionseigenschaften wurde das UV. Spektrum der Substanz in 0,01\% Lösung in n-Hexan im Bereich von 218-340 $\mathrm{m} \mu$ aufgenommen (Abb.1, Kurve A). Die Kurve zeigt ein starkes Maximum bei $230 \mathrm{~m} \mu$ (zwei konjugierte Doppelbindungen) sowie einen zunächst steilen, dann flacher werdenden Abfall bis $340 \mathrm{~m} \mu$, unterbrochen von einer Schulter zwischen 247 und $257 \mathrm{~m} \mu$. Da die Absorptionsmaxima von einfach ungesättigten Fettsäuren unter dem Meßbereich $(215 \mathrm{~m} \mu)$ liegen, konnten aus der aufgenommenen Kurve auf deren Anwesenheit und Menge keine Schlüsse gezogen werden.

Unter anderem führt auch eine größere Anzahl konjugierter Doppelbindungen zu gefärbten Produkten, die also im sichtbaren Spektralbereich absorbieren. Da die Fraktion $B_{1}$ gelb-braun gefärbt war, wurde auch für den sichtbaren Bereich ein Absorptionsspektrum aufgenommen $(50 \%$ Lösung in Diäthyläther $)$.

Die Substanz absorbiert im Bereich unterhalb von $400 \mathrm{~m} \mu$ sehr stark, die Absorption sinkt dann zu längeren Wellenlängen hin sehr schnell ab und weist nur noch bei $680 \mathrm{~m} \mu$ ein kleineres und bei $750 \mathrm{~m} \mu$ ein etwas größeres Maximum auf. 
Tabelle 1. Physikalische und chemische Eigenschaften des Rohlipids (Ätherextrakt)

Fraktionierungsergebni.s

Rohextrakt (Fr. A)

Olfraktion (Fr. B B $_{1}$

Wachsfraktion (Fr. $B_{2}$ )

Freie Fettsäuren (Fr. $\left.C_{1}\right)$

Cnverseifbares (Fr. $\mathrm{C}_{2}$ )

$$
\begin{aligned}
& 44,8 \% \text { d. Tr.S } \\
& 39,9 \% \text { d. Tr.S } \quad 89,0 \% \text { d. Fr. A } \\
& 4,9 \% \text { d. Tr.S } \quad 11,0 \% \text { d. Fr. A }
\end{aligned}
$$

$62,6^{\circ} \%$ d. Fr. $B_{1}$ $37,4 \%$ d. Fr. $B_{1}$

\footnotetext{
Physikalische Eigenschaften der Fraktion $B_{1}$

Dichte (bezogen auf Wasser $+4^{\circ} \mathrm{C}$ )

Relative Viscosität gegenüber Wasser $\left(24^{\circ} \mathrm{C}\right)$

Oberflächenspannung $\left(24^{\circ} \mathrm{C}\right)$

Refraktion

Spezifische Drehung

$$
\begin{aligned}
\varrho_{24} & =0,9081 \\
& =70,4 \\
& =30,9 \mathrm{dyn} / \mathrm{cm} \\
\mathrm{n}_{D}^{20} & =1,4708 \\
& =\text { optisch inaktiv }
\end{aligned}
$$
}

Absorptionsspektren ${ }^{1}$

UV-Bereich

Sichtb. Bereich
Maxima: $230(254) \mathrm{m} \mu$

Minima: $219(250) \mathrm{m} \mu$

Maxima: (525, 580), 680, $750 \mathrm{~m} \mu$

Minima: $(520,575), 645,705 \mathrm{~m} \mu$

Chemische Kennwerte der Fraktion $B_{1}$

$\begin{array}{lc}\text { Säurezahl } & 14,1 \\ \text { Esterzahl } & 152,4 \\ \text { Verseifungszahl } & 166,5 \\ \text { Jodzahl } & 76,11 \\ \text { Mittleres Äquivalentgewicht der Fettsäuren } & 337,0 \\ \text { Mittleres Molekulargewicht der Fette (Triglyceride) } & \\ & 1010,0\end{array}$

${ }^{1}$ Werte in Klammern bezeichnen unbedeutende Maxima und Minima.

${ }^{2}$ Unter der Annahme, daß praktisch alle Fettsäuren als Triglyceride vorliegen. Fr. = Fraktion des Rohextrakts.

\section{Gaschromatographische Untersuchung der Fettsäuremethylester}

Aus den durch Verseifung gewonnenen freien Fettsäuren wurden zunächst mit 0,5 n methanolischer $\mathrm{H}_{2} \mathrm{SO}_{4}$ die Methylester (GLICK 1960, modifiziert) hergestellt.

Diese wurden in einem Argon-Gaschromatographen (Pye, Cambridge) analysiert. Die Probenmengen wurden dabei so variiert, daß einmal die Hauptkomponenten (Abb.2) und einmal die Nebenkomponenten (Abb.3) des Fettsäuregemisches auf den gewonnenen Kurven die für die qualitative und quantitative Auswertung günstigsten Werte hatten.

Es wurden zwei Proben der Substanz $B_{1}$ völlig unabhängig voneinander verseift, verestert, im Gaschromatographen analysiert und quantitativ ausgewertet. Da die Werte beider Bestimmungen gut übereinstimmten, sind ihre Mittelwerte in Tab. 2 angegeben.

Es geht daraus hervor, daß nur drei Fettsäuren, nämlich Palmitin-, Octadecen- und Octadecadien-Säure zu etwa gleichen Anteilen fast drei 


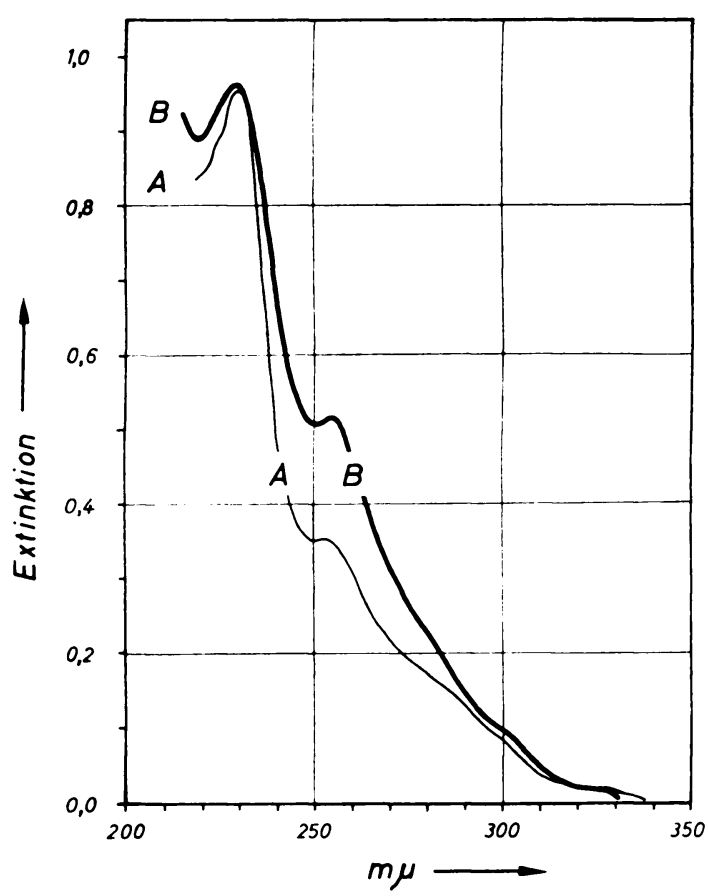

Abb.1. Spektrale Absorptionskurven (UV). Kurve A $0,01 \%$ Losung der Fraktion $B_{1}$ in $n$-Hexan; Kurve $B \quad 0,03 \%$ Lösung der Fettsäure-Methylester in Methylalkohol

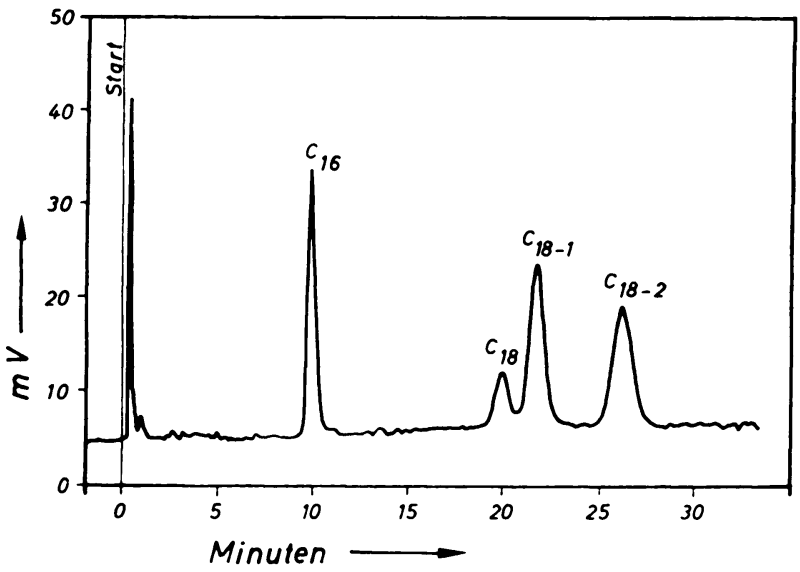

Abb. 2. Gaschromatogramm der Hauptkomponenten der Fettsäuremethylester. Pye-Gaschromatograph. Såule $122 \mathrm{~cm}$ lang, Durchmesser $0,4 \mathrm{~cm}$, gefullt mit Chromosorb W und $10 \%$ Polyäthylenglykoladipat (PEGA). Trăgergas Argon, Druck 1,095 ată, Durchflußgeschwindigkeit $10 \mathrm{ml} / 10,2 \mathrm{sec}$, Verdampfertemperatur $265^{\circ} \mathrm{C}$, Säulentemperatur $175^{\circ} \mathrm{C}$. Zellspannung $1500 \mathrm{~V}$, MeBbereich $10 \times$. Luftdruck 760,2 Torr. Probenmenge 0,1 $\mu \mathrm{l}$ 

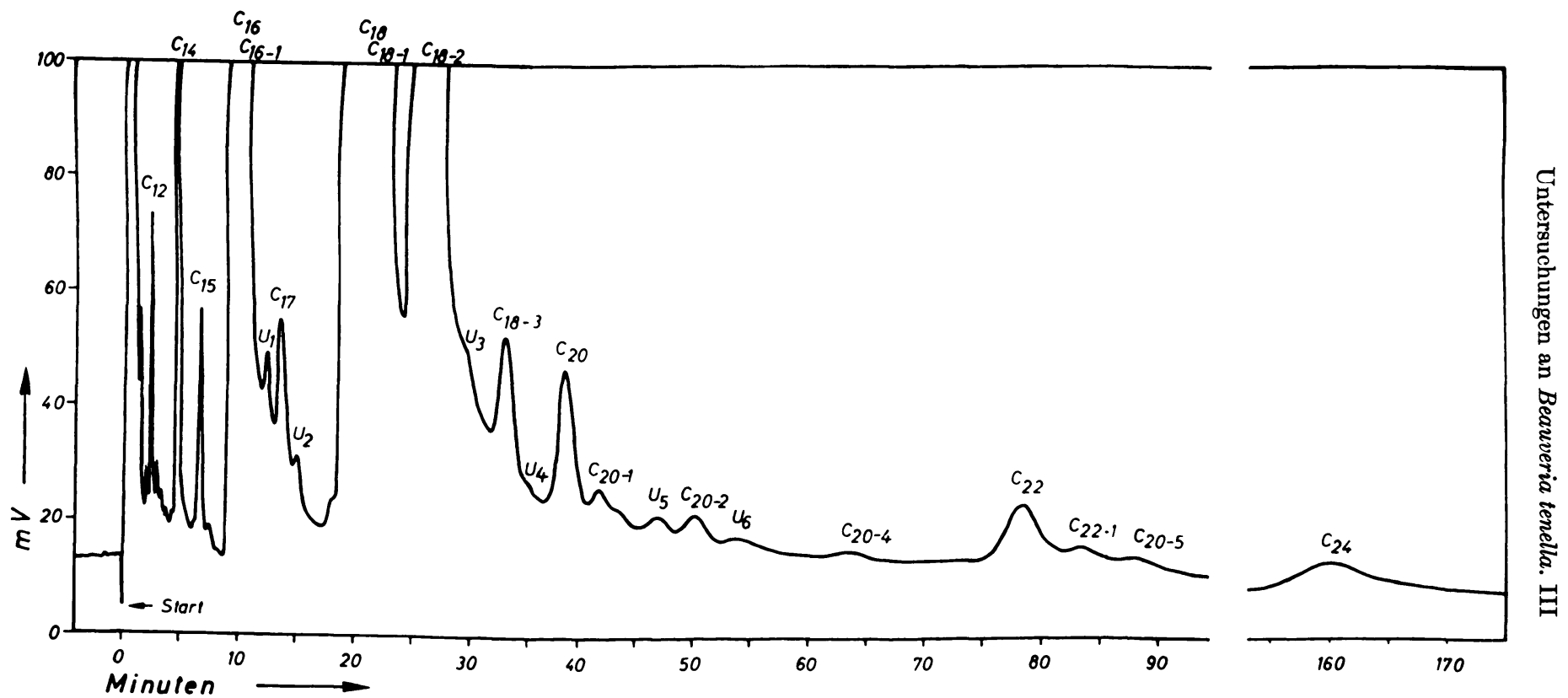

Abb.3. Gaschromatogramm der Nebenkomponenten der Fettsăuremethylester. Gerät wie Abb.2. Trägergas Argon, Druck 1,09 atü, Durchflußgeschwindigkeit $10 \mathrm{ml} / 10 \mathrm{sec}$. Verdampfertemperatur $276^{\circ} \mathrm{C}$, Säulentemperatur $175^{\circ} \mathrm{C}$. Zellspannung $1500 \mathrm{~V}$, MeBbereich $10 \times$. Luftdruck 748,1 Torr. Probemenge $1,0 \mu \mathrm{l}$ 
Tabelle 2. Gaschromatographische Analyse der Fettsäure-Methylester

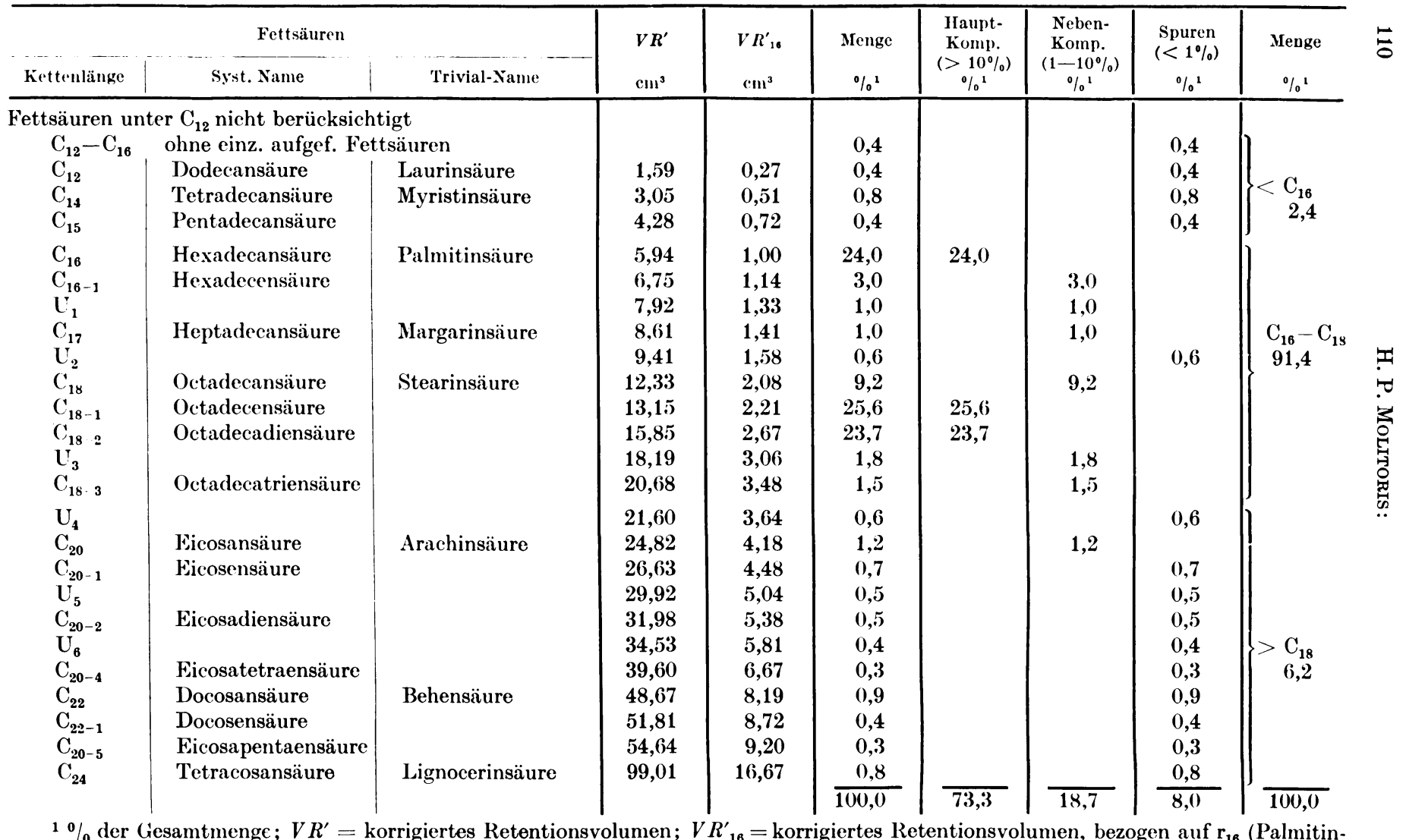
säure) $=1$. Gerät: Pye-Gaschromatograph; Säulenfüllung: Chromosorb W mit 10\% Polyäthylenglykoladipat (PEGA); Trägergas Argon. 
Viertel der Gesamtfettsäuren ausmachen. Fast $60 \%$ bestehen aus ungesättigten Fettsäuren. Diese nehmen mit zunehmendem Sättigungsgrad auch an Menge zu. Dreifach und höher ungesättigte Fettsäuren sind kaum vorhanden. Die unbekannten Fettsäuren machen mit etwa 5\% ebenfalls nur einen geringen Anteil der Gesamtmenge aus. Der Anteil der Fettsäuren mit 16-18 C-Atomen beträgt über $90 \%$.

Das UV-Spektrum der Methylester (Abb.1, Kurve B) in 0,03\% Lösung in p.a. Methanol glich im wesentlichen dem der Fraktion $B_{1}$. Das Maximum bei $230 \mathrm{~m} \mu$ deutet auf die Anwesenheit von Fettsäuren mit zwei konjugierten Doppelbindungen hin.

\section{Diskussion der Ergebnisse}

Die analytische Untersuchung der Fraktion $B_{1}$ des Ätherextraktes ergab bei den physikalischen Konstanten keine Besonderheiten. Es ist auch durchaus die Regel, daß gemischte Glyceride der natürlichen Fette in ihrer Gesamtheit optisch inaktiv sind, obwohl einzelne gemischtsäurige Glyceride durch ihr asymmetrisches C-Atom selbst optisch aktiv sein müssen (Hoppe 1960). Die Fraktion des Unverseifbaren, die nach der Definition von Kaufmave (1937) die natürlichen unverseifbaren Stoffe (Sterine, Kohlenwasserstoffe, Fettalkohole usw.) sowie die bei $100^{\circ} \mathrm{C}$ nichtflüchtigen unverseifbaren organischen Stoffe (Mineralöle usw.) umfaßt, macht mit 37,4\% einen verhältnismäßig hohen Anteil der Fraktion $B_{1}$ aus. Das kann jedoch teilweise durch die Extraktionsmethode bedingt sein.

Die Ergebnisse der gaschromatographischen Analyse des Fettsäuregemisches bestätigen einen allgemein erhobenen Befund (Foster 1949; Hilditch 1956 ; Cochrane 1958), daß die $\mathrm{C}_{16}$ - und $\mathrm{C}_{18}$-Säuren den Hauptteil der Gesamtfettsäuren ausmachen, daß die ungesättigten Säuren dabei überwiegen und Octadecensäure (wahrscheinlich Ölsäure) den höchsten Prozentsatz unter den Einzelfettsäuren ausmacht. Auch daß die Zahl und Menge der Fettsäuren mit weniger als 10 und mehr als 22 C-Atomen nur sehr gering ist, entspricht der allgemeinen Erfahrung. Aus der gaschromatographischen Analyse ist an sich nur die Kettenlänge und der Sättigungsgrad der Fettsäuren zu ersehen, doch kann man bei Vergleich mit anderen Untersuchungsergebnissen wohl annehmen, daß die gefundenen ein- und zweifach ungesättigten $\mathrm{C}_{18}$-Säuren im wesentlichen aus Öl- bzw. Linolsäure bestehen.

Aus den Gesetzmäßigkeiten über das Ansteigen des Retentionsvolumens bei zunehmender Kettenlänge der Fettsäuren (JAMEs 1962) und der Tatsache, daß bei Vorhandensein einer größeren Menge einer Fettsäure meist auch die um 2 C-Atome kürzere und längere Fettsäure in dem Gemisch vorhanden ist, könnte man auch darauf schließen, daß unter den nicht durch Eichsubstanzen identifizierten Fettsäuren $U_{1}$ bis 
$\mathrm{U}_{6}$ die Fettsäuren $\mathrm{U}_{1}, \mathrm{U}_{2}$ und $\mathrm{U}_{3}$ einer $\mathrm{C}_{16}$ (zweifach-ungesättigten), einer $\mathrm{C}_{19}$ und $\mathrm{C}_{21}$ gesättigten Fettsäure entsprechen. Zur Veranschaulichung ist in Abb.4 die Verteilung der Fettsäuren nach Menge, Kettenlänge und Sättigungsgrad unter Einschluß dieser Annahme gezeigt. Ungeradzahlige Fettsäuren, die in den Lipiden der hier diskutierten Stämme

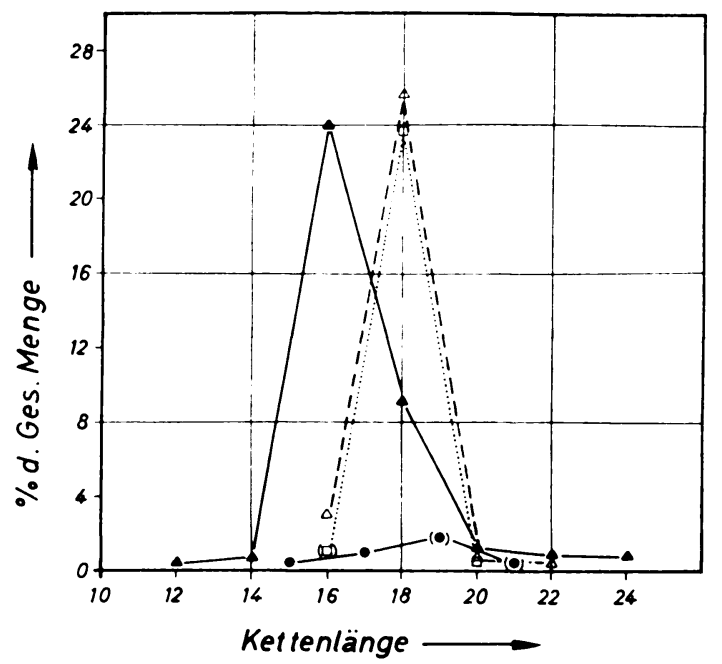

Abb.4. Fettsäureverteilung nach Kettenlänge und Sättigungsgrad. $\Delta-\triangle$ geradzahlig, gesättigt; $\Delta---\Delta$ geradzahlig, $1 \times$ ungesättigt; $\square \cdots \cdots$ geradzahlig, $2 \times$ ungesăttigt; $-\longrightarrow$ zahlig, gesättigt. Werte in ( ): Fettsäure nicht sicher identifiziert

nachgewiesen wurden, sind bisher nur in wenigen Fällen in Mikroorganismen aufgefunden worden. Nach O'LEARY (1962) wurden $\mathrm{C}_{15^{-}}$ und $\mathrm{C}_{17}$-Säuren in Bakterien (Gaschromatographie) gefunden, HuGHES (1963) fand eine $\mathrm{C}_{17}$-Säure bei Agaricus (Gaschromatographie) und Foster (1949) gibt einige Autoren an, die $\mathrm{C}_{19}$-Fettsäuren bei anderen Pilzen festgestellt haben. Der seltene Nachweis dieser ungeradzahligen Fettsäuren kann vor allem auch methodisch bedingt sein, da sie nur in geringen Mengen vorkommen und so leicht dem Nachweis entgehen, sofern nicht mit sehr empfindlichen Methoden wie Papier-, Dünnschichtoder Gaschromatographie gearbeitet wurde.

\section{Zusammenfassung}

Die physikalischen und chemischen Kennzahlen und Daten des durch Ätherextraktion gewonnenen Rohlipids von Beauveria tenella wurden bestimmt und spektrale Absorptionskurven aufgenommen.

Die Methylester der Fettsäuren wurden gaschromatographisch analysiert. Die einzelnen Fettsäuren wurden identifiziert und ihr mengenmäßiger Anteil ermittelt. 
Etwa 90\% der Fettsäuren haben eine Kettenlänge von 16-18 Kohlenstoffatomen. Nahezu $60 \%$ der Fettsäuren sind ungesättigt; der prozentuale Anteil dieser Säuren nimmt mit steigender Zahl der Doppelbindungen ab.

Octadecensäure hatte mit $25,6 \%$ den größten Anteil an der Gesamtmenge.

An seltenen Fettsäuren konnte unter anderem eine gesättigte $\mathrm{C}_{17}$ - und $\mathrm{C}_{24}$-Fettsäure nachgewiesen und das Vorkommen einer gesättigten $\mathrm{C}_{\mathbf{1 9}^{-}}$ und $\mathrm{C}_{21}$-Fettsäure wahrscheinlich gemacht werden.

\section{Summary}

The physical and chemical constants and the spectral absorption curves of crude lipids of Beauveria tenella, obtained by means of etherextraction, were determined.

The methyl esters of the fatty acids were analyzed using gas-liquid chromatography. The individual fatty acids were identified and the amount of each in the complete sample determined.

Approximately $90 \%$ of the fatty acids had a 16-18 carbon-chain length, while almost $60 \%$ of the fatty acids were unsaturated. The percentage of fatty acids with unsaturated bonds was reciprocally proportional to the number of double bonds present.

Octadecenoic acid comprised $25,6 \%$ of the total fatty acids and represented the largest single amount of a specific fatty acid present.

With respect to unusual fatty acids, a saturated $\mathrm{C}_{17}$ and a $\mathrm{C}_{24}$ fatty acid were identified, while the presence of a $\mathrm{C}_{19}$ and a $\mathrm{C}_{21}$ fatty acid was indicated.

Herrn Prof. Dr. H. G. Schlegel danke ich für sein reges Interesse an der Arbeit und ihre stete Förderung.

Für die Möglichkeit zur Benutzung der (ieräte und seinen Rat bei der Gas. chromatographie der Fettsäuren danke ich Herrn Privatdozenten Dr. O. W. THIELE.

Mit Unterstützung durch die Deutsche Forschungsgemeinschaft.

\section{Literatur}

Cochraxe, V.: Physiology of fungi. New York: J. Wiley Sons Inc. 1958.

Euckex, A.. u. R. Suhrmasy: Physikalisch-Chemische Praktikumsaufgaben. 4. Aufl. Leipzig: Akademie-Verlagsgesellschaft 1954.

Foster, J. W.: Chemical activities of fungi. New York: Academic Press Inc. 1949.

GLick, D.: Methods of biochemical analysis. New York: Interscience Publishers Inc. 1960.

Hilditch, T. P.: The chemical constitution of natural fats. New York: J. Wiley Sons Inc. 1956

Hoppe, W.: In Reiff, F., R. Kautzmann, H. L. Lüers u. M. Lindemann: Die Hefen. I. Band. Die Lipide der Hefen, S. 465-507. Lipidstoffwechsel, S. 819 bis 872. Nürnberg: H. Carl 1960.

Hughes, D. H.: Preliminary characterisation of the lipid constituents of the cultivated mushroom Agaricus bisporus. Mushroom Sci. V, 540-546 (1962).

Arch. Mikrobiol., Bd. 47 
JAmes, A. T.: Qualitative and quantitative determination of the fatty acids by gas-liquid chromatography. In GLICK, D.: Methods of biochemical analysis, Vol. VIII, p. 1-61. New York: Interscience Publishers 1962.

Kavfuasi, H. P.: Bericht über die 8. Versammlung der Internationalen Kommission zum Studium der Fettstoffe. Fette u. Seifen 4, 480-482 (1937).

- In Bauer, H., u. H. Moll: Die organische Analyse, 4. Aufl., S. 16. Leipzig: Akad. Verlagsges. Geest u. Portig KG. 1960.

Küster, F. W., A. Thiel u. K. Fischbeck: Logarithmische Rechentafeln. Berlin: W. de Gruyter 1958.

Matula, J.: Allgemeine physikalische Methoden. In KLein, G.: Handbuch der Pflanzenanalyse. Band I, S. 324-341. Wien: Springer 1931.

Molitoris, H.P.: Untersuchungen an Beauveria tenella (NRRL 2334, 2335, 2336; bisher Agaricus campestris). II. Wachstum, Stoffwechsel, Fettspeicherung und Enzymaktivitäten. Arch. Mikrobiol. 47, 104-114 (1963 b).

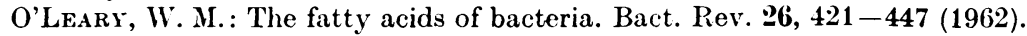

Winkler, L. W.: In Baufr, H., u. H. Moll: Die organische Analyse. 4. Aufl. Leipzig: Akad. Verlagsges. Geest u. Portig KG. 1960.

Dr. H. P. Molitoris,

Institut für Mikrobiologie der Universität, 34 Göttingen, Goßlerstraße 16 
Am 14. Juli 1935 wurde ich, Hans-Peter Molitoris, als Sohn des Facharztes Dr.med. Hans-Albrecht Molitoris und seiner Ehefrau Ursula, geb. Hullen, in Erlangen geboren. Dort besuchte ich von 1941 bis 1945 die Volksschule und vom Herbst 1945 bis Herbst 1950 das humanistische Gymnasium. Nach dem Umzug meiner Eltern nach Coburg trat ich in das Gymnasium Casimirianum zu Coburg ein, an dem ich im Juli 1954 die Reifeprüfung ablegte.

Im Wintersemester 1954/55 begann ich an der Universität Erlangen das Studium der Medizin und $\mathrm{Na}-$ turwissenschaften. Im Sommersemester 1957 immatrikulierte ich mich an der naturwissenschaftlichen Fakultät der Universität Göttingen, wo ich seit dem Sommersemester 1959 (mit einer halbjährigen Unterbrechung) im Institut für Mikrobiologie an der vorliegenden Dissertation arbeite.

Meine akademischen Lehrer, denen ich zu großem Dank verpflichtet bin, sind die Herren Professoren und Dozenten: Deuticke, Firbas, Fleischmann, Fuchs, Harbers, Harder, Hesse, Hollmann, Jost, May, Metzner, Meuwsen, Meyer, Pfennig, Piepho, Pirson, Pringsheim, Scheibe, Schlegel, Schwemmle und Stammer. 